Ann. Génét. Sél. anim., I979, 11 (3), 28I-356.

\title{
Le complexe d'histocompatibilité majeur chez l'homme et chez les animaux
}

\author{
H. LEVEZIEL \\ Laboratoire de Génétique biochimique, \\ Centre national de Recherches zootechniques, I.N.R.A., \\ $7835^{\circ}$ Jouy-en-Josas, France
}

\section{Résumé}

La présente revue bibliographique est une mise au point sur l'état actuel des travaux consacrés aux Systèmes d'Histocompatibilité Majeurs de l'homme et des animaux. Nées de l'étude expérimentale des phénomènes de transplantation, les recherches sur les systèmes d'histocompatibilité connaissent depuis quelques années un développement très importarit, tant par le nombre d'espèces étudiées que par l'ampleur des investigations entreprises dans chaque espèce et l'intérêt des résultats obtenus. Treize espèces animales sont considérées : souris, rat, cobaye, chimpanzé, macaque-rhésus, chien, lapin, porc, bovin, chèvre, moutcn, cheval et poulet.

Le complexe $\mathrm{H}-2$ de la souris est aujourd'hui le mieux connu; considéré comme modèle, il est étudié en détail dars la première partie de cette revue, sous la forme d'une construction progressive respectant autant que pcssible la chronologie des faits historiques; cette étude s'accompagne de rappels de définitions et de l'exposé du principe des techniques utilisées dans ces travaux; il est ainsi montré que l'cn désigne aujourd'hui par "Complexe d'Histocompatibilité Majeur " un segment chromosomique portant un ensımble de gènes fonctionnellement et topographiquement liés, intervenant dans divers mécanismes fondamentaux de l'immunologie : certains interviennent dans la "rezonnaissance du soi " et ont par conséquent un rôle essentiel dans les phénomènes de transplantation; d'autres contrôlent la réponse immunitaire de type humoral et/ou cellulaire; d'autres contrôlent les mécanismes de coopération cellulaire, et d'autres enfin la synthèse de facteurs du complément.

La seconde partie de cette revue est consacrée à l'exposé descriptif des résultats acquis dans les autres espèces. Le complexe HLA de l'homme, le mieux connu parmi les espèces non-consanguines, est décrit de manière précise compte tenu de son intérêt médical; une place particulière est faite à deux espèces d'intérêt zootechnique pour lesquelles les données sont déjà importantes : potc et poulet; les connaissances relatives aux autres espèces mentionnées ne sont que brièvement résumées. Unie comparaison succinte permet alors d'insister sur la très grande similitude de structure et de fonction des divers complexes étudiés.

En conclusion, il est souligné que sans qu'il soit encore possible de rassembler dans un concept général le rôle du Complexe d'Histocompatibilité Majeur, celui-ci apparaît néarimoins comme le centre immunologique de l'organisme; de plus, les études développées chez l'homme viennent de trouver un aboutissement spectaculaire dans la découverte d'associations entre HLA et maladies. Dans ces conditions, le domaine de l'histocompatibilité se présente actuellement comme un des domaines d'investigations les plus prometteurs, et si de nombreuses possibilités ne. sont aujourd'hui perçues que potentiellement, l'on est en droit d'espérer qu'elles seront un jour concrétisées tant chez l'homme que chez les animaux. 


\section{Plan}

INTRODUCTION . . . . . . . . . . . . . . . . . . . . . 283

Chapitre $I$ : Le COMPLEXE D'HISTOCOMPATIBILITÉ MAJEUR DE LA SOURIS I. - RAPPELS - DÉFinitions

I) Rappel historique

2) Notion d'histocompatibilité

3) Système majeur d'histocompatibilité . . . . . . . . . . . . . . . . a) Système d'histocompatibilité . . . . . . . . . . . . . . . . . . 28

b) Système majeur d'histocompatibilité . . . . . . . . . . . . . . 287

4) Notion de complexe d'histocompatibilité majeur . . . . . . . . . . 287

5) Le modèle murin . . . . . . . . . . . . . . . . . . . . . . . . 288

II. - LES GENES SÉROLOGIQUEMENT DÉFINIS . . . . . . . . . . . . . . . . . . ${ }_{288}$

I) Définition - Mise en évidence . . . . . . . . . . . . . . . . . . . 288

2) Résultats génétiques . . . . . . . . . . . . . . 290

3) Résultats biochimiques. . . . . . . . . . . . . . . . . 290

a) L'isolement par clivage enzymatique . . . . . . . . . . . . . 292

b) L'isolement par dissolution des membranes . . . . . . . . . . . . . 292

c) Composition et structure de la partie glucidique. . . . . . . . . 292

d) Structure de la partie protéique . . . . . . . . . . . . 293

c) Nature des sites antigéniques . . . . . . . . . . . . . . . 293

f) Arrangement membranaire. . . . . . . . . . . . . . . . 294

III. - GÈNES CODANT POUR CERTAINS FacteuRS DU COMPLEMment : La Région S. . . . 294

I) Mise en évidence de la tégion S . . . . . . . . . . . . . . . . . . 294

2) Contrôle de certains facteurs de complément. . . . . . . . . . . . . 295

3) Discussion . . . . . . . . . . . . . . . . . . . . . . 295

IV. — LES GÈNES Ir : "Immune Response " . . . . . . . . . . . . . . . . . . 295

I) Définition . . . . . . . . . . . . . . . . . . . . . . . . 295

2) État des résultats actuels . . . . . . . . . . . . . . 297

3) Discussion . . . . . . . . . . . . . . . . . 300

V. - LES GÈNES Ia : "Region I Associated". . . . . . . . . . . . . . . . 3OI

I) Mise en évidence des gènes Ia . . . . . . . . . . . . . . . . 30I

2) Distribution cellulaire des antigènes Ia . . . . . . . . . . . . . 302

3) Caractérisation biochimique des antigènes Ia . . . . . . . . . . . . 303

4) Discussion .................. . . . . 303

VI. — ÉTUdE DE LA RÉPONSE ALLOGÉNIQUE . . . . . . . . . . . . . . . . . . . 304

A. C Evénements cellulaires de la réponse allogénique : leur déroulement . . . . . . 304

I) Culture mixte lymphocytaire $=$ MLR . . . . . . . . . . . . . . . 304

2) Cytotoxicité à médiation cellulaire $=\mathrm{CML}$. . . . . . . . . . . . . . 305

3) Apparition de cellules mémoires (ML,R II, CML II) . . . . . . . . . 307

MLR II . . . . . . . . . . . . . . . . . . . . . . . . . . . . 307

CML II. . . . . . . . . . . . . . . . . . . . . . 307

B. - Spécificité et contrôle génétique de la réponse allogénique. . . . . . . . 307

I) MLR . . . . . . . . . . . . . . . . . . . . . . . . 307

2) CML . . . . . . . . . . . . . . . . . . . . . . 308

3) Relations entre MLR et CML . . . . . . . . . . . . . . 308

4) Discussion . . . . . . . . . . . . . . . . . . . . . . . . . . 309

C. - Physiologie et mécanisme de la réponse allogénique . . . . . . . . . . 3ro

I) La stimulation . . . . . . . . . . . . . . . . . . . . 3ro

2) La réponse ..................... . . . . 3 II

D. - Conclusion. . . . . . . . . . . . . . . . . . . . . . . 3II

VII. - LA RÉACTION DU GREFFON CONTRE L'HOTE . . . . . . . . . . . . . . . . 3I2

I) Définition . . . . . . . . . . . . . . . . . . . . . . . 312

2) Déterminisme génétique . . . . . . . . . . . . . . . . . 312

VIII. - CONTROLE DU MÉCANISYE DE COOPǴRATION CELIULAARE PAR LE COMPLEXE H2 $3^{\text {I } 2}$

I) La suppression immunitaire. . . . . . . . . . . . . . . . . . 31 3

2) La participation des antigènes d'hiscompatibilité à la coopération des cellules immunocompétentes .............. 3 I3 
a) Restriction génétique à la coopération T-B . . . . . . . . . . . . 313

b) Restriction génétique à la coopération lymphocytes T-macrophages 3 I 4

3) Les médiateurs solubles de la coopération cellulaire . . . . . . . . . . 3I4

- Facteurs helper . . . . . . . . . . . . . . . . . . . . . 3I4

- Facteurs suppresseurs . . . . . . . . . . . . . . . . 316

4) Conclusion . . . . . . . . . . . . . . . . . . . . . . 3 I6

IX. - Conclusion : Structure du modèle murin . . . . . . . . . . . . . . . . 3I6

Chapitre 2 : LE COMPLEXE D'HISTOCOMPATIBILITÉ DES AUTRES ESPÈCES 318

I. - INTRODUCTION . . . . . . . . . . . . . . . . . . . . . . . . . . . . . 3 I8

II. - PRíSENTATION DU COMPLEXE HL-A DE L'HOMME. . . . . . . . . . . . . . . 319

I) Mise en évidence du complexe HL-A . . . . . . . . . . . . . . . . 3I9

2) Description $\mathrm{du}$ complexe HI-A . . . . . . . . . . . . . . . . . . $32 \mathrm{I}$

3) Les loci HLA-A, HLA-B, HLA-C. . . . . . . . . . . . . . . . . . 322

4) Le locus HLA-D . . . . . . . . . . . . . . . . . . . . . . . . . 324

a) Contrôle de la réaction lymphocytaire mixte. . . . . . . . . . . . 324

-Déterminisme génétique . . . . . . . . . . . . . . . . . . . 324

- Typage HLA-D . . . . . . . . . . . . . . . . . . . . . . . 324

- Caractérisation des spécificités . . . . . . . . . . . . . . 325

b) La série allélique HLA-DR . . . . . . . . . . . . . . . . . . . 325

c) Le contrôle de la MLR II . . . . . . . . . . . . . . . . . . . . . 327

d) Relations entre déterminants HLA-D (MLR-I,) antigènes HLA-DR et structures PL (MLR II). . . . . . . . . . . . . . . . . . . . 327

5) Les autres manifestations contrôlées par le complexe HL-A. . . . . . . 329

a) Facteurs du complément. . . . . . . . . . . . . . . . . . . . . 329

b) Cytolyse à médiation cellulaire (CML) . . . . . . . . . . . . . . . 330

c) La réaction du greffon contre l'hôte. . . . . . . . . . . . . . . . 330

6) Conclusion . . . . . . . . . . . . . . . . . . . . . . . $33^{\circ}$

III. - PRÉSENTATION DU COMPLEXE B DU POUlET . . . . . . . . . . . . . . . . . . 33 I

IV. - PRÉSENTATION DU COMPLEXE SL-A DU PORC . . . . . . . . . . . . . . . . . . . 333

I) Introduction . . . . . . . . . . . . . . . . . . . . . . . . . . . 333

2) Description . . . . . . . . . . . . . . . . . . . . . . . . . . . . 333

3) Conclusion . . . . . . . . . . . . . . . . . . . . . . . . . . . . 335

V. - LES AUTRES COMPLEXES D'HISTOCOMPATIBILITÍ MAJEURS . . . . . . . . . . . 335

I) Chez les primates, autre que 1'homme. . . . . . . . . . . . . . . . 335

a) Le complexe RhL-A du macaque Rhésus . . . . . . . . . . . . 335

b) Le complexe ChL-A du chimpanzé . . . . . . . . . . . . . . . 335

c) L'histocompatibilité chez les autres primates . . . . . . . . . . 335

2) Le complexe du rat . . . . . . . . . . . . . . . . . . . . 336

3) Le complexe GPL-A du cobaye . . . . . . . . . . . . . . . . . 336

4) Le complexe DL-A du chien . . . . . . . . . . . . . . . . . . . . . 337

5) Le complexe RL-A du lapin . . . . . . . . . . . . . . . . . . . . 337

6) Le complexe d'histocompatibilité des bovins . . . . . . . . . . . . . 337

7) Le complexe d'histocompatibilité de la chèvre . . . . . . . . . . . . 338

8) Le complexe d'histocompatibilité du mouton . . . . . . . . . . . . . 338

9) Le complexe d'histocompatibilité du cheval . . . . . . . . . . . . . . . 339

VI. - COMPARAISON dES RF́SUltatS ObTENUS DANS LES DIVERSES ESPECES. . • . . . 339

CONCLUSION ......................... . . 340

\section{Introduction}

Les recherches relatives aux transplantations d'organe et aux greffes tissulaires débutèrent au cours du $\mathrm{xIx}^{\mathrm{e}}$ siècle. Entreprises dans le but de comprendre la façon dont on pouvait assurer le succès d'une telle opération, elles furent à l'origine du développement d'un nouveau domaine d'investigation : 1'Histocompatibilité. 
Les premières expériences se soldèrent bien souvent par des échecs, et seules les greffes effectuées d'un individu sur lui-même, ou autogreffes, apparurent réalisables; ainsi, les autogreffes de peau s'avérèrent rapidement très utiles dans le traitement des plaies et des brûlures. Il fallut attendre la fin du siècle pour qu'avec les premiers succès, on assistat au nouvel essor de ces travaux; depuis cette époque, un nombre sans cesse croissant de résultats expérimentaux ont abouti à la description minutieuse d'un segment chromosomique, jouant vraisemblablement un rôle fondamental dans la vie de l'espèce humaine et des espèces animales; dénommée complexe majeur d'histocompatibilité, cette portion du génome est de mieux en mieux caractérisée par ses structures génétiques et par ses fonctions dans divers mécanismes fondamentaux de 1'immunologie. C'est l'exposé des connaissances actuelles, relatives aux complexes d'histocompatibilité majeur chez l'homme et chez les animaux qui fera l'objet de cette revue bibliographique.

C'est chez la souris que le plus important effort de recherche a été réalisé, et c'est aujourd'hui cette espèce qui est la mieux connue. C'est pourquoi, nous consacrerons un premier chapitre à l'étude détaillée de ce qui peut être appelé le modèle murin; après avoir essayé de définir de manière plus précise certains termes : histoccmpatibilité, système d'histocompatibilité, complexe d'histocompatibilité majeur, nous rapporterons les données actuelles en nous appuyant autant que possible sur l'ordre de faits historiques, la présentation adoptée étant la construction progressive du complexe d'histocompatibilité majeur de la souris. Ce chapitre nous permettra également d'expliquer le principe des techniques utilisées dans ce type d'étude.

Un second chapitre sera consacré à l'exposé comparatif des résultats obtenus dans les autres espèces étudiées. Une place plus particulière sera attribuée à l'homme, compte tenu de l'importance des découvertes réalisées depuis vingt ans et de leur application directe en médecine (transplantation, transfusion). De même, deux espèces animales seront plus attentivement considérées : le porc et le poulet, seules espèces d'intérêt zootechnique pour lesquelles on dispose aujourd'hui d'un ensemble de connaissances satisfaisant. Le modèle murin étant considéré comme modèle de référence, les observations réalisées dans les autres espèces étudiées apparaîtront très similaires; leur comparaison générale permettra d'envisager le complexe d'histocompatibilité majeur comme une unité de structure et de fonction qui semble avoir été peu modifiée au cours de l'évolution des vertébrés.

Enfin, sans essayer de déninir le rôle biologique attribuable au complexe d'histocompatibilité majeur, nous verrons dans notre conclusion, à l'aide de résultats expérimentaux récents et à la lumière des connaissances rapportées dans les deux premiers chapitres, qu'un rôle préponđérant dans la défense de l'individu semble de plus en plus vraisemblable. Cependant, il apparaîtra également qu'en fait, nous ne faisons actuellement qu'entrevoir la grande subtilité, la grande complexité des mécanismes mis en cause; si certaines illustrations ou applications ont déjà été signalées, de nombreuses possibilités ne sont perçues que potentiellement et nous pouvons espérer qu'elles pourront être un jour concrétisées.

I1 faut souligner dès à présent, que nous assistons depuis plusieurs années à une intensification très nette des recherches se rapportant à l'histocompatibilité. Plusieurs raisons peuvent être invoquées pour expliquer et justifier ce phénomène :

- Un important support médical a permis un aboutissement très rapide de ces études chez l'homme.

- Certains aspects des résultats obtenus, taıt chez la souris que chez l'homme, se traduisent par des espoirs d'application de plus en plus grands. 
- L'essai de transposition à d'autres espèces est favorisé par l'extrême concordance des observations réalisées dans les diverses espèces étudiées jusqu'à maintenant.

Il en résulte un effet stimulant et multiplicatif qui a pour conséquence d'une part, l'augmentation du nombre d'espèces étudiées et d'autre part, l'accroissement des moyens mis en œuvre pour ces travaux. Le domaine de l'histocompatibilité est donc encore dans une phase de développement, mais d'ores et déjà, nous disposons d'une quantité d'information considérable, et nous allons essayer d'en dégager l'essentiel dans notre exposé.

\section{Chapitre I \\ Le complexe d'histocompatibilité majeur de la souris}

\section{I. - Rappels - Définitions}

Les premières études réalisées à la fin du $\mathrm{xIX}^{\mathrm{e}}$ siècle, furent consacrées essentiellement à l'étude de transplantation de tumeurs. Les premiers succès sont à attribuer à HANAU (I889) sur le rat, et à MOREAU (I894) sur la souris. A cette époque, c'était surtout l'étiologie du processus cancéreux qui retenait l'attention. Les études sur les modalités de développement des tumeurs n'ont en fait débuté que quelques années plus tard, avec les travaux de LoEB (I9Or).

\section{I. - Rappel Historique}

La spécificité généralement très étroite d'une tumeur pour la souche indigène chez laquelle elle était apparue fut discutée dès I908 par TyzzER en termes de génétique mendélienne, et la théorie génétique de la transplantabilité tumorale sera formulée par LiTTLE et STRONG en I924 dans les termes suivants : " Lr devenir d'une tumeur implantée chez un hôte donné est lié aux réactions de cet hôte, qui sont déterminées dans une large mesure par sa constitution génétique, et celles des cellules tumorales greffées, contrôlées, jusqu'à un certain point par leur génome propre ". De cette première période, consacrée plutôt à des études descriptives, avec des essais intra-spécifiques (LTITLE et TYZZER, I9I6), ou inter-spécifiques (JENSEN, I903), il ressortait donc qu'il fallait insister sur l'originalité de l'individu, idée reprise par LoEB en I945 dans son ouvrage "The biological basis of individuality ". Mais en aucun cas, ni la nature précise des différences entre individus, ni les mécanismes de la réaction de rejet n'étaient encore clairement perçus.

A côté de ces travaux sur la transplantation des tumeurs, les auteurs s'intéressèrent peu à peu à la transplantation des tissus normaux; MEDAWAR (I944) rapporta pour la première fois l'utilisation de greffes de peau chez le lapin. Les résultats obtenus permirent à LoEB de suggérer que la transplantation de tissus normaux ou tumoraux était sous la dépendance des mêmies lois fondamentales; il faut souligner que ces lois, schématisées par la figure I, ne s'appliquent qu'à des lignées hautement consanguines et à leurs générations hybrides. Confirmées par les expériences de divers auteurs : Cloudman (I932), Prein et Main (I958), elles suggèrent fortement l'existence d'un déterminisme génétique pour les phénomènes de transplantation.

Aussi, les gènes correspondants, bien qu'encore théoriques et hypothétiques furent appelés "gènes d'histocompatibilité " ou "gènes $H$ ", selon la proposition de SNELI. (r948). 


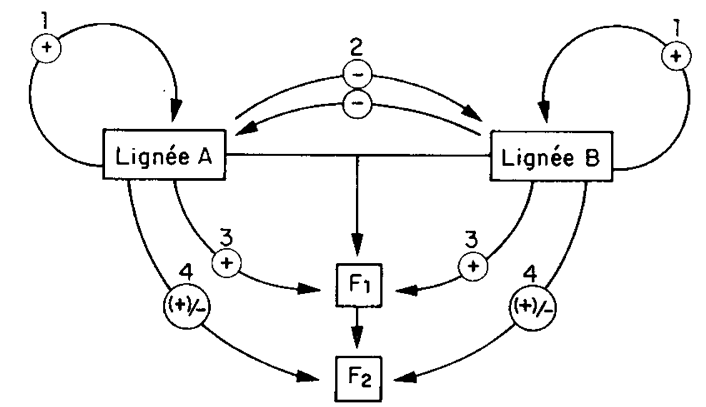

FIG. I. - Représentation des lois de la transplantation (d'après SNELL et al., I976)

Representation of the transplantation laws.

A, B : lignées consanguines.

+ : greffe acceptée.

- : greffe rejetée.

I : isogreffe $=$ greffe effectuée sur un individu génétiquement identique (intra-lignée).

$2:$ allogreffe $=$ greffe entre individus différents, de la même espèce (inter-lignée).

3 : greffe parentale sur les hybrides $F_{1}$.

4 : greffe parentale sur les hybrides $F_{2}$, souvent rejetée, rarement acceptée.

\section{2. - Notion d'histocompatibilité}

Un gène d'histocompatibilité est donc défini fonctionnellement par l'infuence $q$ 'il exerce sur le devenir des allogreffes.

L'établissement sur une base précise de la notion d'histocompatibilité date de la découverte en I936 par GORER des antigènes érythrocytaires de la souris. Parmi ces marqueurs génétiques, l'antigène II se révéla avoir une influence prépondérante sur l'évolution des tumeurs de glandes mammaires après transplantation. Dès les années suivantes, GorER (I937, I938) montrera que le développement normal d'une leucémie ou d'un sarcome indigène de la souche $A$, souche possédant l'antigène $\mathrm{II}$, chez des souris $\mathrm{F}_{2}$ issues de croisement de $\mathrm{A}$ avec $\mathrm{C}_{57} \mathrm{BL}$, souche normalement résistante, est conditionnée par la présence de l'antigène II sur les hématies de 1'hôte. Les $\mathrm{F} 2$ qui n'ont pas cet antigène rejettent régulièrement la tumeur et développent subséquemment des anticorps hémagglutinants dont 1'activité est superposable à celle des anticorps anti II. La présence de 1'antigène II sur les tissus solides était ainsi directement démontrée. LUMSDEN, la même année (I938), retrouvera chez le rat le même type de réactions sérologiques accompagnant le rejet de greffes tumorales. L'antigène II mis en évidence par GorER apparut contrôlé par un seul gène autosomal dominant (GORER et al., I948). Celui-ci fut alors appelé gène d'histocompatibilité 2 ou $\mathrm{Hz}$.

Les recherches pour comprendre les mécanismes du rejet des greffes représentent alors l'aspect complémentaire de la découverte précédente. En I945, MEDAWAR établira que le processus de rejet résulte d'une immunisation suscitée chez le receveur par des structures antigéniques présentes sur le greffon et étrangères à l'hôte. La même année, LOEB, après un important travail, montrera que l'organisme est capable de reconnaître les différences présentées par les cellules d'un autre individu, et il soulignera, du point de vue de l'histologie, la prépondérance ces infiltrations lymphocytaires dans les réactions aux allogreffes, attribuant à ccs cellules un rôle essentiel dans la reconnaissance des structures étrangères. 


\section{3. - Système Majeur d'Histocompatibilité}

\section{a) Système d'Histocompatibilité}

Le gène $\mathrm{Hz}$ considéré au départ comme unique et situé dans le groupe de linkage IX (GORER et al., I948; ALLEN, r955), se révéla en fait être un "système " comportant plusieurs loci. La description de nombreux recombinants, indépendamment par plusieurs équipes (Amos et al., 1955; SHREFFlER et al., I966; STIMPFLING, r97I), et une analyse sérologique de plus en plus complète ( $\mathrm{KLEIN}_{\mathrm{E}} \mathrm{I} 97 \mathrm{I}$ ) ont permis de préciser la structure génétique du " système $\mathrm{H}_{2}$ ". La portion chromosomique correspondante, portant les différents loci étroitement liés est depuis désignée par " région $\mathrm{H}_{2}$ ".

\section{b) Système Majeur d'Histocompatibilité}

A côté du système $\mathrm{H}_{2}$ découvert par GORER, on a pu montrer (BARNEs et KROHN, I957; BAILEY et MOBRAATEN, I969), qu'il existe de nombreux systèmes d'histocompatibilité pouvant entraîner le rejet d'une greffe, BRAMBILLA et al. (I970) estimant à 44 le nombre de loci d'histocompatibilité mis en évidence par leur expérience; cependant le système $\mathrm{H}_{2}$ fut reconnu comme le système majeur d'histocompatibilité, en ce qu'il induisait un rejet rapide des transplants incompatibles et l'apparition d'anticorps humoraux aisément décelables; les autres systèmes existant représentent chacun une barrière d'histocompatibilité beaucoup plus faible que H2 (Counce et al., I956; Graff et BaILey, r973), SNeli, et Strumpling (I966) insistant sur 1'aspect opératoire de ce concept de système majeur. Ce rôle prépondérant attribué au système $\mathrm{H}_{2}$, justifie la somme importante de travaux consacrés depuis à son étude.

\section{4. - Notion de Complexe d'Histocompatibilité Mạ̣eur}

De ces travaux, résulte aujourd'hui une connaissance approfondie du système d'histocompatibilité majeur de la souris, faisant de lui le système génétique vraisemblablemcnt le mieux connu chez les mammifères (VAIMAN, 1974). La localisation de nouveaux loci à l'intérieur de cette même région a apporté une preuve supplémentaire de l'important matériel génétique contenu dans le groupe de linkage IX, porté par le chromosome I7, et support du système Ha. Le contrôle des variations quantitatives d'une protéine sérique par le locus Ss (SHREFFLER et OWEN, I963), le contrôle du taux de synthèse d'anticorps pour des antigènes variés (BENACERRAF et MC DEWITT, I972) par une série de gènes placés dans la région $\mathrm{H}_{2}$ (Mc DewitT et Sela., I965; MC DewitT et Tyan, I968), le contrôle de la transformation lymphoblastique survenant lors du mélange de deux populations de lymphocytes allogéniques (RychL,IKova et al., r97I; BACH et al., r972), et le codage pour des antigènes de surfaces membranaires spécifiques de certaines cellules (SAChs et CONE, I973; HAUPTFELD et al., I974), autant de fonctions attribuées à cette région chromosomique, désormais désignée sous le nom de "complexe $\mathrm{H}_{2}$ " (KLEIN et al., I974; SHREFFLER, 1974) et plus complètement par " complexe d'histocompatibilité mojev:y "). 


\section{5. - Le Modèle Murin: présentation}

Si à leur début les recherches d'histocompatibilité étaient consacrées à l'étude des greffes tissulaires et des transplantations d'organes, il faut souligner qu'aujourd'hui la notion de complexe majeur d'histocompatibilité désigne de manière générale une "vaste " région chromosomique (50o gènes environ pour KLEIN et SHREFFLER, 197I) considérée comme le "centre immunitaire " de l'organismo (DAusseT, I977).

La mise en évidence des divers types de gènes localisés dans cette région a bien sûr été progressive; c'est pourquoi, dans la présentation adoptée, nous les décrirons successivement en respectant si possible l'histoire de cette discipline scientifique. La construction du complexe $\mathrm{H} 2$ apparaîtra ainsi peu à peu, et nous verrons que beaucoup de problèr:es sont encore à résoudre, ces recherches étant en constante évolution.

Pour faciliter la compréhension de notre exposé, précisons dès à présent que le complexe $\mathrm{H} 2$ comprend 4 régions : $\mathrm{K}, \mathrm{I}, \mathrm{S}, \mathrm{D}$ qui ont été définies par l'observation progressive de recombinants entre les marqueurs identifiés (voir fig. 2). Aujourd'hui plusieurs types de gènes peuvent être localisés dans la même région, mais ceci ne signifie en aucun cas, comme nous le verrons, qu'ils sont identiques; il est simplement impossible de connaître plus finement la structure génétique faute de recombinants. Il faut également noter que le terme haplotype désigne une combinaison des allèles des divers gènes de la région $\mathrm{H} 2$.

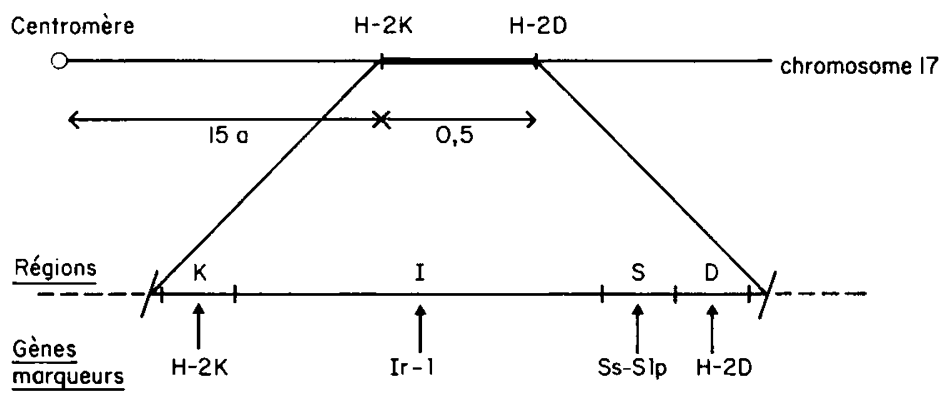

Fig. 2. - Présentation du complexe d'histocompatibilité majeur de la Souris (complcxe $H$-2).

Presentation of the Mouse major histocompatibility complex ( $\mathrm{H}-2$ complex).

$a$ : unités de recombinaison.

\section{II. - Les gènes sérologiquement définis}

\section{r. - Définition - Mise en évidence}

Ce sont par définition les gènes marqueurs des régions $K$ et $D$, définis par leurs produits au niveau de la membrane cellulaire, et identifiables par les immunsérums obtenus par immunisation entre lignées (Colombani, I975).

Les antigènes codés par ces gènes sont présents à la surface de toutes les cellules ou presque, et peuvent donc être reconnus par l'utilisation de techniques sérologiques classiques. Ils sont appelés fréquemment "antigènes classiques " et sont aujourd'hui les mieux connus. 
Ce sont les premiers mis en évidence; en effet, le système II découvert par GORER en r 936 n'était autre que celui-là. Le développement et la complexité sans cesse croissante des études sérologiques conduites depuis lors ont permis d'acquérir une très bonne connaissance de ces gènes et de leurs produits.

Les lignées consanguines de souris s'étaient révélées très tôt un matériel indispensable pour les recherches génétiques. Créées par LrT'TLE à partir de I909 (in StAATs, 1966) pour l'étude des caractères du pelage, elles furent développées entre I 920 et I930 pour les recherches en cancérologie, permettant d'établir les lois de transplantation déjà signalées (LITTLE, J94I).

Par la suite, les lignées congéniques résistantes, c'est-à-dire ne différant que par un segment, chromosomique limité, porteur d'un locus d'histocompatibilité (par exemple $\mathrm{H} 2$ ), introduites et développées systématiquement par les travaux de SNELL, et son équipe (SNELL, I948), ont constitué un matériel de base pour l'étude du système $\mathrm{H}_{2}$, autorisant des études détaillées de ces loci par 1'élimination de l'influence du reste du génome, devenu identique pour toutes les lignées.

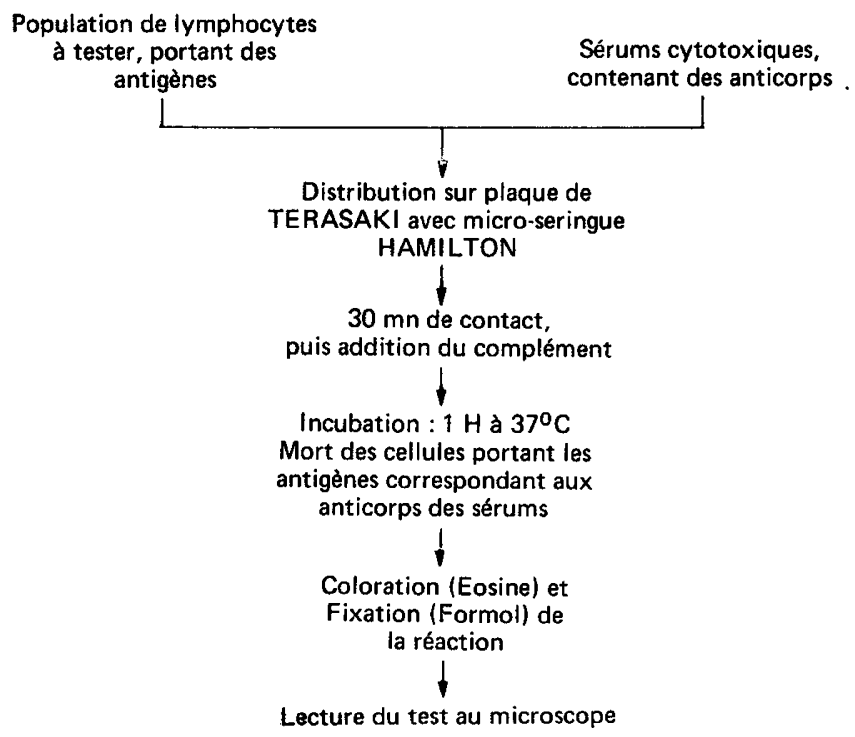

\begin{tabular}{|c|c|c|}
\hline Note & Réaction & $\%$ de cellules tuées \\
\hline $0 \ldots$ & & moins de 20 \\
$1 \ldots$ & & 20 à 40 \\
$2 \ldots$ & - & 40 à 60 \\
$3 \ldots$ & & 60 à 80 \\
\hline $4 \ldots$ & + & plus de 80 \\
\hline
\end{tabular}

Fig. 3. - Test de Lymphocytotoxicité. Principe du test. Lymphocytotoxicity test; outline of the test. 
A partir des lignées originales, parmi lesquelles on a pu identifier II haplotypes (Gorer et al., I948; SNELI, I95I; SNELI et al., I952, 1953) des lignées porteuses d'haplotypes recombinants sont apparues et ont permis une analyse génétique plus fine (ShrEFFlER, I974; SHREFFLER, I970).

En ce qui concerne la sérologie et ses techniques, l'introduction par GORER et MiKulskA (I954) de la technique d'hémagglutination a permis d'augmenter le nombre de spécificités sérologiques décrites. Bien qu'améliorée (STIMPFLING, I96r), par un travail en milieu macromoléculaire, cette technique fut remplacée par la lymphocytotoxicité (GORER et GORMAN, I956), technique aujourd'hui la plus employée dans les diverses espèces où des études d'histocompatibilité sont entreprises, notamment sous la forme de microtechnique mise au point par TERASAKI et MC ClELLAND (rg64) et dont le principe est exposé dans la figure $n^{\circ} 3$. Signalons que la réaction de fixation du complément sur plaquettes (CoLOMBANI et al., I967) est également utilisée dans certains laboratoires.

\section{2. - Résultats génétiques}

Ce système $\mathrm{H} 2$ classique peut être décrit aujourd'hui comme composé de deux séries alléliques à deux loci étroitement liés $(0,5$ p. too de recombinaison) sur un autosome (chromosome I7). Chaque allèle à chaque locus détermine la présence au niveau de la membrane cellulaire d'une molécule glycoprotéique porteuse d'un ou plusieurs déterminants antigéniques.

Chaque produit allélique est défini par un ensemble de spécificités : l'une d'elles est caractéristique de l'allèle considéré, en principe produite exclusivement par cet allèle; elle est qualifiée de privée. Les autres, qui peuvent être communes à plusieurs produits alléliques sont dites publiques. La répartition de différentes spécificités actuellement connues est donnée au tableau I (d'après CorombanI, I $978 a$ ). On observe cependant que ces distinctions sont essentiellement descriptives, puisqu'elles comportent des exceptions $(\mathrm{H} 2-2)$ et des cas extrêmes $\left(\mathrm{H}_{2}-25\right.$ et $\mathrm{H} 2-6)$. Ce modèle, actuellement considéré par les spécialistes comme satisfaisant n'a en fait été suggéré que récemment par KLEIN et SHREFFLER (I97I) et SNELL et al. (I97I). Les interprétations génétiques préalables, conduisaient à un modèle multigénique. Elles ont dû être révisées à la faveur du modèle digénique. Celui-ci satisfaisait l'hypothèse de 1'origine commune des gènes $\mathrm{K}$ et $\mathrm{D}$ dans un gène ancestral ayant ultérieurement évolué par duplication-mutation (SHREFFLER et al., I97 I), hypothèse avancée pour répondre à l'observation de réactions croisées entre les antigènes déterminés aux deux loci (MuRPHy, I974; MURPHy et SHREFFLER, I975).

\section{3. - Résultats biochimiquss}

L'utilisation de la microscopie électronique a permis de montrer la localisation des antigènes classiques à la surface des cellules (MOLLER, I96r ; DAvis et SILVERMAN, I968; AokI et al., I969). La mise au point de techniques basées sur la digestion protéolytique des protéines membranaires (SCHWARTZ et NATHENSON, I97I; TURNER et al., r972) ou sur le fractionnement des membranes cellulaires (NATHENSON, I970) a permis d'isoler ces antigènes pour étudier leur constitution. 


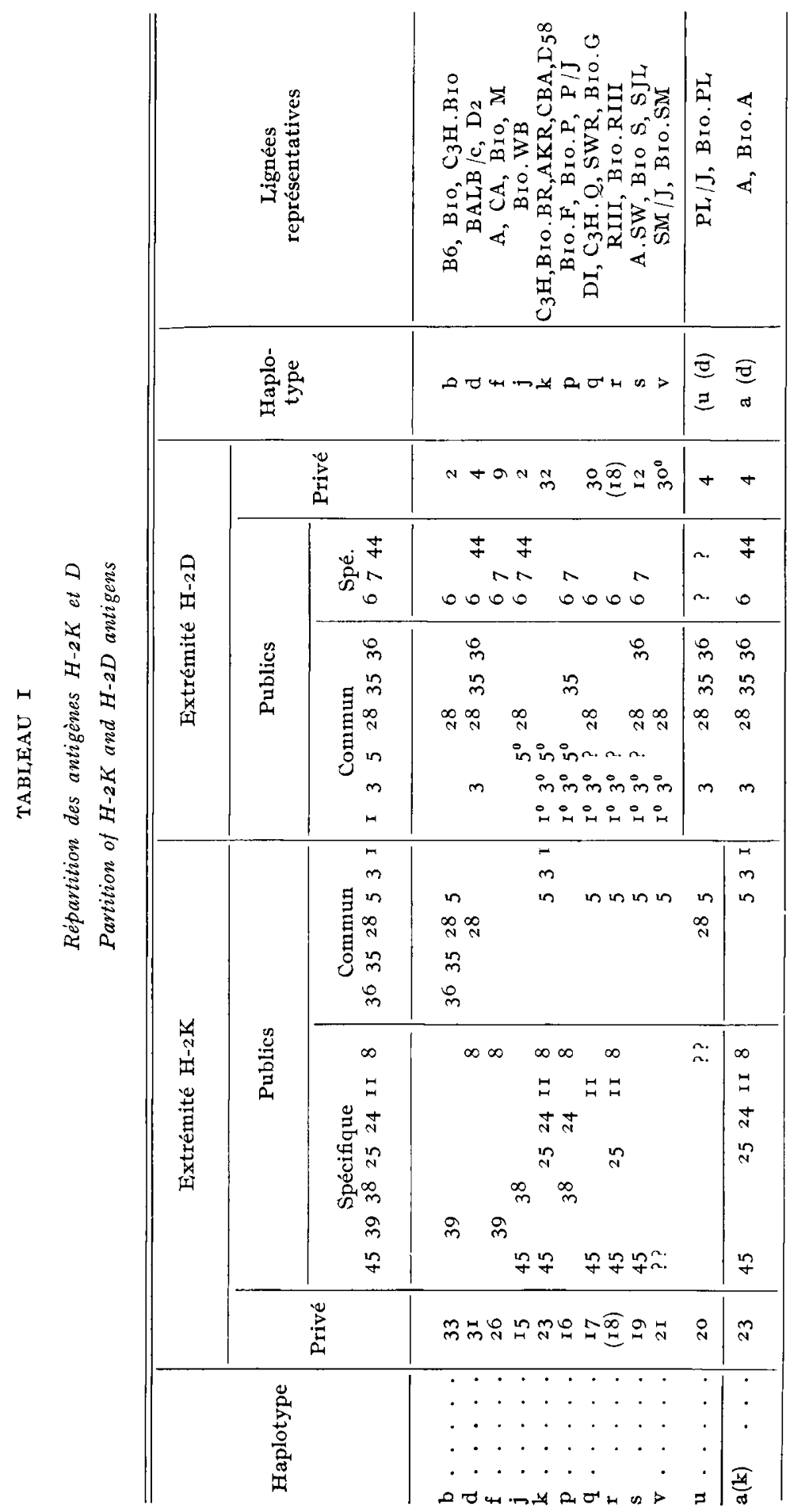

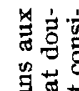

苞苟

要

8

萡西

फs:

วิํำ

ㄹ.

\&

要表

㞋

政

品蔼

형

쿄

is.

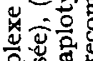

․․ㅇㅇ

웡

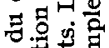

$A$.

论

औ कै

on

目

䟱.

空

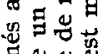

$\Rightarrow$

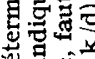

要言

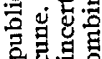

य

为

है

कृ

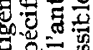

है

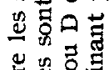

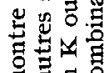

日.

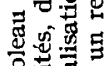

जิ

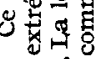

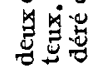




\section{a) L'isolement par clivage enzymatique}

L'action d'enzymes protéolytiques telles que la papaïne (SHImA,DA et NATHENson, I969) permet de recueillir des fragments de molécules portant les déterminants antigéniques. Le poids moléculaire de ces fragments est de 37000 à 44000 . Ce sont des glycoprotéines (SchWARTz et al., I973), constituées de 90 p. Ioo de protéines et de ro $p$. Ioo de cartohydrates.

\section{b) L'isolement par dissolution des membranes}

L'utilisation de détergents dissolvant la membrane cellulaire permet de purifier les glycoprotéines membranaires sous leur forme native, et entre autres les antigènes $\mathrm{H}_{2}$ (SchwARTz et al., I973). Une comparaison importante a été faite par ces auteurs qui ont démontré que le poids moléculaire de la "molécule " isolée par digestion avec la papaïne est de 80 p. roo de celui de la molécule obtenue en travaillant avec les détergents. L'existence d'une forme " dimérique " a été suggérée par l'observation d'une molécule de 90 ooo daltons environ, fractionnable par réduction au 2-mercaptoéthanol, en forme "monomérique " de PM 45000.

c) Composition et structure de la partie glusidique

Cette partie des antigènes $\mathrm{H}-2$ est formée de 5 sucres : galactose, glucosamine, mannose, fucose et acide sialique (Shimada et Nathenson, I969; Muramatsu et Nathenson, I970). L'impossibilité de détecter des différences de charge ou de

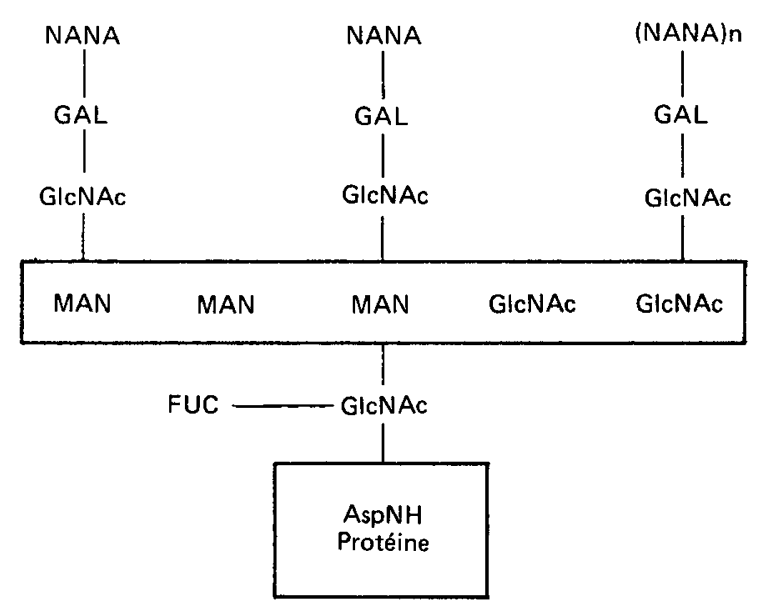

\footnotetext{
NANA $=$ acide sialique.

GAL = galactose.

GlcNAc $=$ glucosamine.

MAN $=$ mannose.

$\mathrm{FUC}=$ fucose.

AspNH $=$ asparagine.
}

FIG. 4. - Structure de la chaîne glucidique des antigènes sérologiquement définis du complexe $H_{-2}$ de la souris

(d'après NATHENSON et CULLFN, I974).

Structure of the carbohydrate chain of the serologically defined antigens of the mouse $H$-2 complex. 
taille entre les résidus carbohydrates de divers haplotypes $\mathrm{H}-2$, laisse supposer que cette partie de la molécule n'a pas de propriétés antigènes; la structure de la chaîne glucidique a été proposée par NATHEnson et Cullen (1974) et est donnée par la figure 4.

\section{d) Structure de la partie protéique}

La partie protéique de la molécule comporte d'une part une chaîne lourde (PM : 40000 environ), et d'autre part, une chaîne légère (PM : I2 000 environ) identifiée à la $\beta 2$-microglobuline (SchwarTz et al., I973; Silver et Hood, I974). Ces deux chaînes sont associées de manière non-covalente.

Une représentation de la molécule $\mathrm{H}_{2}$ et de son organisation est fournie par la figure 5. Signalons que la séquence de la chaîne lourde est partiellement connue aujourd'hui : une trentaine des résidus de la partie $\mathrm{N}$-terminale ont été identifiés alors que la chaîne en comprend sans doute environ $35^{\circ}$ (CunNINGHAM, I977).

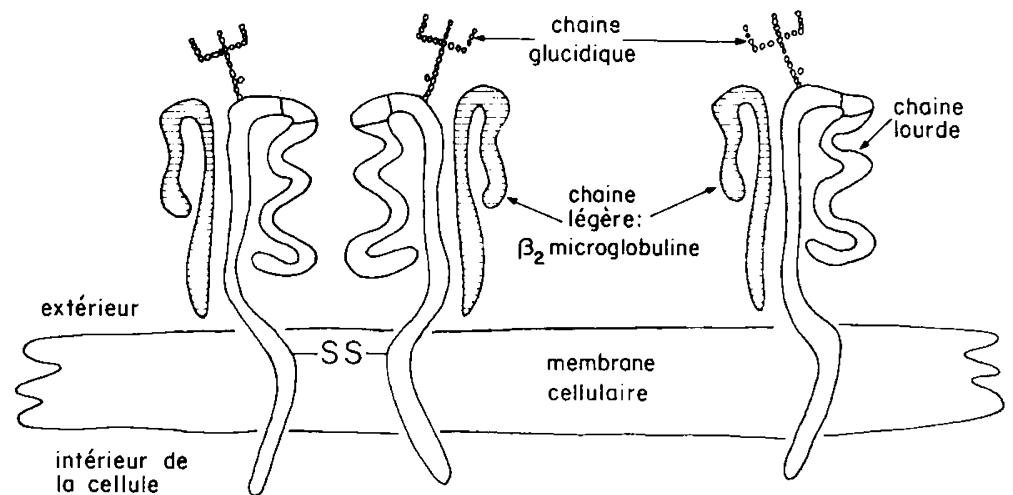

FIG. 5. - Représentation et organisation des antigènes $H-2$ sérologiquement définis, antigènes membranaires

(d'après SNELL, et al., I976).

Representation and organization of the $H$-2 serologically defined antigens, as cell membrane antigens.

I,es antigènes sérologiquement définis sont constitués de deux chaînes protéiques (une légère et une lourde), et d'une chaîne glucidique. L'existence d'une forme dimérique a été suggérée.

e) Nature des sites antigéniques

Nathenson et Muramatsu (I97I) ont mis en évidence que les spécificités antigéniques ne sont pas exprimées par la partie glucidique de la molécule $\mathrm{H}_{2}$. La grande sensibilité des antigènes aux réactifs altérant les protéines a été démontrée dès I957 par KANDUTSCH et REINERT-WENCK; par exemple, en utilisant de 1'urée 6M, ou en plaçant les antigènes à $\mathrm{pH}$ inférieur à 3 ou supérieur à ro, pratiquement toute l'activité antigénique est perdue. Si l'on agit sélectivement sur certains acides aminés, la perte de spécificités peut également être observée lors de la modification chimique de la molécule (PANCAKE et NATHENSON, 1973).

Ces divers résultats permettent de penser que les spécificités sont déterminées par la partie protéique de la molécule. De plus, la composition peptidique des chaînes $\mathrm{H}_{2}$ montre des différences reproductibles entre gènes $\mathrm{H} 2-\mathrm{K}$ et $\mathrm{H} 2-\mathrm{D}$, pouvant correspondre aux "différences sérologiques " (BROWN et al., I974). 


\section{f) Arrangement membranaire}

Les expériences par blocage des spécificités (Boyse et al., I968), ou par la technique de "capping" (voir fig. 6) (NEAUporT-SAUTEs et al., I973) permettent de montrer que chacun des gènes $\mathrm{H}_{2}-\mathrm{K}$ et $\mathrm{H} 2-\mathrm{D}$ contrôle une chaîne glycoprotéique placée à la surface de la membrane. Chacune de ces chaînes est multispécifique, dans le sens qu'elle porte plusieurs spécificités antigéniques déterminées par la structure primaire.

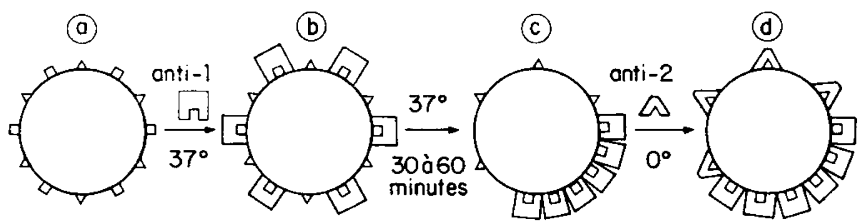

Fig. 6. - Principe de la technique de capping (d'après SNELL et al., I976).

Outline of the technique used for capping experiments.

a) La cellule porte deux types de déterminants antigèniques : $\mathbf{I}(\square)$, et $2(\triangle)$, uniformément répartis à sa surface.

b) Les anticorps anti-i se fixent sur les déterminants I; s'ils sont marqués par la fluorescéine, l'ensamble de la cellule apparaît "vert " au microscope à fluorescence.

c) Les complexes antigènes-anticorps migrent à un pôle de la cellule qui seul apparaît coloré lors de l'observation.

d) Les anticorps anti-2 se fixent sur les déterminants 2 ; deux possibilités :

- ceux-ci sont toujours uniformément répartis s'ils sont portés par des molécules différentes de celles portant les déterminants I;

- ils sont également concentrés à un pôle de la cellule si les deux types de déterminants sont portés par la même molécule.

Le marquage des anticorps anti-2 par de la rhodamine permet d'observer très nettement ce phénomène (coloration "rouge "), et de savoir si les deux types de déterminants sont portés par la même molécule. La figure d représente la première possibilité.

\section{III. - Gènes codant pour certains facteurs du complément La région $\mathbf{S}$}

\section{I. - Mise en éviderce de la Région $S$}

Dès I963, SHREFFLER et OWEN ont décrit des variations quantitatives d'une $\beta$-globuline sérique, détectée par immuno-précipitation en gel, à 1'aide d'un immunsérum de lapin. Contrôlées par le locus Ss (Serum serological), étroitement lié au complexe $\mathrm{H}_{2}$, ces variations (de l'ordre de 20 fois) ont permis de définir deux principaux allèles : $\mathrm{Ss}^{\mathrm{h}}$ (high) et $\mathrm{Ss}^{1}$ (low). La situation exacte du locus Ss entre H2-K et $\mathrm{H}_{2}-\mathrm{D}$ a alors permis de définir la région $\mathrm{S}$ du complexe $\mathrm{H}_{2}$ (SHREFFLER, 1965). De plus, des variations parmi les lignées Ss $^{\text {h }}$ existent, ainsi que selon le sexe (mâle $>$ femelle). La protéine Ss a un poids moléculaire de 120 ooo et est composée de

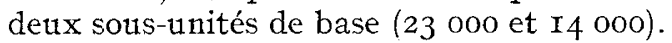

Par la suite, l'immunisation de souris de diverses lignées avec la protéine Ss, a permis de produire un immun-sérum capable de reconnaître une différence allotypique (SHREFfizr et PASSMORE, I97I). Contrôlés par un locus inséparable de Ss, deux allèles ont été décrits : 1'un dominant, Slp ${ }^{a}$ détermine la présence de 
1'allotype, 1'autre Slpo détermine son absence. L'allotype n'est présent normalement que chez le mâle adulte $\mathrm{Ss}^{h}$ d'où la dénomination (Slp = Sex limited protein). Cependant, il peut être induit chez la femelle par administration de testostérone, cette dépendance hormonale n'étant cependant pas absolue puisqu'une souris sauvage $\mathrm{Ss}^{h}$ a été observée transmettant le caractère Slp aussi bien à ses descendants femelles que mâles. Comme pour Ss, les lignées porteuses de 1'allotype présentent d'importantes variations quantitatives.

\section{2. - Contrôle de certains facteurs de complément}

Demant et al. (I973), Capcova et Demant (I974) ont démontré que les différences du taux de complément hémolytique total sont contrôlées par le complexe $\mathrm{H} 2$; l'analyse de recombinants a montré que le locus en cause se situe dans la région $\mathrm{S}$; la question de savoir si la protéine Ss-Slp était une composante du complément se trouvait donc posée.

Les résultats de HANSEN et al. (1975) ont suggéré une relation étroite, puisqu'une corrélation de 0,8 au moins existait entre le taux sérique Ss et le taux de complément; d'autre part, l'addition de fragment $\mathrm{F}(a b)_{2}$ d'anticorps anti-Ss au sérum de souris réduit considérablement son activité complémentaire.

La protéine Ss est maintenant assimilée au constituant $C_{4} d u$ complément et ceci a été démontré par plusieurs équipes : CuRMan et al., I975; LACHMANN et al., r975; de plus, il semble que des réactions croisées avec le $\mathrm{C}_{4}$ humain soient possible (MEO et al., I975a) ce qui indique une ressemblance structurale.

\section{3. - Discussion}

Il convient d'insister sur l'importance de la description de la région $\mathrm{S}$ pour l'étude du complexe $\mathrm{H} 2$. En effet, présentant des produits alléliques bien connus, et se trouvant dans une situation centrale, entre $\mathrm{H} 2-\mathrm{K}$ et $\mathrm{H} 2-\mathrm{D}$, son utilisation dans l'étude des recombinants a été essentielle. De plus, le contrôle de facteurs du complément laisse apparaître un rôle fondamental dans les nombreux processus immunologiques dans lesquels interviennent ces protéines sériques.

Signalons enfin que FERREIRA et NUSSENZWEIG (I976) ont montré que le taux du facteur $\mathrm{C}_{3}$ chez les souriceaux est contrôlé par au moins 2 gènes dont un localisé dans le complexe $\mathrm{H} 2$.

\section{IV. - Les gènes Ir.}

\section{I. - Définitions}

Les gènes Ir contrôlent par définition l'aptitude à développer une réponse immunitaire humorale spécifique contre des antigènes $T$ dépendants.

La première démonstration du déterminisme génétique de la réponse immunitaire a été faite chez le cobaye par LEVINE et al. (I963); par la suite, la souris a été l'espèce la plus étudiée du fait de l'existence de nombreuses lignées consanguines de souches congéniques résistantes et de recombinants. 


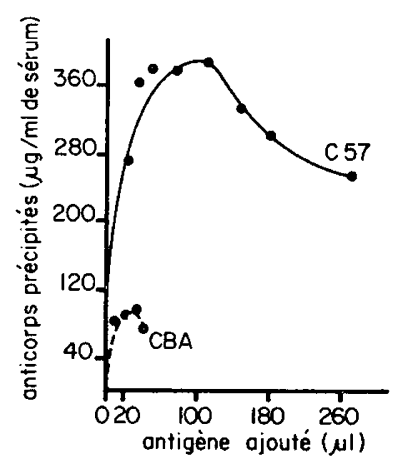

FIG. 7. - Précipitation quantitative d'anti- $(T, G)-A--L$ contenu dans le sérum après immunisation par cet antigène (d'après Mc DEVITT, I968). Quantitative precipitation of anti- $(T, G)-A--L$ contained in the serum after immunization with this antigen.

I.ignée $\mathrm{C}_{57}$ : bonne réponse.

Lignée CBA : faible réponse.

Comme chez le cobaye, le niveau de la réponse immunitaire à certains antigènes définis (particulièrement à des polypeptides synthétiques simples) est apparu être contrôlé génétiquement (MC DEVITT et TyAN, I968; BENACERRAF et MC DEVITT I972; GASSER et SiLVERS, I974). Ces observations ont été faites en immunisant différentes lignées avec un antigène donné; toutes ne répondent pas (mesure de la réponse humorale par le taux d'anticorps produit) de la même manière. On peut citer l'exemple démonstratif des travaux de M. DEviTT et SELA (I965), qui analysent la réponse au ( $T, G$ )-A- $-I$, chez deux souches de souris consanguines $\mathrm{C}_{57}$ et $\mathrm{CBA}$. Après immunisation, les souris $\mathrm{C}_{57}$ sont bonnes productrices d'anticorps, tandis que les CBA sont mauvais répondeurs (voir fig. 7). Les hybrides $\mathrm{F}_{1}\left(\mathrm{C}_{57}\right.$ $\times \mathrm{CBA}$ ) sont répondeurs. Les back-cross avec les parents non-répondeurs donnent une ségrégation I:I avec un mélange du phénotype des hybrides $F_{1}$ et des parents

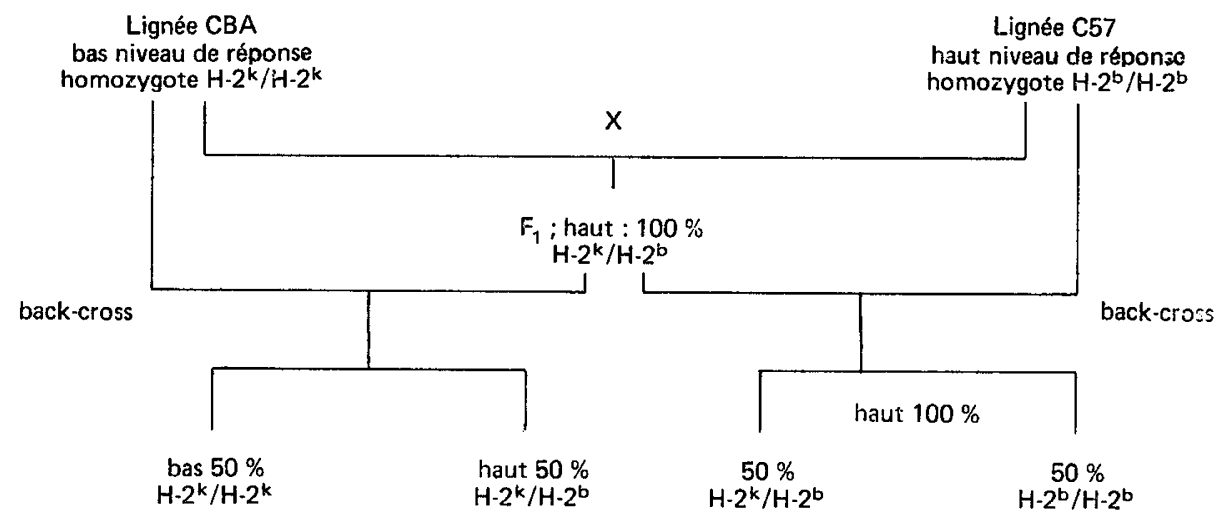

Fig. 8. - Contrôle génétique du niveau de la véponse immunitaire humovale au $(T, G)-A--L$ (d'après Mc DEviT'T et al., r972).

Genetic control of the humoral immune response level to $(T, G)-A--L$.

- Le haut niveau domine le bas niveau.

- Caractère transmis avec $1^{\prime}$ haplotype $\mathrm{H}-2^{b}$. 
non-répondeurs. Ainsi, sur le plan génétique, la réponse immunitaire à cet antigène est contrôlée par un gène autosomal dominant (voir fig. 8), dénommé Ir-I, et dont deux allèles sont ainsi mis en évidence, chacune des lignées considérées étant homozygote. La localisation de ce gèns Ir-l a été ensuite précisée; placé au sein du complexe H2 (Mc DeviT' et al., I972), il a constitué le premier marqueur définissant la région $I$.

\section{2. - État des résultats actusls}

Les animaux étudiés présentent une différence quantitative et qualitative dans la synthèse des anticorps; cependant, le gène Ir-I n'entraîne pas de réponse de type "tout ou rien " comme cela a pu être montré pour les copolymères de 2 ou 3 acides aminés (BENACERRAF et KATZ, r975).

\section{TABLEAU 2}

Liste des antigènes utilisés dans l'étude des gènes Ir chez la souris

(d'après DEBRÉ, I978 et d'après BENACERRAF et KATZ, 1975)

Antigens used for mouse Ir genes studies

I) Copolymères linéaires d'acides aminés (série L) :

- GLA : Terpolymère de L-acide glutamique L-1ysine L-alanine
$\mathrm{GLA}_{5}:\left(\mathrm{Glu}^{5}{ }^{7} \mathrm{Lys}^{38} \mathrm{Ala}^{5}\right)^{n}$
$\mathrm{GLA}_{10}$ : $\left(\mathrm{Glu}^{54} \mathrm{Lys}^{3{ }^{6}} \mathrm{Ala}^{10}\right)^{n}$
$\mathrm{GI}_{1} \mathrm{~A}_{30}:\left(\mathrm{Glu}^{35} \mathrm{Lys}^{35} \mathrm{Ala}^{30}\right)^{n}$

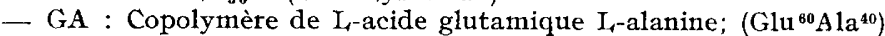

- GAT : Terpolymère de $\mathrm{L}_{\text {-acide }}$ glutamique $\mathrm{L}_{\text {-alanine }} \mathrm{L}_{\text {-tyrosine }}$ $\mathrm{GAT}_{10}$ : (GLU $\left.{ }^{60} \mathrm{Ala}^{30} \mathrm{Tyr}^{10}\right)^{n}$

- GLPro : Terpolymère de L-aside glutamique L-lysine L-proline GLPro $_{5}$ : $\left(\mathrm{Glu}^{5}{ }^{7} \mathrm{Lys}^{38} \text { Pro }^{5}\right)^{n}$

- GLPhénol : Terpolymère de L-acide glutamique L-lysine L-phénol GLPhénol $_{11}:\left(\text { Glu }^{63} \mathrm{Lys}^{36} \text { Phé }^{11}\right)^{n}$

- GLT : Terpolymère de L-acide glutamique L-lysine L-tyrosine $\mathrm{GI}_{1} \mathrm{~T}_{5}:\left(\mathrm{Glu}^{5}{ }^{7} \mathrm{Lys}^{38} \mathrm{Tyr}^{5}\right)^{n}$

2) Copolymères branchés d'acides aminés (série $I_{\text {L }}$ :

- (T, G)-A- - L : Polymère à plusieurs chaînes branchées de poly $\mathrm{L}_{1}$-(tyrosine, acide glutamique)-poly D, L-alanine--poly L-lysine

- (phé, G)-A- -L : Polymère à plusieurs chaînes branchés de poly L-(phényl-alanine, acide glutamique)-poly D, L-alanine--poly L-lysine

- (H, G)-A- - L : Polymère à plusieurs chaînes branchées de poly L-(histidine, acide glutamique)-poly D, L-alanine--poly L-lysine

3) Alloantigènes murins :

- IgA : Déterminants allotypiques d'IgA; myélome de la lignée BALB/c

- IgG : Déterminants allotypiques d'IgG; myélome de la lignée BALB/c

- H-Y : Antigène d'histocompatibilité codé par le chromosome Y

- Thy I.I : Antigène des thymocytes (antigène Théta)

- Ea. I : Antigène érythrocytaire

- Thyroglob : Thyroglobuline

4) Antigènes " étrangers " :

- RE : Extraits de Jacobée

- NASE : Nucléase de staphylocoques

- X.I : Antigène de transplantation associé aux leucémies
- 1-OM : Dosa faible d'ovomucoïde de poulet

- 1-BGG : Dose faible de $\gamma$-globuline bovine

- 1-OVA : Dose faible d'ovalbumine

- LDH : Déhydrogénase lactique $B$ de porc 
Antigènes

\begin{tabular}{|c|c|c|c|c|c|c|c|c|c|c|c|c|}
\hline \multicolumn{13}{|c|}{ Hoplotype } \\
\hline 0 & b & d & $f$ & i & $k$ & $n$ & p & $q$ & $r$ & $\mathbf{s}$ & $t$ & $v$ \\
\hline 0 & $x$ & & & & 0 & & 0 & 0 & 0 & & & \\
\hline 0 & $x$ & & & & 0 & & & 0 & & & & \\
\hline & & & & & & $x$ & $x$ & $x$ & & & & \\
\hline & & & & & & & $x$ & $x$ & & & & \\
\hline & & & & & & $x$ & $x$ & X & & $x$ & & \\
\hline$x$ & $x$ & $x$ & $x$ & & $x$ & & $x$ & $x$ & $x$ & & $x$ & $x$ \\
\hline$x$ & $x$ & & $x$ & & $x$ & & & & & $x$ & & \\
\hline$x$ & $x$ & & $x$ & & $x$ & & $x$ & $x$ & & $x$ & & \\
\hline
\end{tabular}

(T,G)-A--L

(Phé,G)-A--L

$(H, G)-A--L$

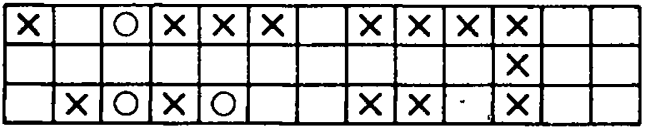

IgA

IgG

H-Y

Thy 4-1

Ea 1

Thyroglob

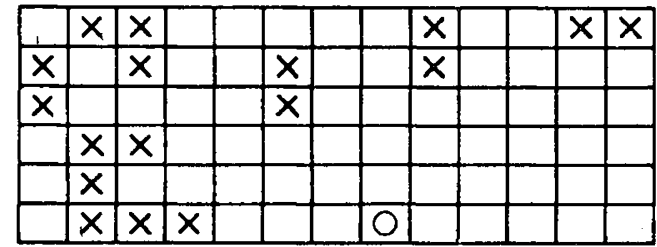

RE

Nose

$\times 1$

$l-O M$

l-BGG

l-OVA

$\mathrm{LDH}_{\mathrm{B}}$

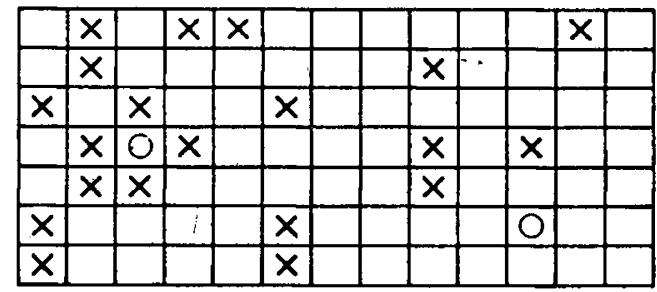
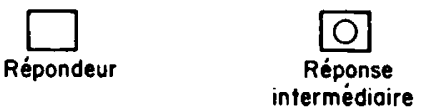

\section{$x$}

Réponse foible ou nulle

FIG. 9. - Ríponses controlées par lcs gènes Ir chez la souris (d'après BENACERRAF et KATZ, I975).

Ir genes-controlled responscs in the mouse.

L'étude systématique de la réponse immunitaire à 24 antigènes (voir tabl. 2) a permis d'avoir aujourd'hui une quantité d'informations importantes sur le contrôle génétique de la réponse humorale.

L'ensemble dcs réponses obtenues est représenté sur la figure 9.

Les observations suivantes peuvent être retenues:

- Malgré quelques exceptions, les gènes Ir semblent distincts et spécifiques pour chaque antigène.

- Quand un nombre suffisant d'antigènes est utilisé, à quelques exceptions près, il n'existe pas de souches qui diffèrent génétiquement (haplotype différent) et présentant un même spectre phénotypique de réponse immune.

$\mathrm{D}$ a nombreux gènes Ir ont pu être localisés avec précision. L,eur relation avec les gènes du complexe majeur d'histocompatibilité, observée préalablement par 
Mc DeviT'T et Tyan (I968), s'est avérée être très strictz, puisque, propriétミ́ remarquable, les gènes Ir sont situés sur le segment $\mathrm{H}-2$. Cette localisation a ainsi permis la division de la région chromosomique $\mathrm{H}_{2}$ en quxtre régions $K, I, S, D$, les gènes $I r$ se situant dans la région $I$, donc distincts de gènes codant pour les spécifucités sérologiques d'histocompatibilité contrôlés par les régions $K$ et $D$.

L'étude des réponses de recombinants a de plus permis de diviser cette région en plusieurs sous-régions, la localisation de certains gènes Ir n'ayant pas encore pu être réalisée avec précision. La figure ro donne la répartition des gènes actuellement placés sur la carte $\mathrm{H}_{2}$, dans les sous-régions $I-A, I-B$ et $I-C$, cette dernière ayant été en fait définie par d'autres marqueurs que nous étudierons ensuite.

Contrairement à l'idée selon laquelle la plupart des gènes contrôlant la réponse à des antigènes distincts étaient à différents loci, la démonstration qu'une réponse immune peut être contrôlée par plusieurs loci distincts est récente. La vérification de cette hypothèse, évoquée pour la première fois par Strmpfling et Durham

Régions

Sous-Régions

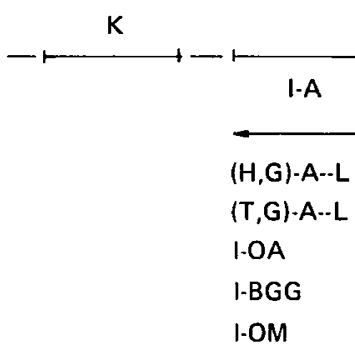

$\lg G$

Nase

GLT

(1)

GAT

GLPro

(Phé,G)-A-L

(1)

(T,G)-A--L

$\lg A$

RE

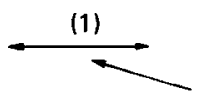

GLPhé

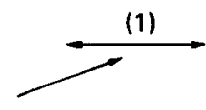

$\mathrm{LDH}_{\mathrm{B}}$

FIG. Io. - Carte génétique des gènes Ir situés dans le complexe H-2 de la souris

(d'après BENACERRAF et KATZ, I975; et d'après DAVID, 1977).

Genetic mapping of the Ir genes within the mouse $H-2$ complex.

(I) : gènes Ir non encore localisés avec précision 
(I972), est due aux travaux de DORF et son équipe. Il est possible d'obtenir un taux élevé d'anticorps contre le GL-phénol, chez des recombinants présentant des crossing-over entre haplotypes non répondeurs ou, chez des hybrides issus de parents non répondeurs; la réponse à ce terpolymère est donc déterminée par l'interaction complémentaire de deux gènes, l'un $\beta$ situé dans la sous-région I-A ou I-B, l'autre $\alpha$ dans la sous-région I-C ou S (DoRF et al., I975), chacun étant dominant et la complémentation se réalisant principalement en position cis. Une complémentation du même ordre a également été démontrée pour d'autres antigènes (DORF et al., I976a; I976b), et les résultats de KATZ et al. (I976) montrent que la coopération entre les cellules $T$ et $B$ au cours de la réponse immunitaire nécessite la présence des deux gènes $\alpha$ et $\beta$ dans chaque type cellulaire.

$\mathrm{Au}$ niveau cellulaire, les gènes Ir sont exprimés dans les cellules immunocompétentes (Mc DEWITT et BENACERRAF, I969) que sont les thymocytes. Fin ce qui concerne les cellules T, l'expression des gènes Ir est admise (BENACERRA F et MC DEWITT, I972). Par contre, leur expression par les macrophages est très controversée, et un certain nombre de résultats plaident pour une non-expression des gènes Ir par les cellules B (MC DEWITT, I968), puisque le phénotype non-répondeur de certaines lignées n'est pas dû à un déficit quantitatif de cellules secrétrices d'anticorps.

\section{3. - Conclusions}

Pour compléter l'exposé des résultats précédents, plusieurs remarques doivent être faites.

I) Il est nécessaire de souligner qu'il est prématuré de tenter une analyse rationnelle de ces faits (DEBRÉ, I978). En effet, les gènes Ir ne sont définis que par leur expression phénotypique dans la réponse immunitaire humorale; la nature de leurs produits est actuellement inconnue, leur rôle exact et leur mode d'action encore mal définis. Leur localisation au niveau du complexe $\mathrm{H} 2$, s'il s'agit d'une propriété remarquable, n'a en aucun cas reçu d'explication définitive; bien sûr, cette situation enrichit considérablement le rôle et l'importance attribués à la région chromosomique portant le complexe $\mathrm{H}_{2}$ de la souris.

\section{TABLEAU 3}

Gènes Ir non localisés dans le complexe $\mathrm{Hz}$

Ir genes not within the Ha complex

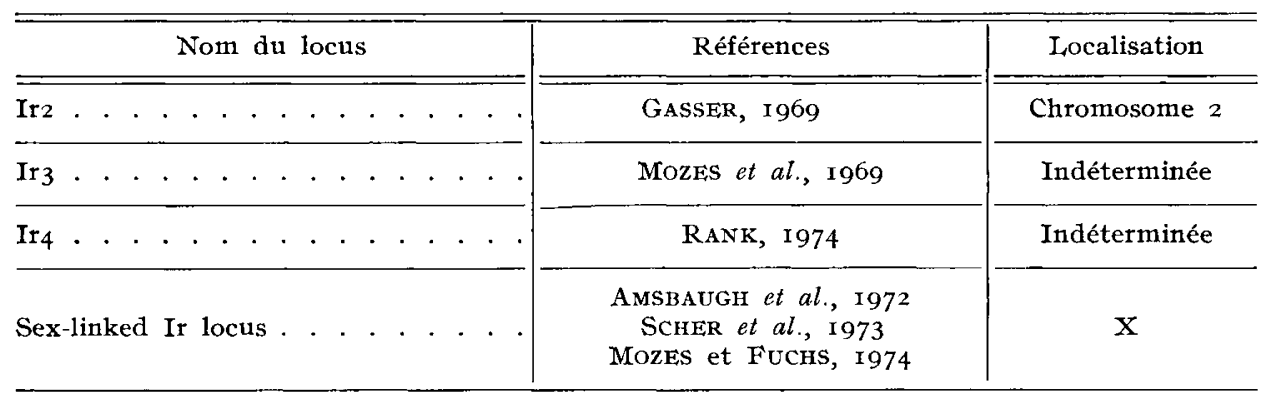

Établi d'après SNELL et al., 1976. 
2) De la même manière qu'il existe plusieurs loci d'histocompatibilité, plusieurs loci Ir ont été définis dans la littérature, soit sur d'autres autosomes (différents donc du $n^{\circ}$ I7 portant $\mathrm{H}_{2}$ ) soit sur le chromosome $X$ (voir tabl. 3), et l'on peut supposer que d'autres seront déterminés (SNEI.L et ai., I976). A noter enfin la liaison existant entre un locus contrôlant la réponse à l'antigène $\alpha-I, 3$ dextrane et un gène de structure, codant pour la région constante des chaînes lourdes des immuno-globulines (RIBLER et al., I975), observation pour l'instant assez isolée.

\section{V. - Les gènes Ia : "région I associated"}

Parmi les 4. régions alors individualisées (K, I, S et $\mathrm{D}$ ), il est apparu que les produits de 3 d'entre elles (les régions $\mathrm{K}, \mathrm{S}$ et $\mathrm{D}$ ) étaient connus; par contre, les produits de la région I restaient inconnus, les gènes Ir n'étant définis que par leur manifestation au niveau phénotypique dans la réponse immunitaire humorale.

L'idée de rechercher les produits des gènes situés dans la région I a donc été émise, et l'existence de recombinants, ne différant entre eux qu'au niveau de cette région $\mathrm{I}$ (et identiques en $\mathrm{H} 2 \mathrm{~K}, \mathrm{~S}$ et $\mathrm{D}$ ), a rendu possible ces travaux. En effet, si les produits hypothétiques de la région I étaient exprimés au niveau de la membrane cellulaire, ces lignées recombinantes permettaient de réaliser des alloimmunisations particulièrement adéquates pour produire des anticorps les détectant.

\section{I. - Mise en évidence des Gènes Ia}

Cette situation d'immunisation privilégiée a permis à de nombreuses équipes de produire des anticorps (GOTZE et al., I973; HAUPTFELD et al., I973; SACHS et CONE, r973; HAMMERLing et al., I974; DAVID et SHREFFler I974a, $b$; Davies et Hess, 1974) détectant des produits de la région $I$. L'étude systématique de ces anticorps a conduit progressivement à la description de 23 spécificités antigéniques.

\section{TABLEAU 4}

Répartition des spécificités Ia parmi les diverses lignées

(d'après CoLOMBANI, I978a)

Partition of Ia specificities in the different strains

\begin{tabular}{|c|c|c|c|c|c|c|c|c|c|c|c|c|c|c|c|c|c|c|c|c|c|c|c|}
\hline Haplotype & I & 2 & 3 & 4 & 5 & 6 & 7 & 8 & 9 & IO & I I & 12 & I3 & I 4 & I 5 & I 6 & I 7 & I 8 & I9 & 20 & $2 \mathrm{I}$ & 22 & 23 \\
\hline b & - & - & 3 & $\longrightarrow$ & 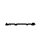 & - & $\ldots$ & 8 & 0 & 一 & - & - & $\ldots$ & $\ldots$ & 5 & $\ldots$ &. & $\ldots$ & - & 30 & & & \\
\hline $\mathrm{d}$ & - & - & - & - & 一 & 6 & 7 & 8 & - & 一 & II & 一 & - & - & $\begin{array}{l}5 \\
15\end{array}$ & I6 & - & - & - & — & - & - & - \\
\hline f & $\mathrm{I}$ & 一 & 一 & 一 & 5 & - & 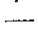 & $\ldots$ & $\longrightarrow$ & - & 一 & - & 一 & I4 & 二 & 一 & I7 & I 8 & - & - & 一 & - & - \\
\hline k & I & 2 & 3 & - & - & - & 7 & 一 & - & - & - & 一 & $\longrightarrow$ & — & I5 & 一 & I 7 & I 8 & 19 & - & - & 22 & 23 \\
\hline $\mathrm{p}$ & 一 & 一 & $\longrightarrow$ & $\longrightarrow$ & 5 & 6 & 7 & - & 一 & - & - & 一 & I3 & - & - & I6 & - & - & - & - & 一 & $\longrightarrow$ & $\longleftarrow$ \\
\hline$q$ & - & - & 3 & - & 5 & $\cdots$ & 一 & - & 9 & Io & - & - & 13 & $\longrightarrow$ & 一 & I6 & - & - & - & - & - & - & - \\
\hline$r$ & I & - & 3 & $\longrightarrow$ & 5 & $\longrightarrow$ & 7 & $\longrightarrow$ & $\longrightarrow$ & - & - & 12 & - & $\longrightarrow$ & 一 & - & 17 & - & 19 & - & - & - & - \\
\hline $\mathbf{S}$ & - & - & - & 4 & 5 & - & - & 一 & 9 & - & - & I2 & $\longrightarrow$ & $\longrightarrow$ & - & - & I 7 & I 8 & - & - & - & - & 23 \\
\hline
\end{tabular}

Chaque ligne du tableau représente la formule antigénique de l'haplotype. Le chiffre indique la présence de l'antigène, - son absence. L,es antigènes Ia déterminés par les haplotypes $j$, $v$ et u n'ont pas encore été définis avec précision. 
TABLEAU 5

Carte génétique et distribution des spécificités Ia sur les sous-régions de la région I du complexe $\mathrm{Hz}$ (d'après Colombani, 1978a)

Chromosome map and distribution of I specificities in the I subregions within the Ha complex

\begin{tabular}{|c|c|c|c|c|c|}
\hline \multirow[t]{2}{*}{ Sous-régions } & I-A & I-B & $I-J$ & $\mathrm{I}-\mathrm{E}$ & $\mathrm{I}-\mathrm{C}$ \\
\hline & $\begin{array}{c}\mathrm{I}, 2^{k}, 3,8,9 \\
\mathrm{I}^{d}, \mathrm{I} 7, \mathbf{I} 8, \mathbf{I} 9,20\end{array}$ & & 23 & 22 & $6,7,2 \mathrm{I} p$ \\
\hline Spécificiés Ia & $\leftarrow \ldots-4^{s}, 5$, I 2, I 3 , & I6- - & $f^{f}-$ & & $\ldots \ldots$ \\
\hline
\end{tabular}

Ies chiffres désignent les spécificités Ia. I,es chiffres avec une lettre en exposant désignent les spécificités privées; la lettre indique l'haplotype d'origine. Les pointillés signifient que les spécificités n'ont pas pu être attribuées à une seule région.

Par définition, les gènes correspondants sont appelés gènes Ia ("I associated"). Le tableau 4 fournit la répartition des spécificités dans les différentes lignées; on observe que, comme pour les antigènes classiques, certaines spécificités ne sont présentes que dans une seule lignée ( $\operatorname{Ia~} 2,4$, Io...) et d'autres dans plusieurs lignées (Ia $5,7,9 \ldots$ ). Le tableau 5 donne la carte génétique des gènes Ia. Certains gènes ne sont pas encore localisés avec précision (Ia I2, I3...); signalons que la spécificité $I a_{22}$ a permis de définir une nouvelle sous-région I.E; la sous-région I.J code pour la 23 mais a été isolée par la présence d'autres gènes qua nous décrirons plus tard.

\section{2. - Distribution cellulaire des antigènes Ia}

Une caractéristique essentielle des antigènes Ia est leur distribution cellulaire restreinte, contrastant avec la distribution ubiquitaire des antigènes sérologiquement définis. Le tableau 6 précise la distribution des antigènes Ia.

\section{TABLEAU 6}

Distribution tissulaive des antigènes Ia

(d'après COLOMBANI, I975)

Tissue distribution of Ia antigens

- Fortemcnt représentés (majorité de la population cellulaire et forte densité par cellule) : lymphocytes B d'origine splénique ou ganglionnaire $(*)$.

- Moyennement représentés (fraction de la population cellulaire et/ou dcnsité variable ou faible par cellule) : lymphocytes $T$ d'origine splénique, ganglionnaire ou thymique (*) (thymocytes mûrs, résistants à la cortisone), macrophages, spermatozoïdes, cellules épithéliales.

- "Absent" (= non détectés par absorption et/ou test direct) : érythrocytes, thrombocytes, fibroblastes, tissu hépatique, rénal, cérébral.

$\left(^{*}\right)$ Il est possible que certains antigènes soient spécifiques de certains types cellulaires. 
Citte caractéristique est utilisée dans la préparation des anticorps anti Ia. En effet, l'étude rétrospective des nombreux sérums "anti $\mathrm{H}_{2}$ " (SD) a montré qu'ils contenaient très souvent des anticorps anti-Ia en plus des anticorps " anti$\mathrm{H} 2$ ". Pour purifier ces sérums, on peut séparer les deux types d'anticorps par absorption-élution en utilisant des cellules ne portant qu'un des types de déterminants antigéniques, par exemple des thrombocytes ou des lymphocytes $T$ (Colombani et al., I975, I976).

\section{3. - Caractérisation biochimique des antigènes Ia}

L'étude par immunofluorescence des antigènes Ia de la membrane cellulaire a montré qu'ils étaient indépendants des antigènes $\mathrm{H} 2 . \mathrm{K}$ et $\mathrm{H} 2 . \mathrm{D}$, ainsi que les immuno-globulines membranaires (UNANUE et al., r974). Les études immunochimiques par immunoprécipitation indirecte ont confirmé ces faits, et ont montré que les molécules porteuses de spécificités Ia contrôlées par des sous-régions distinctes étaient également séparables les unes des autres (CULLEN et al., I974; ViTTE'TA et al., I974). Les résultats récents de CULLEN et al. (I976) démontrent par contre que des spécificités contrôlées par la même sous-région sont sur la même molécule.

Les antigènes Ia sont des glycoprotéines (CULLEN et al., I974); les spécificités sont portées par la partie protéique (CULLEN et al., I975), ce qui confirme les analogies observées avec les antigènes SD (FREED et NATHENSON, I977). L'étude électrophorétique de la partie protéique de la molécule révèle deux fractions de PM 35000 et 25000 , avec dans certains cas, lorsque la préparation a été faite en conditions non réductrices une troisième fraction de PM 58000 ; la sensibilité à la réduction permet de penser qu'il existe deux chaînes liées par des ponts disulfure, ou par des liaisons hydrogène, la nature covalente ou non des liaisons étant encore discutée selon les antigènes étudiés. L'hypothèse de deux chaînes dont une seule porte les spécificités antigéniques et serait codée par le complexe $\mathrm{H} 2$ a été formulée (CULLEN et al., I976). Cette structure correspondrait à ce qui est connu chez l'homme (SNARY et al., I976) et semble devoir être confirmée par des études de séquences récentes (Conk et al., I977).

\section{4. - Discussion}

La mise en évidence des antigènes Ia a été plus tardive dans la mesure où elle nécessite une purification de la préparation cellulaire utilisée; les antigènes Ia sont détectés par sérologie en utilisant le test de lymphocytoltoxicité; or, 1'action des anticorps anti-Ia ne se fait que sur certaines cellules, porteuses des antigènes; sans purification, le pourcentage de cellıles tuées n'est pas très élevé, et la réaction apparaît " partielle "; pour pouvoir tester convenabl=ment ces spécificités, il a donc fallu mettre au point diverses techniques d'enrichiss:anent, en 1ymphocytes B par exemple, des préparations.

La localisation identique des gènes Ir et Ia soulève le problème de savoir si les produits inconnus des gènes Ir sont ou ne sont pas les antigènes Ia. Jusqu'à présent, aucun fait ne permet de confirmer cette assimilation; de plus, la localisation de spécificités Ia dans les sous-régions I-J et I-F, où aucun gène Ir n'est défini, favorise la thèse de gènes structurellement différents. 


\section{VI. - Etude de la réponse allogénique}

Les groupes de gènes que nous avons étudiés jusqu'à présent contrôlent des mécanismes de la réponse humorale (Ir; Ss-Slp), ou du moins ont été détectés à l'aide de techniques sérologiques (SD; Ia). Or, il convient de souligner la remarquable propriété qu'a le complexe $\mathrm{H}_{2}$ de comporter d'autres gènes, contrôlant des mécanismes de la réponse immunitaire à médiation cellulaire que nous allons maintenant considérer.

FRADEIIZI (I978) définit la réponse allogénique comme la réponse de type immunitaire des lymphocytes d'un individu confrontés avec les lymphocytes d'un autre individu génétiquement différent.

La compréhension des mécanismes de la réponse allogénique a bénéficié de la mise au point de méthodes de culture cellulaire in vitro. Il est en effet possible, in vitro:

I) D'observer directement le déclenchement et le déroulement de la réponse allogénique.

2) D'étudier les populations cellulaires impliquées.

3) De varier la disparité génétique entre donneur et receveur.

Ces aspects pouvant bien sûr être complétés par des observations in vivo.

\section{A. - Événements cellulaires de la réponse allogéniqu?: lewr déroulement}

I. Culture mixte lymphocytaire $=M L R$

Lorsque deux populations lymphocytaires provenant de 2 donneurs différents entrent en contact, chacwne d'elle va développer uns réponse allogénique contre l'autre (BA.IN et al., I964; BACH et HIRSCHORN, I964), caractérisée aw début par vne pro-

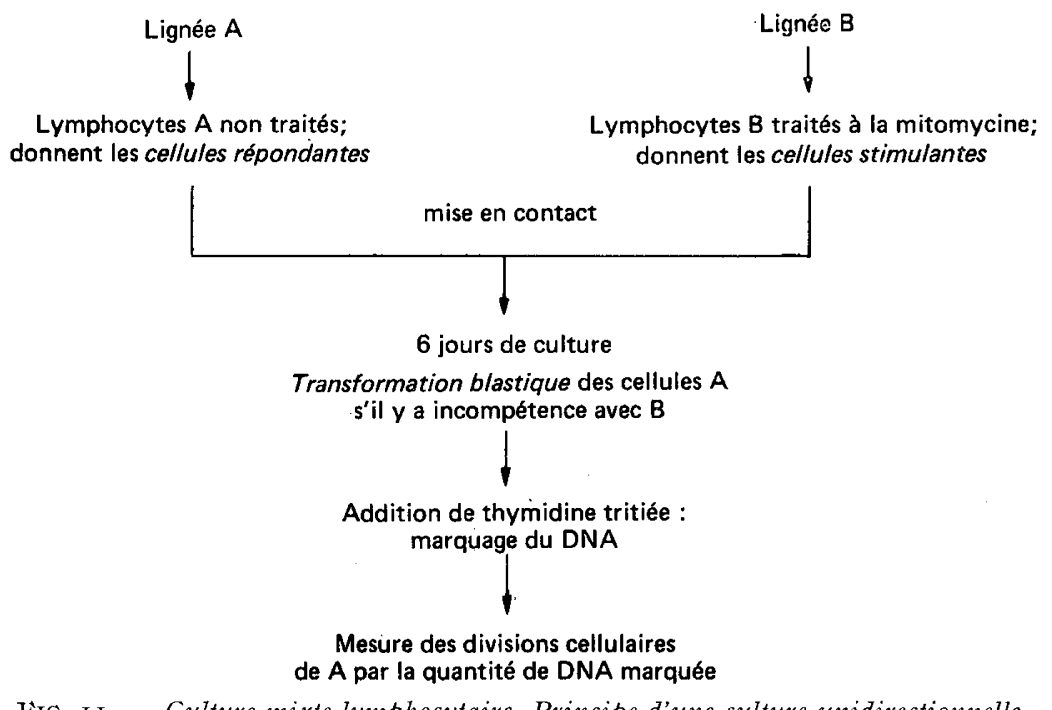

FIG. II. - Culture mixte lymphocytaive. Principe d'une culture unidirectionnelle (d'après CHRISTEN, 1975).

Mixed lymphocyte culture. Description of an unidirectional culture. 
lifération lymphocytaire. C'est ce phénomène qui est actuellement étudié sous le nom de culture mixte lymphocytaire (ou réaction lymphocytaire mixte), notée MLR (mixed lymphocyte reaction).

La réponse peut cependant être rendue unidirectionnelle en traitant l'une des populations (devenue "stimulante") par des agents bloquant la division cellulaire : mitomycine $\mathrm{C}$ ou irradiation $\mathrm{X}$. L'autre population (dite " répondante ") est alors seule capable de développer une réponse allogénique (BACH et Voynow, I966); c'est le principe de cette réaction qui est représenté dans la figure II.

L,a prolifération correspond à 1'apparition de cellules blastiques (SCHREK et DoNNEI, I, I96I), plus volumineuses que les 1ymphocytes, qui se multiplient. Au point de vue cinétique, le nombre des cellules augmente pour atteindre un maximum vers le $5^{\mathrm{e}}-6^{\mathrm{e}}$ jour (voir fig. I2). On peut alors mesurer quantitativement l'intensité de la réaction par 1'incorporation de thymidine tritiée dans le DNA des cellules en division.

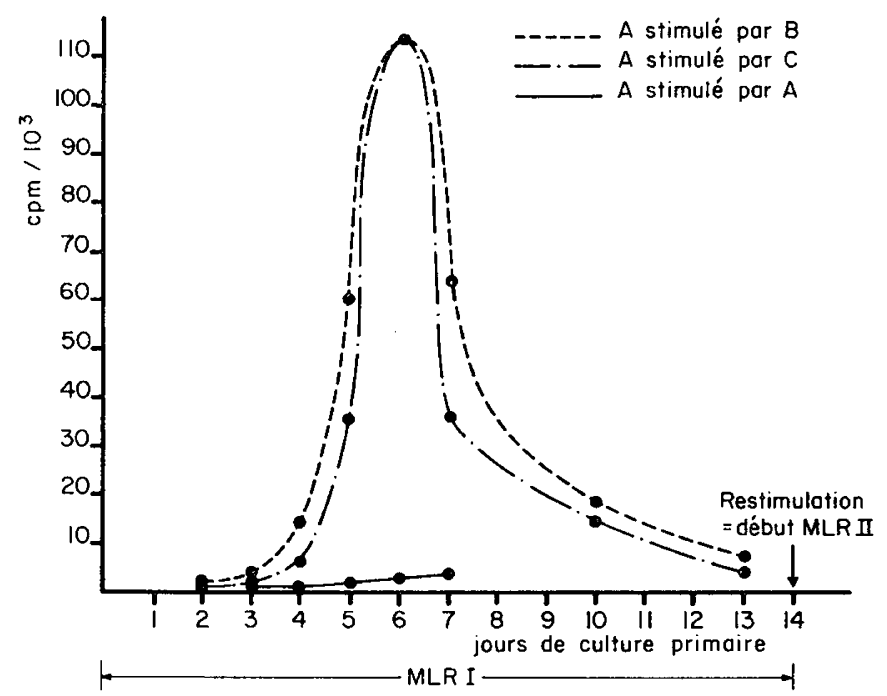

FIG. I2. - Cinétique de la prolifération lymphocytaive en $M L R$ (MLR I = MLR primaire) (d'après FRADELIZI, 1978).

Kinetics of lymphocyte proliferation in the $M L R(M L R I=$ primary $M L R)$.

\section{Cytotoxicité à médiation cellulaire $=C M L$}

Tandis que les lymphocytes répondeurs prolifèrent, il apparaît dans la culture des lymphocytes cytotoxiques, considérés comme les cellules effectrices de la réponse allogénique, et capables de détruire par interaction cellulaire directe des lymphocytes cibles, provenant du donneur des cellules stimulantes. Ce phénomène est connu sous le nom de cytotoxicité à médiation lymphocytaire (SolLyDAY et $\mathrm{BACH}$, I970), et peut être illustré par la figure I3. Pour des raisons d'efficacité du marquage au chrome $5 \mathrm{I}$, et de sensibilité de la méthode, les cellules cibles utilisées sont des lymphocytes préalablement transformés par la PHA (phytohémagglutinine) ou cellules blastiques (LIGH'TBODy et al., I97I).

La lymphocytotoxicité est mesurée par la destruction de cellules cibles marquées au chrome $5 \mathrm{I}$ (relargage du chrome par les cellules détruites). Cette 


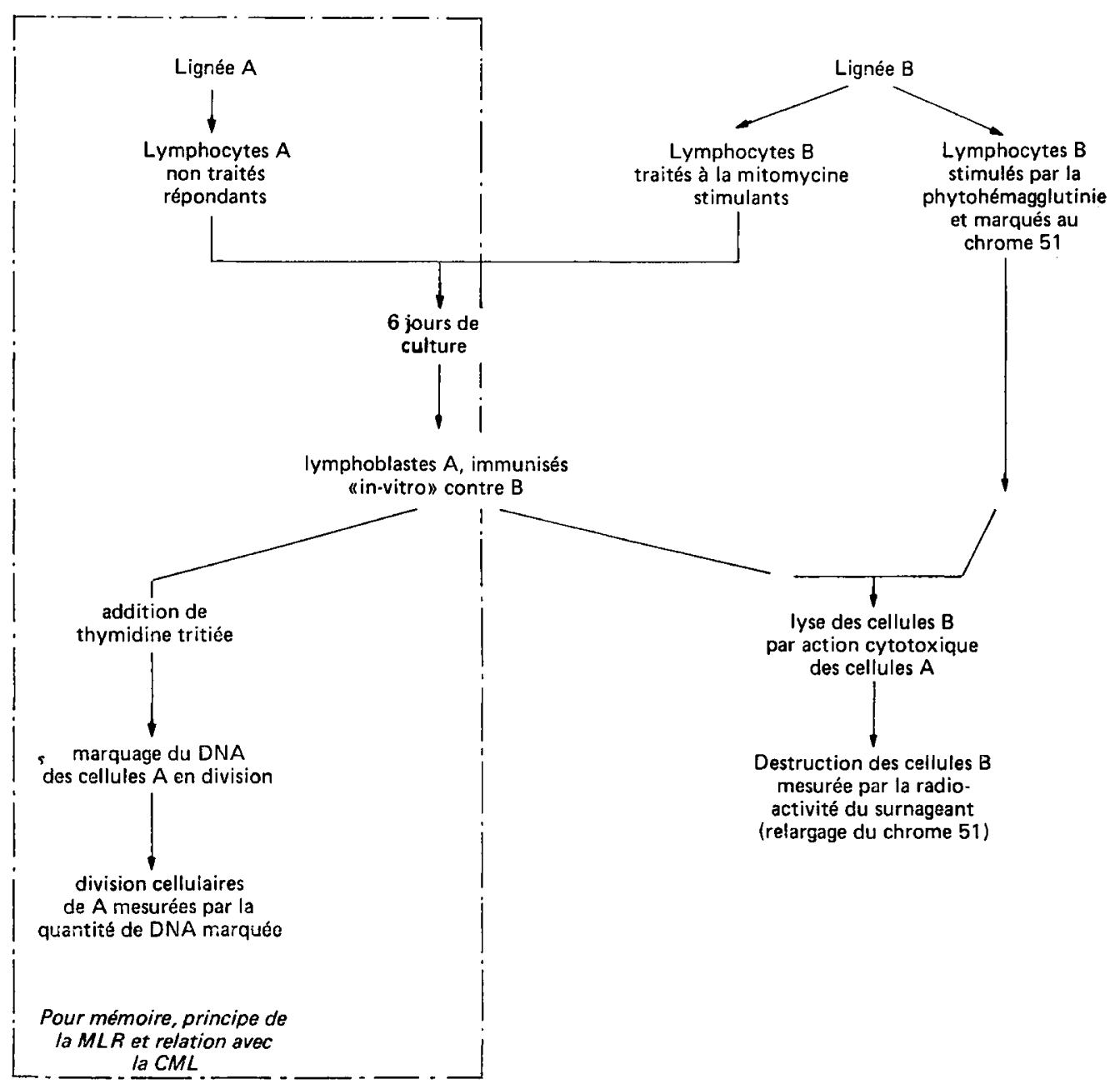

FIG. I3. - Principe de la cytolyse à médiation cellulaire (CML) (d'après CHRISTEN, 1975). Description of the Cellular Mediated Lysis (CML).

cytotoxicité est maximale au $7^{\mathrm{e}}$ jour de culture, et, commc la prolifération, elle s'éteint vers les $\mathrm{I} 3, \mathrm{I}_{4} \mathrm{e}$ jour. La notation habituelle est CML : cellular mediated lysis.

3. Apparition de cellules mémoires (MLR II, CML II)

Après la prolifération de la $M L R$, les cellules sensibilisées ont acquis une mémoire do la cellule stimulante. Un second contact avec les lymphocytes stimulants déclenshe une réaction anamnestique proliférative dénommée par analogie MLR IIaire (FRADEIIZI et DAUSSET, I975) au cours de laquelle on observe la réapparition d'effecteurs hautement cytotoxiques, phénomène alors désigné par CML IIaire (CHARMot et al., I975). 


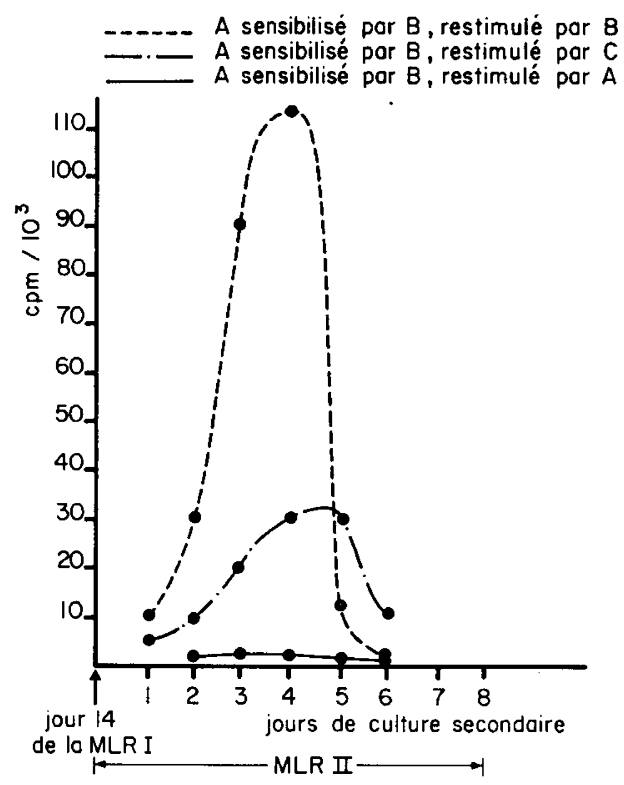

FIG. I4. - Cinétique de la prolifération lymphocytaire en MLR II

(= MLLR secondaire) (d'après FRADELIZI, I978).

Kinetics of lymphocyte proliferation in the $M L R I I(\Rightarrow$ secondary $M L R)$.

$M L R I I$. - La réponse proliférative de cellules restimulées au $\mathrm{I}^{\mathrm{e}}$ jour, alors que ne persistent dans la culture, ni cellules en division, ni lymphocytes tueurs, est qualifiée de secondaire. Ses caractéristiques sont illustrées à la figure I4: elle démarre très rapidement, et est détectable après $24 \mathrm{~h}$, le pic d'incorporation de thymidine se situant au $4^{\mathrm{e}}$ jour (même intensité que lors de la réponse primaire).

$C M L I I$. - La réapparition des lymphocytes tueurs est également très rapide; le pic d'activité est atteint au $5^{\mathbf{e}}$ jour, et 1 'activité cytotoxique est nettement plus intense que dans la réaction primaire.

\section{B. - Spécificité et contrôle génétique de la réponse allogéniqu?}

I) MLR. - Les loci contrôlant la MLR sont généralement désignés comme "lymphocyte defined" (LD) ou plus récemment comme "1ymphocyte activating determinant "(LAD), ceci par opposition aux séries sérologiquement définies.

Le rôle majeur joué par le complexe $\mathrm{H} 2$ dans la réaction lymphocytaire mixte a été démontré par DuTron (r966 a et $b$ ); des lignées consanguines différant par le segment $\mathrm{H} 2$ provoquent une forte stimulation, alors que dans le cas contraire la stimulation reste faible. De nombreuses investigations ont alors été entreprises pour localiser précisément le ou les loci contrôlant la MLR.

Ceci a été réalisé par l'utilisation de lignées recombinantes. Les déterminants LD ont tout d'abord été placés à 1'extrémité $\mathrm{K}$ du complexe $\mathrm{H} 2$ (RYchlikova et al., I970), sans plus de précision. L'organisation et la situation des loci LD ne sont apparus que peu à peu (Rychlikova et al., I97I), notamment grâce aux travaux des équipes de BACH et MEo (BACH et al., I972; Mro et al., I973a), qui ont 
localisé ces déterminants dans la région I. Depuis, un rôle primordial a été accordé aux gènes des sous-régions $I-A$ et $I-B$, mais des déterminants "faibles " seraient contrôlés par la sous-région I-C et par les régions SD, à savoir H2-K et H2-D (ABBASI et al., 1973; DżMANT, I973; MEO et al., I973b).

2) CML. - Las premiers résultats de ALTER et al. (I973), confirmés par les expériences de NABHOLZ et al. (I974), très démonstratives, ont mis en évidence que, si la stimulation et la prolifération des cellules répondantes a lieu lorsqu'il y a incompatibilités des gènes $\mathrm{LD}$, il ne peut y avoir lymphocytotoxicité que lorsque les cellules cibles sont différentes des cellules tueuses aux loci SD (H2-K et H2-D).

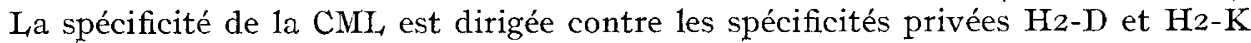
(BRONDZ et al., I975; FORMAN et MOLLER, I974).

\section{Relations entre $M L R$ et $C M L$}

Les relations entre les deux phénomènes, leurs spécificités peuvent être schématisées (voir fig. I5); la MLR peut être considérée comme une phase de reconnaissance et la CMI, comme la phase destructive de la réaction allogénique. La CML a été mise en évidence en travaillant avec les cellules stimulées par des différences $\mathrm{LD}$; or, si l'expression de la CML, est bien liée à l'existence de différences $\mathrm{SD}$, on peut se demander si les différences $\mathrm{LD}$ sont réellement nécessaires, au moins dans la phase initiatrice du processus. ScHendEL et BACH (I974) considérent qu'en
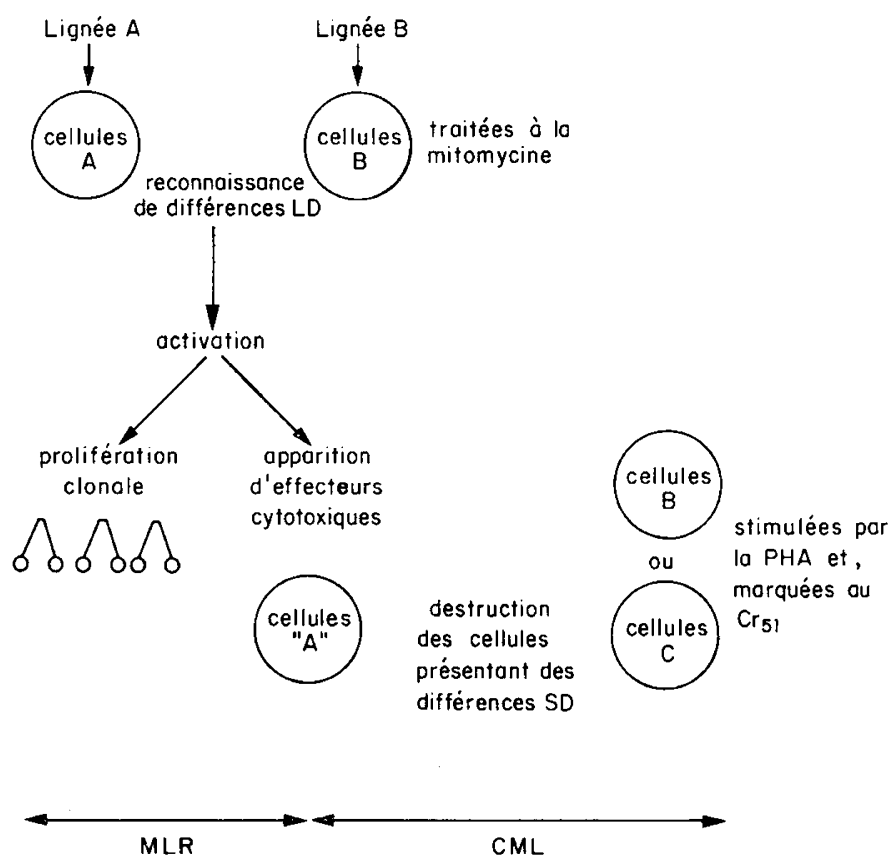

FIG. I5. - Relations entre la véaction lymphocytaive mixte (MLR) et la cytolyse à médiation cellulaive (CML).

Relationships between Mixed Lymphocyte Reaction (MLR) and Cellular Mediated Lysis (CML).

La CML est dirigée contre les cellules portant des déterminants SD différents et présentes dans la MLR, qu'il s'agisse des cellules stimulantes (B) ou d'autres cellules (C). 
effet des différences SD et $\mathrm{LD}$ sont nécessaires; par contre, des résultats obtenus avec des lignées mutantes pour $\mathrm{H}_{2}-\mathrm{K}$ ou $\mathrm{H}_{2}-\mathrm{D}$ laissent penser que les différenc ss SD se suffisent à elles seules (FORMAN et KLEIN, I975; NABHOLZ et al., I975; Rychilikova et $a l$., I 972). Dans ces conditions, l'on peut observer les diverses situations représentées par la figure I6; mais en fait, même en l'absence de différences $\mathrm{LD}$, la faible stimulation en MLC due à l'incompatibilité SD peut sans doute expliquer l'initialisation de la CML. Les deux types de conclusions rapportées ne permettent donc pas de statuer et le modèle proposé, avec 2 phases de reconnaissance et de destruction n'est donc en aucun cas remis en question.

\begin{tabular}{|c|c|c|c|}
\hline Cellules stimulantes & Cellules répondantes & $\begin{array}{l}\text { Réponse } \\
\text { en MLR }\end{array}$ & $\begin{array}{c}\text { Cytotoxicité } \\
\text { contre les cellules }\end{array}$ \\
\hline \multirow{4}{*}{$\underset{\mathrm{SD}}{\stackrel{a}{⺊}} \mathrm{LD}_{\text {Ss-Slp }}^{\mathrm{a}} \underset{\mathrm{SD}}{\mathrm{a}}$} & $\stackrel{a}{\longrightarrow}, a, a, a$ & - & - \\
\hline & $\begin{array}{llll}a & b & a & a\end{array}$ & & \\
\hline & $\stackrel{b}{\longmapsto}, b, a, 2$ & + & + \\
\hline & $\stackrel{b}{\longrightarrow}, a, a, a$ & $( \pm)$ & + \\
\hline
\end{tabular}

FIG. I6. - Représentation des diverses situations d'incompatibilité possibles pour les loci SD (ici, seul le cas de Hz-K est considéré) et LD; influence sur la $M L R$ et la $C M L$

Representation of the different possibilities of incompatibility for the $S D(H z-K$ only) and LD loci; influence upon the MLR and the CML

\section{Discussion}

Le complexe $\mathrm{H} 2$ ne contient pas tous les gènes contrôlant la MLR. Dès I 966 , Du'Tron a signalé que plusieurs différences " non $\mathrm{H}_{2}$ " (c'est-à-dire des différences à des loci autre que $\mathrm{H}_{2}$ ) pouvaient provoquer la stimulation. Aujourd'hui, l'influence possible de plusieurs loci d'histocompatibilité ou de loci codant des antigènes spécifiques des lymphocytes a été rapportée. Le tableau 7 donne un reflet de ces résultats. Chacun de ces loci n'entraîne qu'une réponse faible, et dans certains cas 1'utilisation de techniques spéciales a été nécessaire; ceci a permis à SMITh (I972) de souligner le rôle limitant des conditions de culture dans la démonstration de ces faits.

L'activité des différents loci contrôlant la MLR ne semble pas indépendante. Rychlikova et al. (r973), ont montré que le complexe $\mathrm{H}_{2}$ pouvait influencer l'intensité de la réponse due à des différences " non $\mathrm{H}_{2}$ "; ces faits correspondraient 
à l'existence d'un gène de la réponse immunitaire (type Ir) ayant un effet sur la culture mixte.

\section{TABLEAU 7}

Autres loci pouvant infuencer la réaction lymphocitaire mixte.

(d'après SNELL et al., 1976)

Other loci able to influence the mixed lymphocyte reaction

\begin{tabular}{|c|c|c|}
\hline Référence & Locus & $\begin{array}{c}\text { Situation } \\
\text { chromosonique }\end{array}$ \\
\hline FEStenstetn, Demant, I973 . . . . . . . . & M1s & I \\
\hline Mangi, Mardiney, I97I & $\begin{array}{c}\mathrm{H}-\mathrm{I} \\
\mathrm{H}-3+\mathrm{H}-\mathrm{I} 3 \\
\mathrm{H}-4\end{array}$ & $\begin{array}{l}7 \\
2 \\
7\end{array}$ \\
\hline ADLER et al., 1970 & $\mathrm{H}-3+\mathrm{H}-\mathrm{I} 3$ & 2 \\
\hline SMITH, $197^{2}$. . . . & $\mathrm{H}-7$ & 9 \\
\hline RAMSEIER, LINDFNMANN, 1972 . . . . . . . & $\mathrm{H}-\mathrm{Y}$ & $\mathrm{Y}$ \\
\hline PECK, Click, I973. . . . . . . & Thy-I & 9 \\
\hline
\end{tabular}

Mentionnons enfin le manque de données génétiques concernant la MLR II et la CMI. II chez la souris; d'intenses recherches sont en cours chez l'homme, et il s'agit d'un point en rapide évolution. L'importance de la région $\mathrm{H}_{2}$ a cependant été signalée (ANDERSSON et HAYRY, I973).

\section{C. - Physiologie et mécanisme de la réponse allogénique}

Il est impossible d'expliquer aujourd'hui l'ensemble des phénomènes observés au cours de la réponse allogénique. Cependant, l'abondance des résultats permet d'essayer de résumer les mécanismes, soit de la stimulation, soit de la réponse cellulaire.

\section{La stimulation}

De nombreuses causes peuvent provoquer la stimulation. Le débat le plus intéressant étant cependant de savoir quel est le rôle respectif des lymphocytes 
T et $B$, puisque l'on a vu que les déterminants $L D$ étzient codés dans la région $I$, qui code également pour les antigènes Ia, spécifique de certaines cellules, nota nment les cellules $B$.

Malgré des résultats contradictoires, il n'est pas contesté aujourd'hui que las lymphocytes B soient fortement stimulants (LHORMANN et al., I974; PIATE et MC KENZIE, I973). La capacité stimulante des lymphocytes $T$ est par contre discutée : égale à celle des lymphocytes B pour certains (SONDEL et al., I975), plus faible pour d'autres, et nulle enfin d'après d'autres équipes (HAN et DADEY, I976).

D'autres types de cellules peuvent déclencher une MLR. Par ex?mple, des fréparations cellulaires de peau ou d'endothélium vasculaire (LANE et LINC, I973; VE'TTO et BURGER, I972). Il est à noter que les cellules épithéliales expriment les cntigènes Ia.

Certains auteurs observent une corrélation entre la présence de spécificités Ia et la stimulation de MLR (LOzNER et al., I974), l'hypothèse d'un effet de concentration étant même rencontrée (PLATE et MC KENZIE, I973). Le fait le plus convaincant concernant le rôle éventuel des antigènes Ia dans la ML, est qu'un sérum anti-Ia, spécifique des cellules stimulantes bloque la réaction de MLR (SANDERSON et DAVIES, I974; MEO et al., I975b).

S'il est possible de conclure que la réponse en MLR est une fonction des lynphocytes qui prolifèrent après stimulation par des cellules $B$, il ne faut cependant en aucun cas conclure à l'équivalence des déterminants $L_{1} D$ et des antigènes $I a$; les résultats obtenus chez l'homme notamment, montrent certaines discordances (SASPORTES et al., I978), dues à une complexité plus grande des phénomènes étudiés.

\section{La Réponse}

Les cellules qui prolifèrent en réponse à une incompatibilit:́ LD, et les effectcurs cytotoxiques dirigés contre les antigènes SD de la cellule stimulante, appartiennent tous deux à la classe des lymphocytes T (matures) (PI,ATE et MC KENZIE, I973). Il est probable, cependant, que ces cellules appartiennent à deux sousclasses, deux populations distinctes de lymphocytes T (Dyminski et SmITH, I975).

\section{D. - Conclusion}

En résumé, on peut donc envisager la réponse allogénique comme le développement d'une série de réactions intégrées dans un processus séquentiel, débutant par la reconnaissance du "non-soi ", aboutissant à la formation de cellules immunologiquement réactives, capables de détruire des cellules cibles représentées par la popilation stimulante, et accompagné de l'apparition d'une mémoire immunologique.

La nature et les mécanismes exacts de ce phénomène ne sont que partiellement élucidés, mais les travaux actuels mettent en évidence l'importance de ces réactions immunologiques à médiation cellulaire. A partir de l'étude de la culture mixte, très tôt considérée comme un test d'histocompatibilité fondamental, et à juste titre assimilée à une réaction à médiation cellulaire de type " réaction du greffon contre l'hôte ", on est aujourd'hui en possession de connaissances permettant de mieux envisager les événements accompagnant le rejet d'une greffe.

Des études in vivo de la réponse allogénique ont pu être réalisées chez l'homme, notamment au cours des greffes d'organes. Nous signalerons simplement que le 
parallélisme des observations est frappant, la plupart des événements cellulaires observés in vitro existant in vivo. Bien sûr la comparaison reste et doit rester limitée pour de multiples raisons :

- in vitro, seule une partie des lymphocytes est mise en jeu,

-- in vivo, l'antigène reste présent "longtemps ",

- in vivo, l'on peut observer des phénomènes immunologiques de tolérance.

\section{VII. - La réaction du greffon contre l'hôte}

\section{I. - Définition}

La réaction du greffon contre l'hôte est déclenchée par la greffe de cellules immunocompétentes (lymphocytes, greffe de moelle osseuse), et correspond à la réaction allogénique in vivo. S'il existe des différences entre le donneur et le receveur, les cellules injectées sont capables d'une réponse allogénique contre 1'hôte. Ceci se traduit par un grossissement de la rate (splénomégalie) et des ganglions périphériques, envahis par les cellules stimulées. Le phénomène entraîne la mort de l'individu lorsque cette réaction n'est pas contrôlée, et ceci constitue un risque majeur dans le cas des greffes de moelle osseuse en chirurgie humaine. La notation habituelle est GvHR: graft versus host reaction.

Cette réaction d'histocompatibilité a été décrite initialement chez des embryons de poulet par Srmonsen (I957); elle a ensuite été étudiée essentiellement dans cette espèce; les travaux de BoYer (I 960) ont abouti à la définition d'une forme locale, appelée réaction du greffon contre 1'hôte sous la forme de pustules chorio-allantoïdiennes, qui a été très utilisée expérimentalement en raison de sa sensibilité accrue pour détecter les incompatibilités.

\section{2. - Déterminisme Génétique}

Chez la souris, le rôle essentiel du complexe $\mathrm{H}_{2}$ a été signalé par Srmonsen (r962). Les études de DEmant (I970) ont permis d'attribuer le contrôle de la réaction du greffon contre l'hôte à l'extrémité $\mathrm{H}_{2}-\mathrm{K}$, résultat affiné plus tard en travaillant sur le poids de la rate ou des ganglions lymphatiques. La MLR et la GvHR semblent être gouvernées par les mêmes déterminants (OPPLTOVA et DEMANT, I973; KLEIN et PARK, I973), ces deux réactions détectant donc les mêmes facteurs.

\section{VIII. - Contrôle du mécanisme de coopération cellulaire par le complexe $\mathrm{H}_{2}$}

La réponse immunitaire met en ceuvre deux types de mécanismes: la réponse humorale (aboutissant à la production d'anticorps), et la réponse cellulaire (faisant intervenir des phénomènes cellulaires); nous avons vu jusqu'à présent que chacun de ces mécanismes était en partie contrôlé par le complexe d'histocompatibilité majeur. Or, au cours du déclenchement, du fonctionnement de ces mécanismes, interviennent plusieurs types de cellules: macrophages, lymphocytes B, lympho- 
cytes T..., et des phénomènes de coopération cellulaire existent pour coordonner l'ensemble, et faire apparaître la réponse immunitaire.

On s'est aperçu peu à peu que ces mécanismes de coopération cellulaire étaient également contrôlés par les gènes situés dans la région $\mathrm{H}_{2}$; bien sûr, pour l'instant les résultats ne permettent pas de comprenđre et d'expliquer l'ensemble des événements se produisant lors de la réponse immunitaire, mais comme nous le verrons, certaines hypothèses de travail apparaissent assez séduisantes.

\section{I. - La suppression immunitaire}

Depuis la première observation de GERSHON et Kondo (I970), les propriétés et activités des cellules $T$ suppressives ont suscité de nombreux travaux. La présence de cellules suppressives a par la suite été démoncrée chez des animaux non répondeurs, étudiés pour les gènes Ir (BENACERRAF et al., I975); 1'hypothèse selon laquelle le phénotype "non répondeur " était constamment lié à la présence de cellules suppressives (GERSON et al., I973) était alors admise comme explication générale.

En fait, cette généralisation est impossible, Il a été démontré que la différenciation des cellules suppressives n'est pas constante. Le phénotype " développement d'une suppression spécifique " est transmis comme un trait dominant chez les hybrides $F_{1}$ (résultant du croisement d'animaux suppresseurs et non suppresseurs); le contrôle génétique est effectué par les gènes appelés I's (Immune suppression), liés au complexe majeur d'histocompatibilité. Les régions $\mathrm{K}$ et $\mathrm{D}$ ne codent pas pour ce phénomène; il est contrôlé par des gènes complémentaires agissant en interaction, localisés de part et d'autre de régions IB et IC (DEBRÉ et al., I975; DEBRÉ et al., r976). Cette situation peut, par conséquent, être comparée au contrôle génétique de la réponse; cependant, dans le cas des gènes Is, les recombinants entre souches possédant des haplotypes suppresseurs ne sont ni suppresseurs, ni répondeurs.

Les gènes Ir et Is sont parfois regroupés en tant que "gènes de la réponse immunitaire spécifique "); cependant, il faut remarquer que les gènes Ir sont définis par la présence d'une réponse, alors que les gènes Is contrôlent une suppression, qui n'est qu'un des phénomènes pouvant conduire à 1'absence de réponse; si présence ou absence de réponse sont deux événements "équivalents ", les gènes Ir et Is n'ont donc pas une définition identique.

\section{2. - La participation des antigènes d'histocompatibilité à la coopération des cellules immunocompétentes}

\section{a) Restriction génétique à la coopération $T-B$}

Certaines observations tendent à prouver qu'une identité entre produits du complexe majeur d'histocompatibilité est nécessaire à l'interaction des cellules immunocompétentes. KATZ et al., en 1975 montrent que les gènes de la région I sont nécessaires à l'établissement d'une coopération efficace. Cependant, il apparaît, que même en situation d'histocompatibilité, les cellules $T$ des animaux répondeurs ne peuvent coopérer avec les cellules $B$ d'animaux non répondeurs; ces faits suggèrent soit la présence de gènes Ir sur les lymphocytes $B$, soit, du moins, que ces gènes modulent l'interaction des cellules $T$ et $B$ histocompatibles (KATZ et al., I973). 
D'autres résultats sont en contradiction avec les précédents, une coopération efficace ayant pu être obtenue en situation d'incompatibilité (HERBER-KATZ et al., I975; WALDMANN et al., I976) notamment en utilisant des chimères produites par fusions d'embryons (VON BOEHMER et al., I975; BECHTOL et al., I974). Les raisons de ces discordances ne sont pas encore analysées et comprises aujourd'hui.

\section{b) Restriction génétique à la coopération lymphocyte T-macrophages}

SHEVACH et ROSENTHAL furent les premiers à souligner le rôle des antigènes d'histocompatibilité dans l'interaction des macrophages et des lymphocytes T. Chez le cobaye ces cellules doivent être syngénéiques pour l'établissement d'une réponse spécifique secondaire (ROSENTHAL et SHEVACH, I973). D'une manière analogue, ERB et FELDMANN (I975) démontrent que l'induction de cellules "helper" nécessite des cellules $T$ et macrophages syngénéiques.

\section{3. - Les médiateurs solubles de la coopération cellulaire}

Une nouvelle classe de molécules biologiquement actives comme intermédiaires de la coopération cellulaire a été récemment individualisée à partir des macrophages ou des cellules $T$ activées. Ces molécules, solubles et appelées médiateurs ou facteurs solubles, peuvent avoir soit un effet "Helper " pour certaines, soit un effet "suppresseur" pour d'autres.

\section{Facteur "Helper "}

Parmi ceux-ci, il existe deux catégories de molécules, les unes spécifiques, les autres non spécifiques.

Le premier facteur $\mathrm{T}$ helper spécifique fut individualisé par TAUSSIG en I974: des thymocytes de souris sensibilisés par un antigène ((T, G)-A-- $\mathrm{L}$ ou $(T, G)$-pro-- $\mathrm{L}$ ) et cultivés " in vitro " en présence du même antigène, peuvent secréter un facteur soluble capable de remplacer les cellules $\mathrm{T}$; il peut coopérer " in vivo " avec les cellules de moelle osseuse pour développer une réponse IgM, $T$ dépendante chez un receveur irradié. Ce facteur n'est pas absorbé par un sérum anti Fab de souris, mais peut être retenu de manière spécifique par un immunoabsorbant fait avec l'antigène utilisé. Munro et al. (I974), ont montré qu'il s'agit d'une glycoprotéine de PM 50 ooo. La comparaison des résultats obtenus par diverses combinaisons des cellules médullaires et $d u$ facteur $T$ de souches bons ou mauvais répondeurs a permis d'établir plusieurs points qu'il convient d'analyser avec attention :

a) Les facteurs possèdent les déterminants Ia de cellules $T$ qui les ont induits. Ainsi, pour le facteur ( $T, G)-A--L$, il est possible d'établir que son activité est liée à la présence de gènes situés dans la sous-région I-A, où est également localisé le gène Ir-I contrôlant la réponse à cet antigène. D'un autre côté, le traitement des cellules $B$ avec un antisérum anti Ia empêche ces cellules d'absorber le facteur, ce qui implique qu'une partie des sites récepteurs soit également codée par des gènes de la région I (MUNRo et TAUSSIG, I975).

b) Les facteurs $T$ helper peuvent coopérer à travers la barrière allogénique. Il n'y a pas de restriction d'espèce puisque des facteurs $T$ de souris peuvent être spécifiquement absorbés par des lymphocytes $\mathrm{B}$ humains, ou simuler la réponse $\mathrm{T}$ dépendante anti ( $T, G)-A--L$ de ces lymphocytes. 
c) $\mathrm{L} \approx$ contrôle génétique de la réponse immune n'est pas nécessairement lié à la production d'un facteur helper. Ainsi, des lymphocytes de souris $\mathbf{H}-2^{\mathbf{k}}$ produisent un facteur spécifique, mais leurs cellules médullaires ne peuvent répondre à son effet.

Les facteurs non spécifiques mis en évidence peuvent être induits par des mitogènes, des antigènes (WALDMANN et MUNRo, I973) où lors d'une culture mixte lymphocytaire, tel 1'AEF (Allogenic Effect Factor), qui porte des déterminants Ia et est absorbé par un sérum anti $\beta_{2}$-microglobuline (AMERDING et al., I975; AMERDING et KATZ, I974).

De plus, dans certains systèmes expérimentaux chez la souris, les macrophages peuvent coopérer avec les cellules T par l'intermédiaire de facteurs l'un non spécifique, l'autre spécifique, portant des déterminants Ia. L'étude de ce dernier permet de postuler que deux gènes contrôlent 1'induction des cellules $T$ helper par les macrophages (ERB et al., I976).

Compte tenu de ces observations, Munro et TAussig ont suggéré que la production d'anticorps était contrôlée par deux types de gènes fonctionnellement distincts, localisés dans le complexe (Munro et Taussig, r975):

- un gène contrôlerait la reconnaissance de l'antigène par les cellules $T$, et la production d'un facteur helper;

- un autre contrôlerait la réponse des cellules $B$ à ces médiateurs solubles.

La présence des déterminants Ia sur les facteurs produits par les lymphocytes $T$ laisse supposer que ces cellules synthétisent ces déterminants alors que nous avons vu qu'elles n'exprimaient pas ces antigènes à leur surface cellulaire. TAUssig et MunRo (I975) suggèrent un schéma, dans lequel ils attribuent un rôle important aux antigènes Ia dans la coopération T-B (voir fig. I7); cependant, il s'agit d'hypothèse de travail, le récepteur des facteurs helper sur les lymphocytes B est encore inconnu.

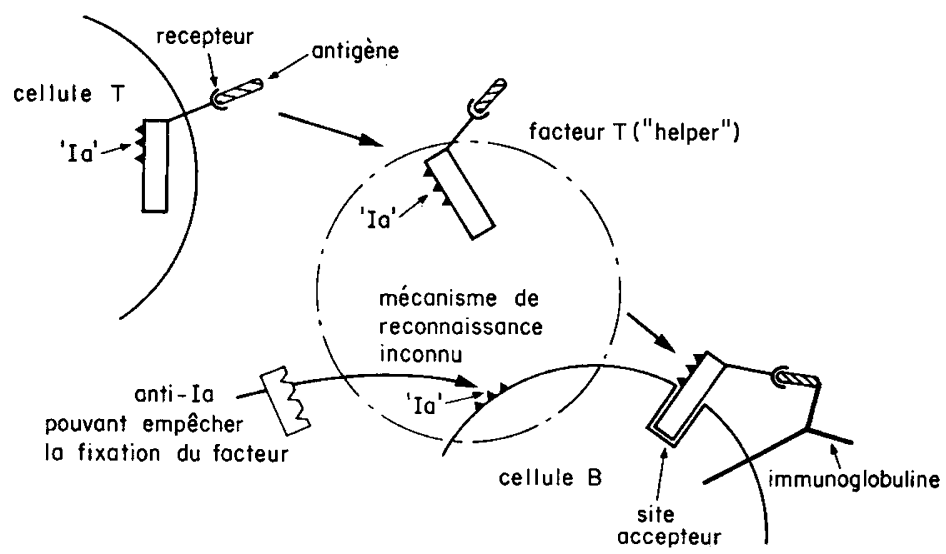

FIG. I7. - Hypothèse de TAUssig et MunRo (1975); coopération au cours de la réponse immunitaive humorale.

Hypothesis of TAUSSIG et MUNRO (1975); cooperation during the tumoral immune response.

Le facteur helper porte des déterminants Ia; ils sont également exprimés par les cellules B; un anticorps anti Ia empêche la fixation du facteur; la nature exacte des sites accepteurs est inconnue. 


\section{Facteurs suppresseurs}

D'une manière similaire, mais non exactement identique, des facteurs spécifiques interviennent dans la différenciation et 1'activité des cellules $\mathrm{T}$ suppressives; Ces facteurs, mis en évidence très récemment ('TADA et TANIGUCHI, I976; KAPP et al., I 976) sont obtenus par sonication de cellules spléniques, ou de thymocytes sensibilisés. Injectés "in vivo " ou utilisés " in vitro ", ils inhibent l'apparition d'une réponse spécifique $\operatorname{IgG}$.

Les cellu'es cibles de ces facteurs n'ont pas été déterminées de manière définitive, bien que TADA et al. (I976), aient proposé que ce soient les cellules T helper. Le facteur suppressif décrit par TADA peut être totalement absorbé par un antisérum spécifique des régions I-A ou I-B. De plus, il peut être retenu par une souspopulation de cellules $T$ mais non par les macrophages ou les cellules médullaires (TANICUCHI et al., I976). I1 existe une restriction allogénique à l'action de ce facteur; ainsi, une identité est nécessaire entre des gènes de la région $K$ et $I$ des donneur et receveur pour établir une suppression efficace. De plus, la capacité d'absorption de ce facteur par les cellules est reliée à des produits de la région I.

Compte tenu du fait qu'il existe deux types de déficit fonctionnel dus, soit à la production, soit à la réception de ce facteur, TANIGUCHI et al. (r976) suggèrent que 1a suppression nécessite la présence d'au moins deux gènes complémentaires du complexe majeur d'histocompatibilité, l'un d'eux se situant dans une nouvelle sous-région I-J (TADA et al., I976), cinquième sous-région de la région I donc, à avoir été définie.

On remarque que certaines suggestions concernant le rôle des déterminants Ia dans les cas des facteurs " helper " sont également valables ici pour les facteurs suppresseurs.

\section{4) Conclusion}

Il est clair qu'il est prématuré de tenter une analyse complète de ces faits. I a nature des produits des gènes Ir étant inconnue, leur identification au sein du conıplexe $\mathrm{H}_{2}$ n'a pas reçu d'explication définitive. Le rôle des antigènes d'histocompatibilité dans la coopération cellulaire, la présence de déterminants Ia des facteurs helper ou suppresseurs, comme le lien possible des gènes Ir avec les antigènes Ia, suggèrent que l'interaction des gènes Ir et Is avec les autres gènes du complexe n'est pas fortuite et peut avoir un rôle important dans le contrôle de l'activation des cellules immunocompétentes.

\section{IX. - Conclusion : stucture du modèle murin}

L'étude du complexe majeur d'histocompatibilité de la souris a permis de découvrir peu à peu la complexité de cette région chromosomique, nous avons vu que divers types de gènes avaient différentes fonctions et étaient localisés dans une petite portion chromosomique. Pour résumer l'exposé de ces résultats, le tableau 8 récapitule les propriétés caractéristiques du complexe $\mathrm{H} 2$, et la figure I 8 présente synthétiquement l'état des connaissances actuelles. Comme nous l'avons souligné à plusieurs reprises, il est actuellement impossible de comprendre les phénomènes étudiés dans leurs détails, mais il est désormais bien établi que ce complexe contrôle 


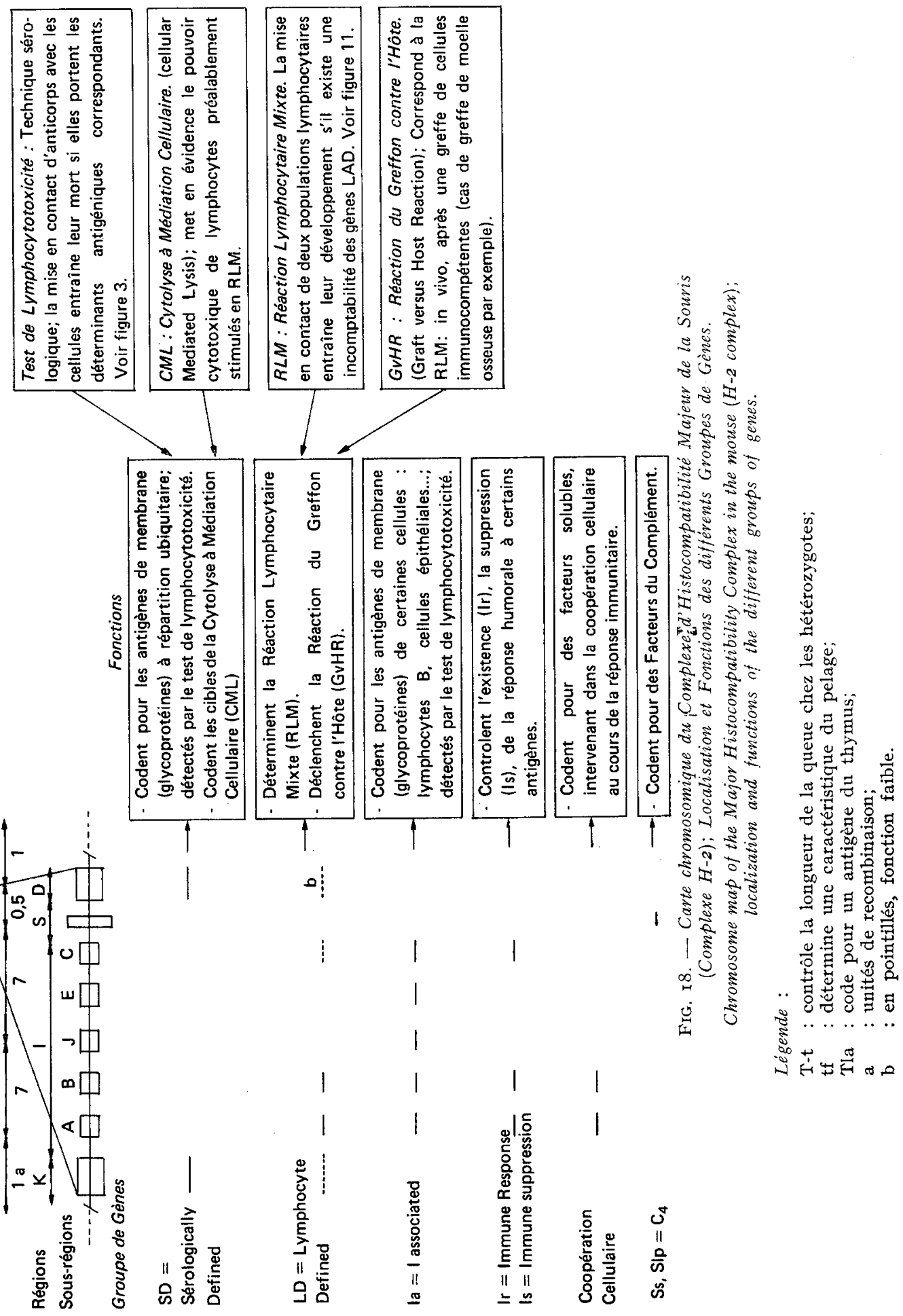


nombre de phénomènes de la réponse immunitaire qu'elle soit de type humoral ou cellulaire.

Ce modèle murin est de loin le mieux élaboré, mais les résultats obtenus dans d'autres espèces, et dont nous allons résumer succintement l'essentiel, contribuent cependant à une meilleure connaissance de ce système tout à fait remarquable.

\section{TABLEAU 8}

Propriétés caractéristiques du complexe d'histocompatibilité majeur de la Souris

Characteristic properties of the major histocompatibility complex of the Mouse

\begin{tabular}{|c|c|c|}
\hline \multicolumn{2}{|c|}{$\begin{array}{l}\text { Propriétés } \\
\text { générales }\end{array}$} & $\begin{array}{l}\text { I. Système génétique unique pour une espèce } \\
\text { 2. Système complexe, comprenant plusieurs loci étroitement liés } \\
\text { 3. Polymorphisme élevé à chaque locus } \\
\text { 4. Système d'histocompatibilité le plus "fort ": influence pré- } \\
\text { pondérante sur le rejet des greffes }\end{array}$ \\
\hline \multirow{6}{*}{$\begin{array}{l}\text { Groupes de } \\
\text { gènes et } \\
\text { fonctions }\end{array}$} & SD & $\begin{array}{l}\text { - Codent les antigènes lymphocytaires sérologiquement détectables } \\
\text { et largement distribués sur les autres tissus } \\
\text { - Obtention d'anticorps cytotoxiques facile par immunisation } \\
\text { - Contrôlent les cibles de la cytolyse à médiation cellulaire }\end{array}$ \\
\hline & LD & $\begin{array}{l}\text { - Contrôlent la réaction lymphocytaire mixte } \\
\text { - Contrôlent la réaction du greffon contre l'hôte }\end{array}$ \\
\hline & Ia & $\begin{array}{l}\text { - Codent les antigènes sérologiquement détectables présents sur } \\
\text { certaines cellules }\end{array}$ \\
\hline & C & - Codent certains facteurs du complément \\
\hline & Ir, Is & $\begin{array}{l}\text { - Gènes de la réponse immunitaire : contrôle de la réponse ou de la } \\
\text { suppression }\end{array}$ \\
\hline & $\begin{array}{l}\text { Coopération } \\
\text { cellulaire }\end{array}$ & $\begin{array}{l}\text { - Contrôlent certains facteurs solubles impliqués dans les méca- } \\
\text { nismes de coopération cellulaires de la réponse immunitaire }\end{array}$ \\
\hline
\end{tabular}

\section{Chapitre II \\ Le complexe d'histocompatibilité des autres espèces}

\section{I. - Introduction}

Parallèlement aux recherches développées chez la souris, des études d'histocompatibilité ont été entreprises dans de nombreuses espèces; toutes les classes de la systématique des vertébrés ont été abordées, mais nous ne nous intéresserons, dans ce chapitre qu'à l'étude des mammifères, classe pour laquelle le plus 
grand nombre d'espèces sont 1'objet de recherches; seul le poulet viendra compléter cette liste. De nombreuses revues bibliographiques ont été consacrées à l'exposé des résultats obtenus pour chacune de ces espèces; il sera impossible ici de présenter dans le détail, les méthodes et techniques d'études spécifiques de chacune; nous essayerons cependant d'apporter des informations précises sur le complexe d'histocompatibilité majeur de l'homme compte tenu de son intérêt en médecine; nous nous intéresserons également plus longuement à la connaissance de deux espèces d'intérêt zootechnique : le porc et le poulet, dans la mesure où les résultats déjà acquis sont assez nombreux. Pour les autres espèces, nous ne rapporterons que quelques particularités méritant d'être signalées; le tableau 9 fournit la liste des espèces que nous mentionnerons, et l'on peut constater que les recherch ss d'histocompatibilité ont connu un très grand développement depuis r96o. Enfin, et c'est là notre principal objectif dans ce chapitre, nous pourrons voir que la comparaison des résultats des diverses espèces, y compris la souris considérée comme modèle de référence, permet de constater une extraordinaire similitude de structure et de fonction attribuable aux complexes d'histocompatibilité majeurs.

TABLEAU 9

Espèces autres que la souris ayant fait l'objet d'études d'histocompatibilité

Species (mouse exepted) in which histocompatibility studies have been developped

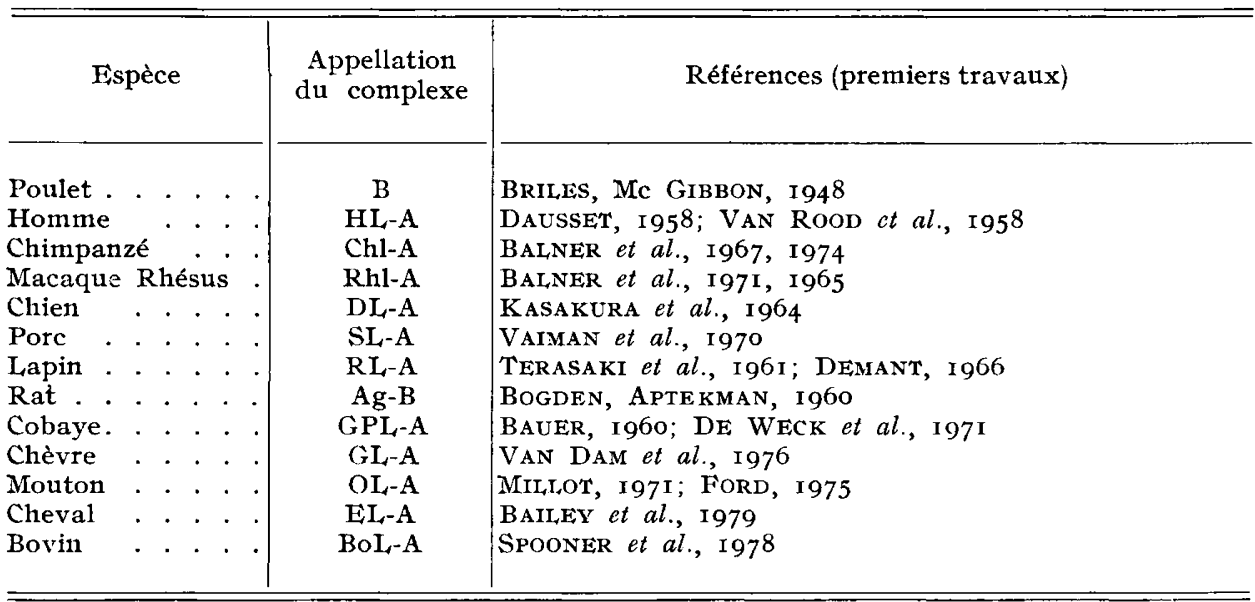

\section{II. - Présentation du complexe HLA de l'hom me}

\section{I. - Mise en évidence du complexe $H L A$}

Les premiers travaux n'ont pas été une transposition de ceux réalisés chez la souris; 1'homme ne semblait pas présenter d'antigènes d'histocompatibilité détectables sur les érythrocytes par hémagglutination et les résultats de Amos (1953) prouvant que des antigènes $\mathrm{H}_{2}$ pouvaient être exprimés par les lymphocytes ont dirigé les investigations vers cet autre type cellulaire. De I920 à I950, 
1'existence de substances leucolytiques dans le sang de malades leucopéniques n'a pas pu être démontrée, malgré de nombreux travaux. C'est en travaillant dans cette direction que DAUSSE'T et NENNA (I952), et indépendamment MoESchis et WAGNER (I952) ont décrit les premières réactions de leucoagglutination, d'origine immunologique, marquant ainsi le début des études sérologiques d'histocompatibilité chez 1'homme.

Les années suivantes, l'étude systématique des anticorps développés après transfusion, en utilisant la technique de leucoagglutination, a amené à la définition d'une première spécificité leucocytaire : MAC (DAusSET, I958). Cette même année, deux équipes ont découvert indépendamment la grande fréquence d'anticorps anti-leucocytes dans le sérum de femmes multipares (VA.N Rood et al., I958, PAYNE et Rolfs, I958).

TABLEAU IO

Récapitulatif des séminaives organisés en histocompatibilité humain?

List of the human histocompatibility workshops

\begin{tabular}{|c|c|c|c|c|}
\hline Année & Numéro & Organisateur & Thème & Résultats \\
\hline I964 & $\mathbf{I}$ & Amos & $\begin{array}{l}\text { - Comparaison des techni- } \\
\text { ques et des sérums }\end{array}$ & - Discordants \\
\hline $\mathbf{1} 965$ & 2 & VAN ROOD & - Comparaison des sérumis & $\begin{array}{l}\text { - Définition de spécificités } \\
\text { cohérentes, rerdant possi- } \\
\text { ble les études génétiques }\end{array}$ \\
\hline I967 & 3 & CEIPELIINI & $\begin{array}{l}\text { - Étude génétique de fa.. } \\
\text { milles }\end{array}$ & $\begin{array}{l}\text { - I_es spécificités sont con- } \\
\text { trôlées far un système } \\
\text { unique }\end{array}$ \\
\hline $197^{\circ}$ & 4 & TERASAKI & $\begin{array}{l}\text { - Idem au 3; étude de } \\
\text { 3oo familles }\end{array}$ & $\begin{array}{l}\text { Définition de deux séries } \\
\text { polyalléliques HLA-A, } \\
\text { HLA-B (SD) }\end{array}$ \\
\hline 1972 & 5 & DAUSSET & - Fitudes antliropologiques & $\begin{array}{l}\text { - Variations entre popula- } \\
\text { tion }\end{array}$ \\
\hline I975 & 6 & $\begin{array}{l}\text { KISSMEYER- } \\
\text { NIELSIEN }\end{array}$ & $\begin{array}{l}\text { - Étude de la réaction lym- } \\
\text { phocytaire mixte } \\
\text { - F́tude des antigènes séro- } \\
\text { logiquement définis }\end{array}$ & $\begin{array}{l}\text { - Définition de la série } \\
\text { HLA-D (LD) } \\
\text { - Définition d'une troisième } \\
\text { série HLA-C (SD) }\end{array}$ \\
\hline I977 & 7 & BODMER & $\begin{array}{l}\text { - Étude des antigènes équi- } \\
\text { valents des Ia murins }\end{array}$ & - Définition de la série \\
\hline
\end{tabular}


L'analyse des résultats sérologiques apparaissait cependant inextricable, ce qui laissait présager une grande complexité immunogénétique. L'introduction de l'ordinateur dans ces études a permis de poursuivre la description des spécificités; VAN ROOD et VA.N LEUWEN (I963) ont découvert ainsi les spécificités $4 a$ et $4 b$, et PAyne et al. (r964) ont trouvé les spécificités LAI et LA2, identiques à MAC et ségrégeant comme allèles dans les études familiales.

A partir de cette date, les progrès très rapides de l'étude du complexe HLA sont à attribuer à une intense collaboration internationale, qui a pris forme par exemple, en organisant un séminaire régulièrement, sur un thème particulier (voir tabl. Io). Dès I970, à la suite du $3^{\mathrm{e}}$ séminaire, le système HLA est apparu comme un système unique, formé de loci polyalléliques étroitement liés, les spécificités sérologiques étant contrôlées par 2 loci. Cependant, la possibilité de l'existence d'un troisième locus sérologiquement défini a été évoqué (SANDBERG et al. I970; KISSMEYER-NIELSEN et al., I97I).

Depuis, la connaissance du complexe HLA s'est développée, et la similitude existant avec les résultats obtenus chez la souris est importante. Les déterminants $\mathrm{SD}, \mathrm{LD}$ ont été mis en évidence, la liaison avec des facteurs du complément a été établie, des antigènes Ia équivalents ont été identifiés... Cependant, compte tenu de particularités biologiques (impossibilité d'avoir des individus homozygotes), on n'a pas pu pour l'instant retrouver de gènes Ir, ces particularités offrant par ailleurs d'immenses possibilités en génétique des populations, domaine dans lequel les résultats sont déjà abondants.

\section{2. - Description du complexe HLA}

Le complexe majeur d'histocompatibilité de l'homme dont l'étude a commencé par les loci HLA-A et HLA-B (loci sérologiquement définis), a été situé sur le chromosome 6, soit par hybridation cellulaire somatique (JoNGSMA et al., I974), soit

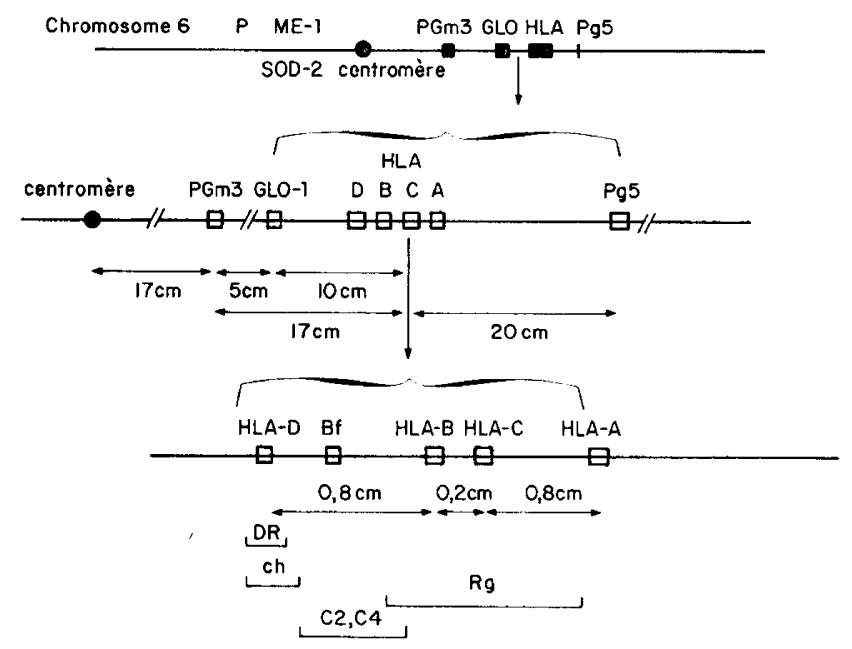

FIG. I9. - Carte provisoive du chromosome 6; localisation du Complexe HLA et des gènes liés (d'après FEILLUS, I978).

Provisional chromosome 6 map; HLA complex and linked loci localization. 
par étude familiale (LAMm et al., I974); des résultats récents (FRANCKE et al., I977) situent les gènes HLA sur le petit bras du chromosome 6 , submétacentrique, à $\mathrm{I} 7$ centimorgans du centromère (OT'T et al., I976).

La carte de cette portion de chromosome a pu être établie et figure à la figure I9. Jusqu'à présent le complexe HLA comprend essentiellement 4 loci, 3 étant sérologiquement définis (HLA-A,B et $C)$, le $4^{e}$ étant le déterminant de la réaction lymphocytaire mixte (déterminant $L D$ ). L'ensemble des autres loci portés par cette portion du génome et liés à HLA, figure au tableau II, et l'on constate que ces études ont pris une très grande expansion depuis quelques années.

\section{TABLEAU II}

Les différents loci liés génétiquement au complexe $H L-A$

(d'après FEL,LOUS, I978)

The different loci linked to the $H L-A$ complex

\begin{tabular}{|c|c|c|c|c|}
\hline Locus & Symbole & $\begin{array}{l}\text { Liaison par } \\
\text { famille (F) ou } \\
\text { Hybridation } \\
\text { somatique (S) }\end{array}$ & $\begin{array}{l}\text { Provi- } \\
\text { soire }(\mathrm{P})\end{array}$ & Références \\
\hline $\begin{array}{l}\text { Groupe Chido } \\
\text { Groupe } \mathrm{P} . \\
\text { Groupe Rodgers }\end{array}$ & 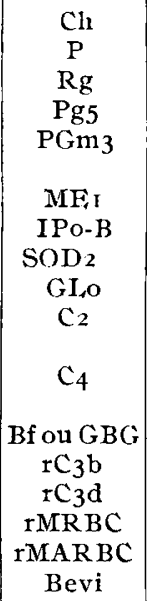 & $\begin{array}{l}\text { F } \\
\text { S et } F \\
F \\
F \\
\text { F et } S \\
\text { S } \\
\text { S } \\
\text { S et } F \\
\text { F } \\
F \\
\text { F } \\
F \\
F \\
\text { S } \\
\text { S } \\
S \\
S\end{array}$ & $\begin{array}{l}\mathrm{P} \\
\mathrm{P} \\
\mathrm{P} \\
\mathrm{P}\end{array}$ & 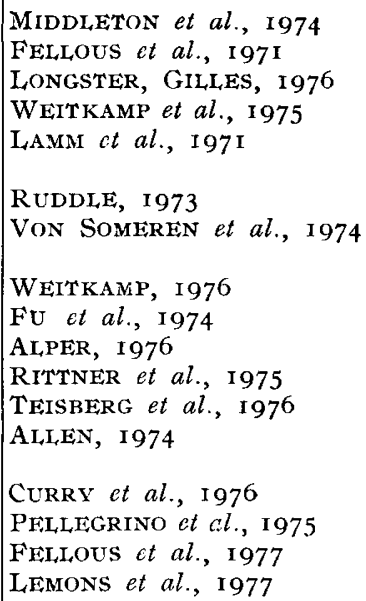 \\
\hline
\end{tabular}

\section{3. -- Les loci $H L A-A, H L A-B, H L A-C$}

Correspondant aux loci $\mathrm{H} 2-\mathrm{K}$ et $\mathrm{H}_{2}-\mathrm{D}$ de la souris, ils ont été décrits les premiers, à partir des études sérologiques. La définition d'une spécificité dépend de l'emploi de sérums monospécifiques; c'est pourquoi la sérologie HLA a été difficile et la définition d'une spécificité a été basée surtout sur la comparaison de nombreux sérums, comparaison effectuée en calculant à l'aide d'un ordinateur les $\mathrm{X}^{2}$ ainsi que les coefficients de corrélation qui ont l'avantage d'indiquer le sens de 1'association (FEINGOLD, I g66) entre les divers sérums. Une association positive signifie que les deux sérums ont des similitudes qui sont plus fréquentes que ne le 
voudrait le hasard, une association négative signifiant que les deux sérums ont tendance à réagir avec des cellules différentes (ce qui correspond plutôt à une situation d'allélisme). La réalité de ces spécificités a, par la suite, été prouvée par des relations génétiques qui les unissent entre elles et qui sont apparues au cours d'étude de populations ou de familles : ainsi, la génétique est venue à l'aide de la sérologie.

L'ensemble des études sérologiques menées depuis 20 ans a conduit à la définition de 3 séries alléliques, chacune étant contrôlée par un des loci HLA-A, B ou C. Les fréquences des divers allèles identifiés dans la population caucasoïde sont fournies au tableau I2, qui utilise la nomenclature officielle. Il est très difficile d'attribuer la découverte de tel ou tel antigène à une équipe ou à une autre; souvent les spécificités ont été découvertes simultanément et indépendamment dans plusieurs laboratoires à la fois. Une table des équivalences se trouve dans "Histocompatibility testing I972 ", et permet de retracer 1'histoire des découvertes jusqu'à cette date.

\section{TABLEAU I2}

Fréquences géniques des séries $H L A-A, B$ et $C$ dans la population caucasö̈de

(d'après DAUSSET, I978)

Gene frequencies of $H L-A, B$ and $C$ antigens in the Caucasian population

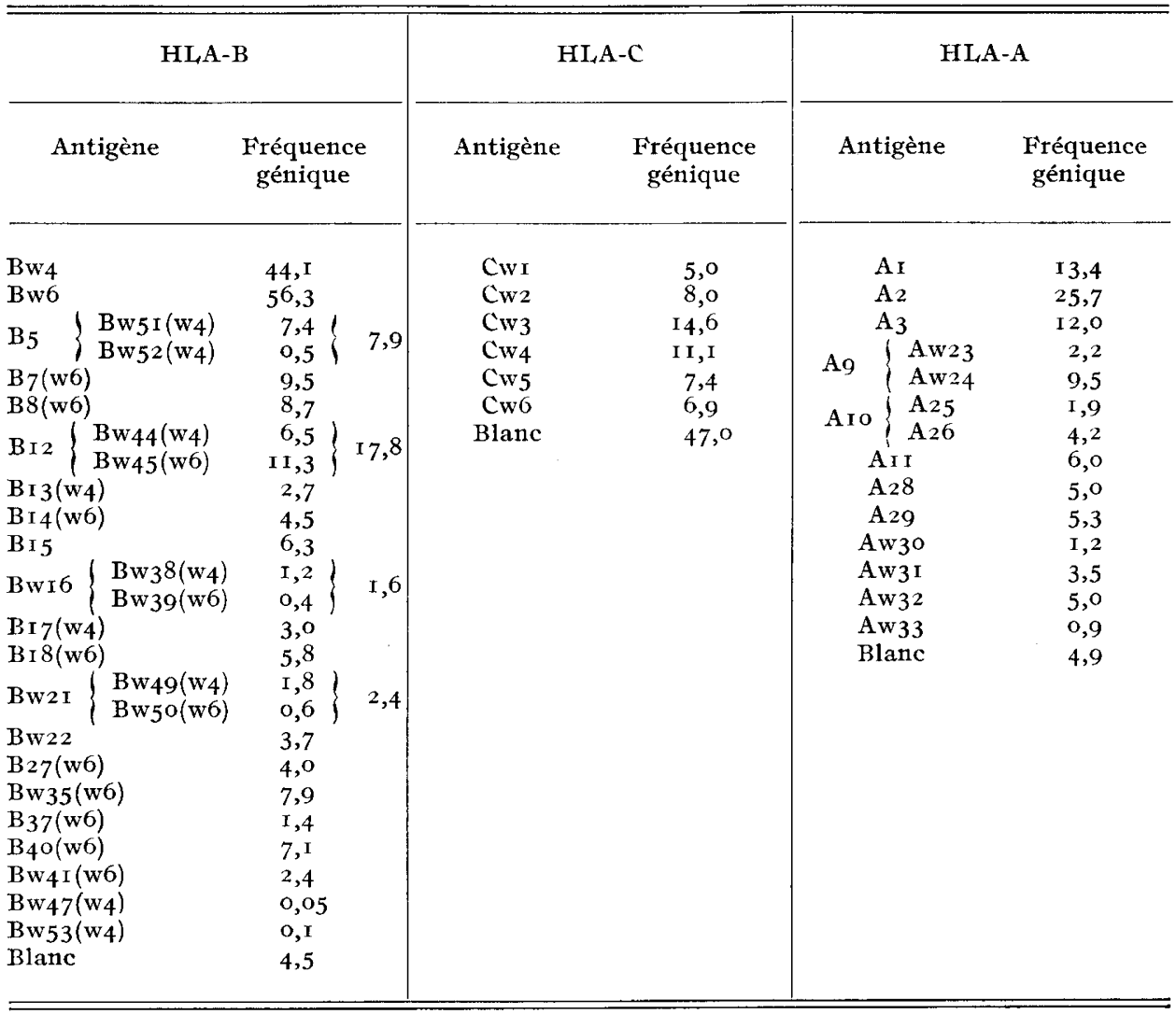


Si le caractère allélique des différentes spécificités ne fait plus aucun doute, il faut, néanmoins, souligner le côté arbitraire de cette classification; 1'existence de spécificités publiques fait que la tendance est de subdiviser les spécificités existantes; il est certain qu'atjourd'hui, le processus de subdivision n'est pas achevé. D'autre part, il reste, des spécificités encore inconnues; les "blancs » correspondent vraisemblablement non pas à des produits alléliques peu ou pas immunogéniques, mais à des spécificités plus rares qui seront découvertes.

Les antigènes HLA contrôlés par les 3 loci $\mathrm{A}, \mathrm{B}$ et $\mathrm{C}$ sont des glycoprotéines de surface membranaire; leur distribution est ubiquitaire; on retrouve donc les résultats déjà connus chez la souris. La structure de la molécule est identique, et des résultats récents mettent en évidence une analogie de séquence des chaînes protéiques (SILVER et al., I976).

$$
\text { 4. - Le locus HLA-D }
$$

La région chromosomique environnant le locus HLA-D est certainement celle qui suscite actuellement le plus d'investigations compte tenu des nombreuses fonctions qui lui sont attribuées.

\section{a) Contrôle de la réaction lymphocytaire mixte (MLR)}

Déterminisme génétique. - Le contrôle de la réaction lymphocytaire mixte d'abord attribué sans précision au déterminant HI,A-B, ou à un gène étroitement lié, par de nombreux auteurs (DUPONT et al., I97I; LEBRUN et al., I97I; GATTI et al., I97I; EIJSVOOGEL et al., I972; Yunis et Amos, I97I), a été définitivement attribué au locus HLA-D, ainsi défini, placé à l'extérieur du segment HLA-A / HLA-B, à I centimorgan du côté de HLA-B (EIJsvoogé et al., I972; MEMPEL et al., I972; SASPORTES et al., I972). Comme chez la souris, l'existence de loci " mineurs" a été postulée (SASPoRTEs et al., I973; THORsir et al., I973), mais ils demeurent difficiles à localiser au niveau du complexe HLA, et sont encore l'objet de controverses.

Typage HLA-D. - Le contrôle génétique de la MLR par le locus HLA-D étant établi, il est apparu intéressant, dans le but de pouvoir typer des individus, de définir des spécificités " HLA-D ». L'observation de familles où les parents partageaient un haplotype HLA a permis d'atteindre cet objectif; en effet, il a été possible de rencontrer dans la descendance de telles familles, d'une part, des enfants HLA phéno-identiques à l'un des parents, et d'autre part, des enfants homozygotes HI, A; la ML R entre les divers individus a donné les résultats suivants:

- une réaction négative entre hétérozygotes phéno-identiques;

- une réaction négative ou faiblement positive dans le cas d'un hétérozygote stimulé par un homozygote;

-- une réaction positive dans le cas où l'homozygote est stimulé par un hétérozygote.

Dans ces conditions, il est apparu pessible d'utiliser ce type de situations pour arriver à identifier les spécificités en travaillant avec des cellules homozygotes. De nombreux groupes ont rapporté des cas de familles de ce type : MEMPEL et al., I973; Dupont et al., 1973; SASportes et al., I973. En fait, 1'utilisation de cellules homozygotes avait été proposée par BRADLEY et al. (I972), dans l'étude de la ML R chez le porc; l'idée a ensuite été reprise et largement développée chez l'homme (MEMPEL, et al., I973). 
Une réponse de typage est définie comme la faible réponse obtenue en $M L R$, quand une cellule répondante à une spécificité HLA-D en commun avec la cellule HLA-D homozygote stimulante de référence. La recherche de cellules homozygotes est alors devenue essentielle; une des sources comme nous 1'avons vu est constituée par les familles où les parents ont un haplotype en commun; une autre source est représentée par les familles à forte consanguinité (VAN DEN TWEEL et al., I973; JORGENSEN et al., I973); une étude systématique de familles normales a également permis de trouver des cellules homozygotes HLA-D, même chez des hétérozygotes pour HLA-A, B et $\mathrm{C}$.

Caractérisation des spécificités $H L A-D$. - Elle a été réalisée grâce à un travail international (voir tabl. Io) qui a consisté précisément en l'échange de cellules homozygotes; 6 spécificités ont été définies. Leurs fréquences antigéniques et géniques figurent au tableau I3; l'analyse génétique a révélé qu'elles sont contrôlées par des allèles codominants d'un locus unique.

TABLEAU I3

Fréquences des spécificités $H L A-D$ dans la population caucasoïde

(d'après SASPORTES, I978)

Frequencies of $H L A-D$ specificities in the caucasian population

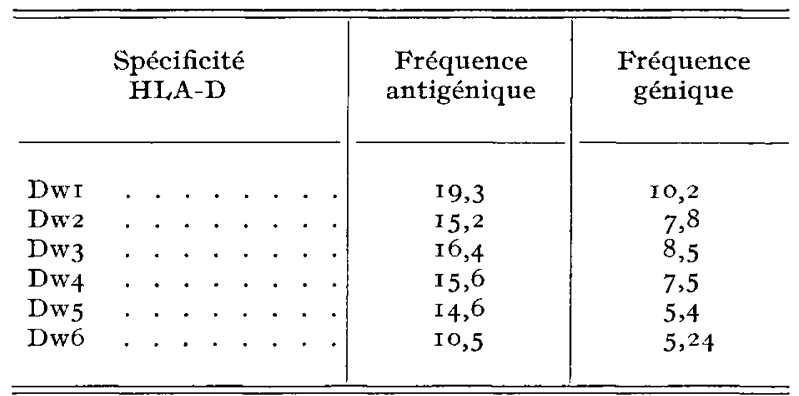

\section{b) La Série allélique $H L A-D R$}

Définie officiellement en I977 (voir tabl. ro), cette série allélique correspond aux antigènes humains équivalents des Ia murins, DR signifiant " D-related "; 7 spécificités ont été reconnues. Actuellement, le problème de la monospécificité des sérums anti-DR n'est pas résolu. De nombreux sérums sont polyspécifiques; une étape ultérieure sera donc l'absorption sur lymphocytes pour démontrer ou obtenir la monospécificité. Un effort dans ce sens a déjà été fait avec l'emploi des anticorps élués de lymphocytes; cette méthode (élution) sélectionne un nombre limité d'anticorps à partir d'un immun-sérum polyspécifique.

Les spécificités définies répondent aux critères d'une série allélique : corrélation négative entre spécificités dans le panel de référence, absence de triplets pour un individu donné, transmission comme des unités mendéliennes simples dans les familles. Le tableau I4 fournit les fréquences géniques obtenues pour cette série allélique. La liaison au complexe d'histocompatibilité majeur et plus particulièrement à HLA-D a été obtenue par des études familiales. Les résultats obtenus permettent, par diverses caractéristiques résumées au tableau $\mathrm{I}_{5}$, de considérer que les antigènes $D R$ décrits sont bien l'équivalent des Ia murins. 
TABLEAU I4

Fréquences géniques de la série allélique $H L A-D R$

$H L A-D R$ gene frequencies

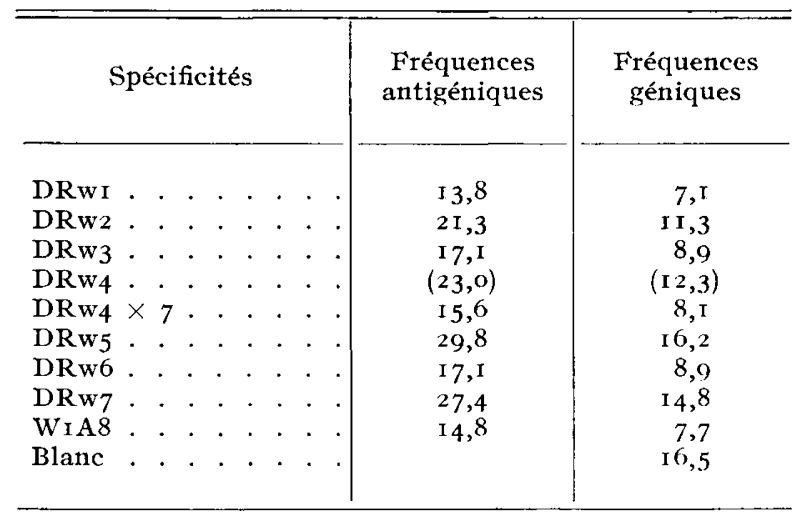

Les fréquences sont établies dans un panel de sujets caucasoïdes européens $(\mathrm{N}=35 \mathrm{I})$, d'après les données de plusieurs laboratoires (7th Histocompatibility Workshop, I977). D'après Colombani, I $978 b$.

\section{TABLEAU I5}

Caractéristiques communes aux antigènes Ia murins et aux antigènes DR humains Common properties of murin I a antigens and human DR antigens

I. Mise en évidence par sérologie.

2. Contrôle par des gènes étroitement liés aux gènes sérologiquement définis.

3. Indépendance de ces antigènes par rapport aux antigènes sérologiquement définis, au niveau membranaire.

4. Distribution cellulaire restreinte à certaines cellules, et identique (voir tabl. 6).

5. Même structure biochimique :

- deux chaînes glycoprotéiques (PM 290oo et 34000);

- spécificités portées par une des chaînes (2900o) qui serait seule codée dans le complexe.

6. Capacité de bloquer la réaction lymphocytaire mixte par les anticorps anti-Ya ou anti-DR.

La discussion fondamentale porte chez l'homme comme chez la souris sur les relations entre les structures responsables de la stimulation en MLR et les antigènes DR; en d'autres termes, le locus D et le locus DR sont-ils identiques ou étroitement liés et distincts? les expériences de blocage de MRL suggèrent une identité sans permettre de l'affirmer. En effet, les immuns-sérums anti-DR peuvent 
contenir des anticorps méconnus dirigés contre les structures stimulantes. Mêmc si ce sont les anti-DR eux-mêmes qui sont responsables du blocage, celui-ci peut être dû à un empêchement stérique au niveau de deux molécules voisines mais distinctes. En fait, comme nous allons le voir, la discussion doit être élargie aujourd'hui à 3 catégories de gènes.

\section{c) Le Contrôle de la MLR II}

La réponse proliférative secondaire accélérée est spécifiquement déclenchée par des structures stimulantes de la cellule cible codées par la région HLA-D. Ceci a été démontré par l'étude d'une famille avec recombinaison $H L A-B / D$ (MAwas et al., I975; FRAdELIzI et al., I976). Ainsi, le produit HLA-D responsable de la stimulation dans la MLR I et les structures stimulantes de la prolifération secondaire sont codés par la même région chromosomique; ceci pourtant n'implique pas que ces 2 produits stimulants soient absolument identiques.

La précocité de la stimulation, notable dès la $48^{\mathrm{e}}$ heure, et la spécificité pour la région HLA-D de la réponse allogénique secondaire, ont conduit à proposer l'usage de lymphocytes préalablement sensibilisés au cours d'une MLR I, in vitro, pour le typage des produits stimulants en MLR II, contrôlés par la région HLA-D (ShEehy et al., I975; Fradelizi et al., I975). Cette méthode est appelée "PLT" (Primed lymphocytes typing method), et les produits correspondants, stimulants la MLR II, sont appelés structures " PL » (Primed lymphocyte stimulating product).

La nature exacte des structures PL est à l'heure actuelle l'objet d'intenses recherches, de même que la nature des relations entre ces structures PL et produits HLA-D. Deux observations méritent d'être retenues :

- l'action des rayons ultra-violet est la même sur les structures PL et HI,A$\mathrm{D}$ : inactivation de la stimulation. Par contre, les antigènes $\mathrm{SD}$ ne sont pas modifiés (Mawas et al., I975);

- le typage d'individus par les deux méthodes (PLT et cellules homozygotes HLA-D) indique une corrélation significative (CROSIER et al., I977), mais les structures ne coïncident pas exactement.

d) Relations entre déterminants $H L A-D(M L R I)$, antigènes $H L A-D R$ et structures $P L(M L R I I)$

Les produits de la région HLA-D ont pu être étudiés par trois méthodes différentes : la MLR I (HLA-D), la MLR II (structures PL), et la sérologie (antigènes DR).

Il a donc été possible d'étudier les relations existant entre les 3 types de déterminants ainsi mis en évidence, afin d'essayer d'expliquer les faits observés, tels que ceux relatés dans des travaux préliminaires, soit chez la souris (PECK et al., I977; FAthMAN et al., I977), soit chez 1'homme (SASPORTEs et al., I976) suggérant que des déterminants Ia ou $D R$ respectivement, pouvaient induire une réponse secondaire.

Lcs 3 techniques utilisées ont donné des résultats concordants, mais non corrélés de façon absolue; ceci peut correspondre soit à une sensibilité différente des méthodes, soit à une réalité biologique due à la complexité des produits de la " région HLA-D "; il n'est actuellement pas possible de conclure. De nombreuses équipes consacrent leurs travaux à cet aspect du complexe HLA, et pour illustrer les disparités obtenues lors du typage d'un certain nombre d'individus par les 
3 techniques, l'on peut rapporter les résultats récents de l'équipe de 1'hôpital St-Louis (SASPORTES et al., I978; FRADELIZI et al., I978; NunEZ-Rol,dan et al., I978), représentés et visualisés à la figure 20 :

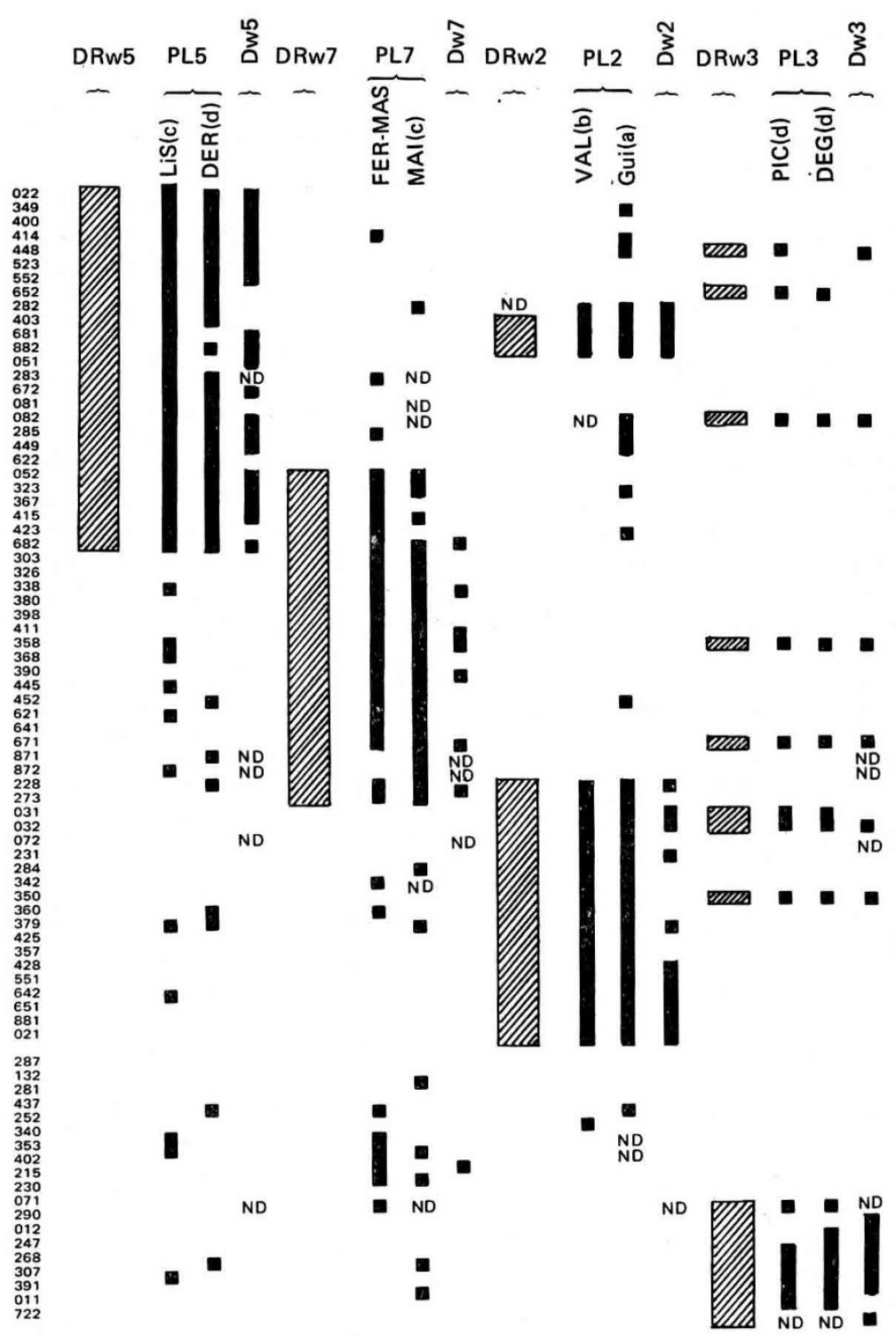

FIG. 20. - Répartition dans un échantillon de sujets non-apparcntés, de groupe HLA connu, des produits " $P L$ " (MLR II), en comparaison avec les antigènes DR (équivalents des Ia) et les spécificités HLA-D (MLR I) (d'après SASPORTES et al., 1978).

Partition in a population of known HL-A type, unvelated individuals, of the "PL " products (MLR $I I)$, in comparison with the DR antigens (I a cquivalent) and the HLA-D specificities (MLRI). 


\section{TABLEAU I6}

Coefficients de corrélation ( $r$ entre les spécificités $D R, D$ et $P L$

(d'après Col,OMBANI, 1978b)

Corrclation coefficients $(v)$ between the $D R, D$, and PL specificities

\begin{tabular}{c|c||c|c||c|c}
\hline \hline DRw/Dw & $r$ & DRw $/ \mathrm{PL}$ & $r$ & Dw $/ \mathrm{PL}$ & $r$ \\
\hline $\mathrm{I} / \mathrm{I}$ & & & & & \\
\hline $2 / 2$ & 0,6 & & & & \\
$3 / 3$ & 0,7 & $2 / \mathrm{II}$ & 0,8 & $2 / \mathrm{II}$ & 0,8 \\
$5 / 5$ & 0,8 & $3 / \mathrm{III}$ & 0,9 & $3 / \mathrm{III}$ & 0,5 \\
$6 / 6$ & 0,8 & $5 / \mathrm{V}$ & 0,9 & $5 / \mathrm{V}$ & 0,7 \\
$7 / 7$ & 0,6 & $6 / \mathrm{VI}$ & 0,6 & $6 / \mathrm{VI}$ & 0,6 \\
& 0,4 & $7 / \mathrm{VII}$ & 0,8 & $7 / \mathrm{VII}$ & 0,4 \\
\hline
\end{tabular}

- bien qu'une spécificité HLA-D donnée soit toujours corrélée à un produit $P L$, de nombreux individus porteurs d'une spécificité $P L$ donnée n'ont pas la spécificité $\mathrm{D}$ correspondante attendue;

- les déterminants DR sont plus étroitement corrélés aux produits PL que ne le sont les spécificités HLA-D. Ceci se constate visuellement (fig. 20) et le calcul des corrélations entre les diverses réactions permet de quantifier les associations existantes; le tableau I 6 donne les valeurs calculées. Le coefficient de corrélation très élevé observé entre les produits $\mathrm{DR}$ et $\mathrm{PL}$ favorise 1'hypothèse d'une identité de fonctions entre ces différents déterminants :

- les déterminants DR ou PI, ou des structures étroitement associées, semblent avoir un rôle prépondérant dans l'induction de la MLR II, inversement, les spécificités HLA-D (MLR I) ne paraissent pas impliquées dans la MLR II;

- les divergences entre la sérologie $(\mathrm{DR})$ et la réponse secondaire (PL) sont observées; ces faits suggèrent que ce sont bien des déterminants différents des produits $\mathrm{DR}$ qui induisent la MLR II;

- certains résultats suggèrent que les produits $P L, D R$ et HLA-D sont des déterminants distincts;

- enfin, il semble exister une interaction des déterminants DR ou PI sur la MLR I : en situation intrafamiliale HLA haploidentique, l'intensité de MLR I varie, selon qu'il y a une incompatibilité HLA-D seule ou associée à une incompatibilité PL ou DR.

La complexité de la région "HLA-D », semble devoir susciter encore de nombreux travaux avant d'être appréhendée.

\section{5. -.. Les autres manifestations contrôlées par le complexe HLA}

\section{a) Facteurs $d u$ complément}

Plusieurs facteurs du complément sont codés par des gènes localisés dans la région $\mathrm{HL}$, A. Le facteur $\mathrm{Bf}$ (properdine), proactiveur de $\mathrm{C}_{3}$ par la voie alternative, 
est contrôlée par un gène lié à HLA (ALLEN, I974). Il en est de même d'un gène contrôlant la déficience du composant $\mathrm{C}_{2}$ (Fu et al., I 974) et d'un autre concernant le composant $\mathrm{C}_{4}$ (RIT'TNER et al., I975), $\mathrm{C}_{2}$ et $\mathrm{C}_{4}$ étant des facteurs de la voie classique. Ces trois gènes sont situés entre HLA-D et HLA-B.

\section{b) Cytolyse à médiation cellulaire (CML)}

Les antigènes des séries $\mathrm{A}$, $\mathrm{B}$ et $\mathrm{C}$ sont considérés comme les cibles principales des effecteurs cytotoxiques. Les résultats de Kristensen et GrunNeT (I975) suggèrent cependant l'intervention d'autres déterminants dans la CML.

La physiologie de la réponse allogénique semble correspondre à celle rencontrée chez la souris, avec 2 phases, 1'une de reconnaissance et 1'autre destructive, et des résultats récents suggèrent l'existence de deux populations lymphocytaires distinctes accomplissant chacune de ces deux tâches.

Comme nous l'avons déjà vu, les structures responsables de la MLR II ne sont pas exactement identiques à celles entraînant la $\mathrm{I}^{\text {re }}$ stimulation allogénique (MLR I) (MAwAS et al., I975).

La cytolyse secondaire (CML, II) n'est pas en fait caractéristique d'une réponse secondaire. La cytloyse après MLR II est bien dirigée contre les cibles SD, mais n'est pas stimulée spécifiquement par les déterminants I,D.

\section{c) La réaction du greffon contre l'hôte (GvHR)}

En fait, il s'agit ici de données cliniques concernant les cas de greffes de moelles osseuses. Si celles-ci ne posent aucun problème entre jumeaux monozygotes, l'étude des diverses situations rencontrées permet de dégager un rôle essentiel du locus HLA-D (Koch et al., I973; Neithammer et al., I 976). Mais les résultats ne sont pas toujours très facilement interprétables, et l'action d'autres gènes d'histocompatibilité, encore inconnus, est vraisemblable. De plus, la préimmunisation par exemple de la mère par l'enfant au cours de la grossesse vient compliquer ces études (GLUCKMAN et al., I975) puisqu'on a alors à considérer une réponse secondaire.

\section{6. - Conclusion}

L'étude du complexe HLA montre qu'il ressemble en tous points au complexe $\mathrm{H} 2$ et ceci renforce 1'idée de 1'importance et de l'intérêt de ces travaux.

Chez l'homme, il existe également d'autres systèmes d'histocompatibilité; l'action du système $\mathrm{ABO}$ avait été très tôt signalée, mais plus récemment ORIOI, et al. (1977), ont montré le rôle du système Lewis; il est certain bien sûr que d'autres systèmes inconnus interviennent.

Pour finir, il faut souligner cependant que l'existence de gènes Ir au sein du complexe HLA n'a pour l'instant pas été montrée; 1'hypothèse la plus logique est de penser qu'ils existent, mais comme le phénotype répondeur est dominant, il est difficile de rencontrer des individus non répondeurs, d'autant que les immunisations systématiques et expérimentales d'un grand nombre de personnes sont impraticables.

Enfin, l'observation de déséquilibres de linkage est une des données nouvelles apportées par l'étude du complexe HLA; de l'association préférentielle de certains allèles, résulte certaines combinaisons haplotypiques plus fréquentes que ne laisse prévoir le calcul de leur fréquence à partir des fréquences géniques. L'existence 
de ces déséquilibres n'est pas encore interprétée, mais elle a permis néanmoins, de formuler diverses hypothèses relatives à la sélection et aux migrations, illustrées par des études de génétique des populations (DEGos et DAUSSET, I975; RYDER et al., I978).

\section{III. - Présentation du complexe «B $"$ du Poulet}

L'existence d'alloantigènes érythrocytaires a été démontrée dès r924 par LANDSTEINER et MILLER, qui ont produit par hétéroimmunisation de lapins, des sérums leur permettant d'individualiser une série de poulets. Cette approche a par la suite été développée par Todd (I930, I93I).

Les premiers travaux génétiques sont dus à KOZELKA (r933a); ils ont suggéré que les différences exprimées par les antigènes érythrocytaires devaient être sous la dépendance de déterminants mendéliens.

Peu à peu, I2 systèmes de groupes sanguins ont été reconnus chez le poulet (Gilmour, I960; MC DERMid, I964), dont les hématies présentent la particularité d'être nucléées.

En ce qui concerne 1'histocompatibilité, les premiers résultats sont à attribuer à KOZELKA (I93I, I933b), qui a essayé en vain d'établir une relation entre alloantigènes érythrocytaires et rejet de greffes. Les premiers succès de greffes ont été obtenus par Cock et CLOUGH en I956 (greffes de peau).

La connaissance des groupes sanguins s'étant développée, c'est en effectuant le même type de travaux que SchIERMAN et NorDskog (I96I) ont démontré que le système $B$ (système érythrocytaire) était le système d'histocompatibilité majeur : des greffes de peau, effectuées sur des poulets de I 6 jours, ont survécu I 2 jours dans les combinaisons B-incompatibles, et au moins 40 jours dans les combinaisons compatibles. Le système $B$ avait été identifié en tant que système érythrocytaire en I948 (BRILEs et MC GIBBON, I948; BRILES et al., I948). Les populations consanguines de laboratoire ont permis d'approfondir sa connaissance; aujourd'hui, plus de vingt allèles sont connus, contrôlant des antigènes dont la classification en spécificités privées et publiques s'ébauche (PAZDERKA et al., I975). L'étude des populations commerciales, compte tenu d'un polymorphisme élevé, a rencontré des problèmes analogues à ceux déjà décrits dans 1'étude de HLA (DrobNA et HALA, I969); les sérums " monospécifiques " dans les lignées consanguines réagissent avec de nombreux animaux non-apparentés (90 à Ioo p. Ioo des animaux testés), ce qui en fait reflète la complexité sérologique de ce système, comme dans les autres espèces.

La présence des antigènes du système $B$ sur les lymphocytes (Schrérman et NoRDSKOC, I962) a été démontrée. La réaction du greffon contre 1'hôte, étudiée sous la forme locale de pustules chorio-allantoïdiennes (BOYER, I960; BURNET et BOYER, I961), est contrôlée par un locus identique ou étroitement lié au locus " B " (JAFFE et MC DERMID, I 962). La réaction lymphocytaire mixte est gouvernée par le locus B (MrGGIano et al., I974) ou du moins par un locus étroitement lié. La production d'anticorps vis-à-vis de divers antigènes : sérum albumine humaine, polysaccharide de pneumocoque, $\operatorname{DNP}(2,4$ dinitrophénol) couplé à des immunoglobulines de poulet, varie selon les allèles, comme l'ont démontré BaLcarova et al. (I973a, r973b, r974), travaillant avec des lignées homozygotes. GuNTHER et al. (I974) ont rapporté une association de certains allèles avec la production de l'anti (T-G)-A-L. KARA Koz et al. (I974) ont relaté l'association avec le locus B 
de la sensibilité à la tuberculine. BENEDICT et al. (I975) ont démontré le contrôle de la réponse au GAT et GA, par un gène lié au complexe B. L'existence de cellules T suppressives, a été suggérée par des travaux récents ( $\mathrm{KoCH}$ et SrmoNsEN, I977). CHANH et al. (1976), ont mis en évidence une association entre le niveau d'activité hémolytique du complément sérique et le complexe B. L'existence d'équivalents aux antigènes Ia murins a été découverte, le complexe $B$ comprenant deux types de gènes codant les uns les antigènes " $B$ " (homologues des SD des autres espèces), les autres, les antigènes " $B-L$ " absents de la surface des globules rouges (équivalents des Ia) (ZIEGLER et PrNK, I975-I976). Les résultats d'analyse biochimique (ZIEGLER et PINK, I976), mettent en évidence l'existence de deux catégories de molécules à la surface des leucocytes : la première catégorie se compose de 2 chaînes polypeptidiques de PM respectifs 40000 et I2 000, la chaîne lourde étant une glycoprotéine portant les spécificités antigéniques. La chaîne légère pourrait être la $\beta_{2}$-microglobuline découverte par ailleurs (WINKLER et SANDERS, I977) mais l'homologie n'a pas été démontrée; la seconde catégorie possède un poids moléculaire d'environ 30 ooo et serait constituée d'une chaîne unique.

L'organisation génétique $\mathrm{du}$ complexe $\mathrm{B}$, est actuellement en cours de définition. L'observation de recombinants (SchIERMAN et Mc BRIDE, I969) a suggéré l'existence de plusieurs loci codant pour les antigènes $B$. $D$ ss travaux récents permettent de distinguer deux régions (HALA et al., I976), l'une étant porteuse des déterminants " $B$ " et " B-L " déjà décrits; l'autre, portant les déterminants " $B-G$ ", codant pour des antigènes érythrocytaires, n'ayant aucune fonction en histocompatibilité. La synthèse de ces résultats (voir fig. $2 \mathrm{I}$ ) nécessite 1'hypothèse d'un modèle à 3 loci (PINk et al., I977), la relation entre les antigènes B et B-G n'étant pas entièrement expliquée. L'étude de séquence des chaînes lourdes des antigènes SD classiques montre une analogie remarquable avec les résultats obtenus chez l'homme et la souris (VITETTA et al., I977).

En conclusion, il convient de signaler quelques détails supplémentaires : il existe un deuxième système d'histocompatibilité bien caractérisé, qui est le

Chromosome?

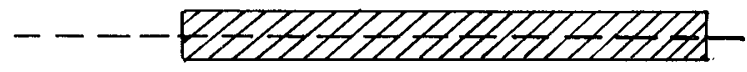

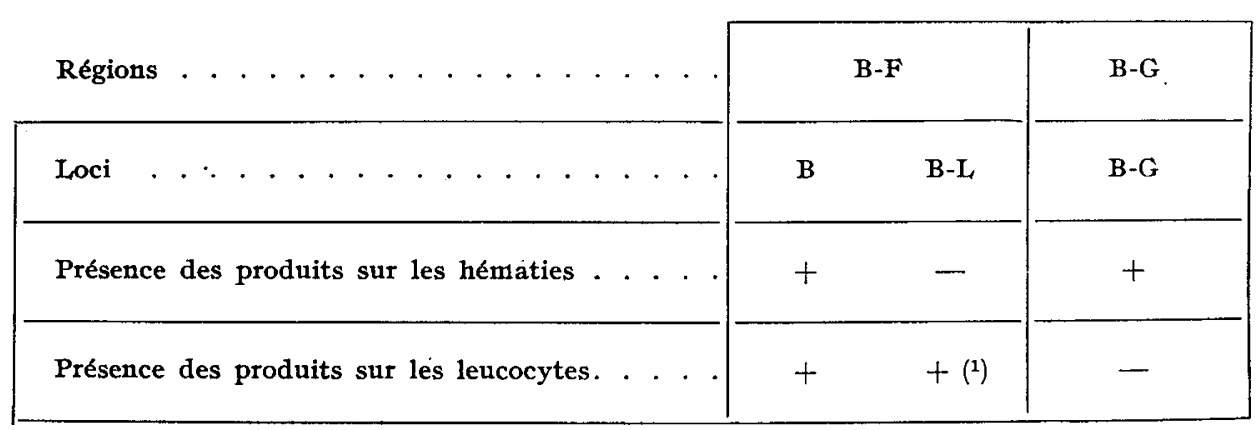

FIG. 21. - Présentation du Complexe $B$ du poulet; modèle à 3 loci (d'après PINK et al., I977). Prosentation of the chicken " $B$ " complex; 3 loci model.

(1) Seulement lymphocytes B et monocytes. 
système C érythrocytaire (SHIERman et Nordskog, I965); d'autres systèmes sont bien sûr inconnus, HaLA (I969) distinguant 5 à 9 loci différents. La comparaison des propriétés du système $B$ avec celles de $\mathrm{H}_{2}$, déjà très semblables en I97I (HALA et HASEK, I97I) appazaît aujourd'hui indiscutablement en faveur d'une grande similitude.

\section{IV. - Présentation du complexe "SL-A » du porc}

\section{I. - Introduction}

Les recherches consacrées au système d'histocompatibilité dans cette espèce étaient pratiquement inexistantes jusqu'à ces ro dernières années. BINns (I968) a montré que le porc était capable de développer une réaction de rejet de greffe dès le $80^{\mathrm{e}}$ jour de vie fotale. Les quelques données de la littérature se rapportant aux allogreffes de peau indiquaient des capacités de réaction violentes de la part de 1'hôte, se traduisant par des survies brèves de 6 à 12 jours. BAKER et ANDRESEN (1964) n'ont pas observé de prolongations notables des greffes de peau faites entre frères, identiques pour de nombreux facteurs de groupe sanguins. Il avait d'ailleurs été suggéré que, parmi les I5 systèmes érythrocytaires connus (80 antigènes différents), le système $\mathrm{E}$ (qui a avec le système $\mathrm{L}$ une structure complexe, comparable au système thésus de l'homme) pouvait représenter le système d'histocompatibilité majeur chez le porc (Ivanyi, I970). Des tests de transfert de lymphocytes normaux entre porcs, dans le but de déterminer le degré d'histocompatibilité n'avaient pas fourni de résultats convaincants (JAFFE et al., I967). L'absence de réponse chez un certain nombre d'animaux avait conduit les auteurs à supposer l'absence d'antigènes forts dans certaines races.

Par absorption, HALA (I967) a montré la présence d'antigènes $A, E, N$, marqueurs érythrocytaires, sur les lymphocytes de porc. SAIson et INGRAm (I963) ont observé l'apparition dans le sang des hôtes, d'anticorps anti-érythrocı̃taires à la suite de greffes cutanées; certains de ces anticorps correspondaient à des spécificités déjà connues.

Les études de transplantations d’organes réalisées sur cet animal se sont multipliées depuis les travaux de GARNIER et al., I965, qui proposèrent son utilisation dans l'étude de la greffe hépatique; aujourd'hui, de nombreuses greffes ont été pratiquées : foie (CALNE et al., I967), cœur (CULLUM et al., r970), intestin (KEAVENY et al., I970); le porc est donc apparu comme un animal de laboratoire de choix, pour les investigations sur les problèmes immunologiques liés à ce type d'intervention; de plus, il est considéré comme biologiquement proche de l'homme.

C'est dans ce contexte que l'équipe de VaIman a entrepris en I968-I969, l'étude des antigènes de transplantation dans l'espèce porcine, étude qui apparaissait être nécessaire, afin de pouvoir aborder l'étude de la greffe osseuse chez les animaux irradiés, thème de recherche mis en œuvre par le C.E.A. (Commissariat à 1'Energie Atomique).

\section{2. - Description}

Le complexe d'histocompatibilité majeur du porc, appelé SL-A présente une organisation génétique très comparable à celle connue pour le complexe HL-A.

Les antigènes d'histocompatibilité classique, dont 20 sont actuellement assez bien définis, sont contrôlés par des gènes appartenant à 3 séries alléliques dis- 
tinctes groupées dans une même région (VAIman, I978). La tableau I7 fournit les fréquences dans les races Large-White et Landrace. Un seul recombinant, parni I 000 porcelets étudiés dans des familles, concernait deux gènes de la région $\mathrm{SL}$-A, apportant la preuve de l'existence d'au moins deux séries alléliques. L'existence de la troisième série SD, suggérée par les études génétiques familiales, a été confirmée par les résultats d'expériences de séparations biochimiques et par ceux obtenus par la technique de capping. Chacune des trois populations moléculaires sont constituées d'une sous-unité protéique de poids moléculaire 27 ooo daltons, associée à une molécule de PM I2 000, identique à la béta-2-microglobuline. Un même antigène porte une spécificité privée associée à une ou plusieurs spécificités publiques.

La réaction lymphocytaire mixte est, quant à elle, sous le contrôle d'une région située à environ 0,5 centimorgans de la précédente; 6 cellules homozygotes de référence sont aujourd'hui disponibles, mais ceci est loin de représenter toutes les

\section{TABLEAU I7}

Fréquences géniques des antigènes des séries $S D$ chez le porc (d'après VAIMAN, I978)

Gene frequencies of the $S D$ antigens in the pig

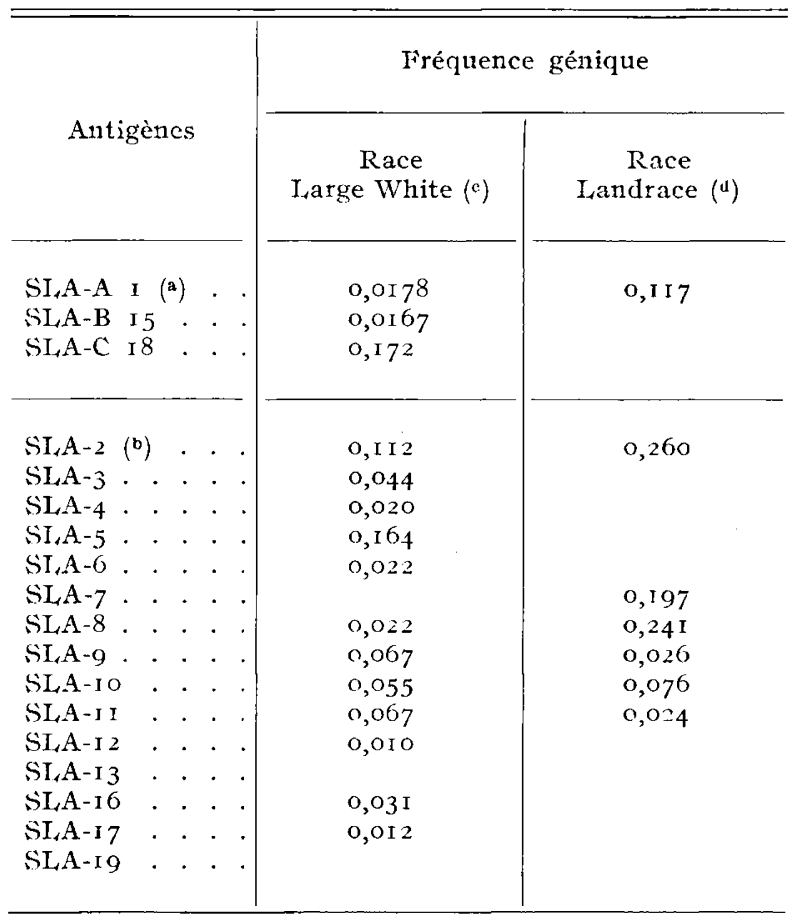

(a) Les trois séries SD connues sont SLA-A, SLA-B, SI,A-C.

(b) I es antigènes SLA-2 à I7 n'ont pas encore pu être répartis dans l'une des 3 séries SD.

(c) Fréquences calculées sur 90 animaux.

(d) Fréquences calculées sur 60 animaux. 
spécificités existantes. Des immunisations entre frères ne différant que pour cette région $\mathrm{du}$ complexe, ont permis de produire des antisérums dirigés contre des antigènes homologues des antigènes $\mathrm{DR}$ de l'homme (VAIMAN et al., 1975).

\title{
3. - Conclusion
}

Le complexe SL-A appartient au même groupe de linkage que les systèmes de groupes sanguins $\mathrm{J}$ et $\mathrm{C}$ (HRUBAN et al., I976); Io unités de recombinaison séparent $\mathrm{J}$ et $\mathrm{SL}-\mathrm{A}, 5,5$ urités séparent $\mathrm{J}$ et $\mathrm{C}$, mais l'ordre de ces 3 régions n'est pas connu. Des résultats récents montrent que le complexe SL-A code pour certains facteurs du complément et contrôle la réponse immunitaire au lysozyme de poule (Varman et al., I977, r979). Par ailleurs, un autre système érythrocytaire (E) paraît être un système d'histocompatibilité mineur (HRUBan, I975). Signalons enfin qu'un essai de localisation chromosomique par hybridation cellulaire est actuellement en cours.

\section{V. - Les autres complexes d'histocompatibilité majeurs}

\author{
I. - Chez les primates, autres que l'homme
}

A cause de leur parenté phylogénique avec l'homme, l'étude du complexe majeur d'histocompatibilité chez d'autres primates est d'un grand intérêt biologique.

\section{a) Le complexe Rh-L-A du macaque Rhésus}

Cette espèce a été particulièrement étudiée du fait de la grande facilité d'approvisionnement, et des possibilités de reproduction en captivité.

Historiquement, c'est la première espèce animale, non consanguine, dans laquelle on a démontré la liaison génétique de plusieurs loci sérologiquement définis (Rogentine et al., I97I), la fréquence de recombinaison étant de l'ordre de 0,5 p. Ioo.

\section{b) Le complexe $C h L-A$ du chimpanzé}

Contrairement au rhésus, le nombre de chimpanzés disponibles est faible. Aussi, les connaissances relatives au complexe ChL-A sont-elles moins importantes et se limitent à des résultats sérologiques obtenus soit avec les anti-sérums allogéniques, soit avec des sérums anti HL-A. La stimulation lymphocytaire entre cellules de chimpanzé et cellules humaines est possible. L'homologie avec HL-A apparaît très grande, mais il faut toutefois considérer qu'il s'agit plutôt de réactions croisées entre antigènes $\mathrm{HL}_{\mathrm{L}} \mathrm{A}$ et ChL-A que d'une réelle identité.

\section{c) L'histocompatibilité chez les autres primates}

Il faut signaler 1'existence de travaux chez trois espèces de Babouins (Papio ursinus, $P$. cynophalus, $P$. anubis) mais, aucun système majeur d'histocompatibilité n'a pu être mis en évidence, la production de quelques sérums n'ayant 
pas pu être accompagnée d'étude génétique; cependant, un certain nombre de réactions cytotoxiques ont été obtenus par immunisation avec des leucocytes ou des greffes de peau.

Deux espèces du genre Macaca (M. irus et M. arctoïdes) ont également fait l'objet de quelques investigations peu fructueuses. L'utilisation de sérums anti HL-A, anti RhL-A, anti ChL-A pour tester des cellules humaines, des cellules de macaque Rhésus, de chimpanzé ou d'autres singes (gorilles, orang-outans), permet de constater que d'une part, il existe des similitudes entre les antigènes HL-A et ChL-A et que d'autre part, il existe des similitudes entre les autres espèces; seules les spécificités $\mathrm{HL}_{4}$-A $4 a$ et $4 b$ semblent être présentes dans toutes les espèces; BALNER et al. (I97I), ainsi que VAN Rood et al. (I972), désignent alors les antigènes correspondants " substance de base ", à partir desquelles les antigènes tissulaires des primates auraient évolués.

\section{2. - Le complexe du rat}

Le complexe d'histocompatibilité majeur du rat a été mis en évidence par plusieurs équipes, indépendamment les unes des autres; ceci explique les diverses appellations rencontrées dans la littérature : Ag-B (ELKINS et PAI,M, I956), RtH-I ou H-I (STARK et KREN, I967), R-I (Bogden et APTEKMAN, r960). Les études sérologiques ont permis de définir un nombre relativement limité d'haplotypes différents; le polymorphisme est restreint, et de plus, par opposition avec le complexe $\mathrm{H}_{2}$ de la souris, ici, une seule spécificité privée caractérise chaque haplotype : ceci signifiant, qu'une seule extrémité analogue à $\mathrm{H} 2-\mathrm{K}$ ou $\mathrm{H} 2-\mathrm{D}$ serait présente.

De la même manière, le polymorphisme des gènes contrôlant la réaction lymphocytaire mixte est faible (CRAMER et al., I977), la distinction entre les deux types de gènes ayant été établie à 1'aide de recombinants (WILI,IAMS et MoORE, I976), sans que plus de précision sur l'organisation génétique du complexe $H$-I ne soit disponible. Cette "carence " de polymorphisme ne peut pas être attribuée à un biais d'échantillonnage, car les populations sauvages ne présentent pas plus de diversité.

\section{3. - Le complexe GPL-A du cobaye}

La mise en évidence du complexe GPL-A du cobaye a été accompagnée de faits particuliers, et est très récente. En effet, ne disposant au départ que de 2 souches hautement consanguines, les sérums cytotoxiques produits lors des premières greffes (WALFORD et al., I962), se révélèrent être en fait dirigés contre les antigènes Ia. Les deux souches utilisées étaient identiques pour les antigènes d'histocompatibilité classiques, et c'est par immunisation entre des souches consanguines et des animaux d'un élevage clos, mais maintenu par croisement au hasard que les sérums ont pu être obtenus; comme dans les autres espèces, les gènes " sérologiquement définis " et les gènes contrôlant les antigènes Ia sont localisés à des loci différents. Inversement, l'utilisation du cobaye dans l'étude de la réponse immunitaire à certains antigènes a été rapidement récompensée; dès I963, KANTOR et al, et LEVINE et al., rapportaient l'existence de bonne ou mauvaise réponse sous un contrôle génétique dominant autosomal; la liaison avec le complexe majeur d'histocompatibilité fut établie par ELLMAN et al., en I970. Depuis, de nom- 
breux gènes Ir ont été identifiés. Les travaux actuels permettent de définir l'organisation génétique un peu mieux, cependant, deux remarques sont à faire : d'une part, les études génétiques chez le cobaye sont freinées par le fait d'une faible taille de portée et d'une faible vitesse de reproduction (une génération par an); d'autre part, l'étude des populations sauvages n'apporte pas beaucoup d'information puisque I $p$. Ioo seulement des animaux ne portent pas les spécificités définies avec les populations consanguines.

\section{4. - Le complexe DL-A du chien}

Le chien a été utilisé de manière importante dans l'expérimentation sur les allogreffes de tissus et d'organes; en effet, après une première approche réalisée avec les espèces typiques de laboratoire (souris, rat), le besoin de clarification et de vérification des observations dans une espèce non apparentée explique que 1'on ait souvent fait usage de chiens; c'est pourquoi les recherches sur l'histocompatibilité dans cette espèce ont été activement poursuivies. L'organisation génétique du complexe DL-A est très semblable à celle du complexe HL-A; 3 loci sérologiquement définis ont été identifiés (VRIESENDORD et al., I976); 2 loci contrôlant la MLR sont connus, mais un seul a été placé avec certitude dans la région DL-A; enfin on observe également chez le chien l'existence d'un déséquilibre de linkage pour certaines combinaisons haplotypiques, et la présence du locus codant pour la $\mathrm{PGM}_{3}$ (phosphoglucomutase 3) auprès du complexe $\mathrm{DL}-\mathrm{A}$. La mise en évidence de gènes Ir par contre différencie les résultats obtenus chez le chien de ceux obtenus chez l'homme.

\section{5. - Le complexe RL-A du lapin}

Les études chez le lapin sont anciennes, puisque MEDAWAR utilisait ce matérie1 animal dans ses recherches sur la nature immunologique de réactions de transplantation, en I944-I945. De nombreuses greffes furent réalisées et MFDAwAR suggéra l'existence d'antigènes d'histocompatibilité leucocytaires dans la mesure oì la compatibilité des systèmes érythrocytaires était insuffisante pour obtenir la survie des greffons.

Chez le lapin, 6 systèmes érythrocytaires ont été décrits (CoHEN, I958), et l'un d'entre eux, le système $\mathrm{Hg}$ a longtemps été soupçonné d'être le complexe majeur d'histocompatibilité. Il a fallu attendre les premières études sérologiques, avec des sérums lymphocytotoxiques obtenus après transplantation (TERASAKI et al., I96r), et la définition définitive du complexe RL-A par plusieurs équipes DEMANT, I968; MATEJ, I970; EhlERs et Ahrons, I97I) pour écarter cette hypothèse. Aujourd'hui, 7 allèles sont connus et définis à partir de Io spécificités (TISsoT et CoHEN, I972). Le contrôle de la réaction lymphocytaire mixte par un locus lié au complexe RL-A a été démontré (TISsot et CoHEN, 1974), et des études préliminaires indiquent la présence de gène Ir.

\section{6. - Le complexe d'histocompatibilité des bovins}

Les recherches sur les systèmes d'histocompatibilité des bovins se sont réellement développées à partir de I975. A cette date, seuls les systèmes de groupes sanguins érythrocytaires étaient bien connus; parmi les II systèmes établis, 
3 systèmes " complexes " ( $\mathrm{B}, \mathrm{C}$ et $\mathrm{S}$ ) étaient apparus à certains auteurs, en raison de leur complexité, ou de relations sérologiques particulières, comme pouvant s'identifier au complexe d'histocompatibilité majeur; ces hypothèses restaient cependant à confirmer ou à infirmer. Diverses investigations préliminaires et contradictoires permettaient bien de montrer l'existence d'antigènes lymphocytaires spécifiques mais aucun travail important sur les groupes lymphocytaires n'avait été publié. C'est dans ce contexte que plusieurs équipes ont entrepris des recherches ayant pour but principal la mise en évidence des gènes d'histocompatibilité sérologiquement définis. Rapidement, CALDwELl et al. (I977), Amorena et Stone (I978), Spooner et al. (I978) décrivaient, indépendamment les uns des autres, l'existence d'antigènes lymphocytaires génétiquement contrôlés par un système qui pouvait être considéré comme le complexe d'histocompatibilité majeur. De plus, les données obtenues en France permettaient de montrer qu'aucun des II systèmes érythrocytaires connus n'était confondu, ni même étroitement lié, avec le système lymphocytaire identifié (LEVEZIEL, I978). La synthèse de ces divers résultats a pu être réalisée grâce au développement d'une importante collaboration internationale des I 2 laboratoires travaillant aujourd'hui sur l'histocompatibilité bovine.

Fn I978, un premier test de comparaison international de réactifs lymphocytotoxiques a été réalisé ( 9 laboratoires ont participé à ce test); 1a grande majorité des 248 réactifs soumis à ce test, parmi lesquels se trouvaient ceux utilisés dans les travaux déjà mentionnés, sont apparus comme détectant les antigènes d'un seul et même système; II spécificités ont pu être définies; elles se comportent comme reconnaissant une seule série allélique dans la population utilisée, constituée de I30 animaux non-apparentés (SPOONER et al., I979). Ce fait est d'autant plus remarquable que les réactifs sont produits et purifiés dans les divers laboratoires par des techniques différentes; le système mis en évidence, appelé BoLA, est désormais considéré comme le complexe d'histocompatibilité majeur des bovins. Les résultats obtenus en I979, tant aux États-Unis qu'en Europe, confirment ces faits, et de nouvelles spécificités ont été définies ( 3 en Europe et 5 aux Êtats-Unis).

En ce qui concerne les autres groupes de gènes habituellement présents au sein d'un complexe majeur d'histocompatibilité, peu de résultats ont été obtenus jusqu'ici chez les bovins; mentionnons simplement la publication de CURIECOHEN et al. (1978) concluant que la culture mixte lymphocytaire est contrôlée par au moins 4 loc., mais n'établissant pas formellement leur appartenance au complexe BoLA. Signalons enfin la publication de CALDWELI, et Cumberi,AND (I978) relatant l'association de certaines spécificités avec le carcinome à cellules squameuses de l'œil; par ailleurs, un essai de localisation chromosomique par hybridation cellulaire est actuellement en cours en France. Il est certain que le nombre important d'équipes travaillant en histocompatibilité bovine est un facteur qui devrait permettre d'aboutir rapidement à une définition détaillée du complexe BoLA.

\section{7. - Le complexe d'histocompatibilité de la chèvre}

Peu de travaux sont à signaler. Sa mise en évidence par VAN DAm et al. (I976) est récente et l'organisation génétique du système n'est pas encore connue.

\section{8. - Le complexe d'histocompatibilité du mouton}

Les travaux de MrLLor (1978) permettent de définir un système d'antigènes lymphocytaires sérologiquement définis, comportant 2 loci : OLA-A et OLA-B 
distants de o,6 unités de recombinaison, correspondant au complexe majeur d'histocompatibilité; deux autres systèmes mineurs auraient également été mis en évidence par cet auteur. Une tentative de localisation chromosomique par hybridation cellulaire est actuellement en cours.

\section{9. - Le complexe d'histocompatibilité du cheval}

Plusieurs équipes développent actuellement des investigations dans ce domaine. Signalons la mise en évidence récente d'une liaison génétique entre le système de groupes sanguins érythrocytaires $\mathrm{A}$ et un système sérologiquement défini de groupes lymphocytaires (BAILEY et al., I979), appelé ELA et pouvant être considéré comme la première ébauche du complexe d'histocompatibilité majeur du cheval.

\section{VI. - Comparaison des résultats obtenus dans les diverses espèces}

Les études d'histocompatibilité développées dans de nombreuses espèces ont donc permis de mettre en évidence, dans tous les cas où il a été recherché, un Complexe d'Histocompatibilité Majeur (du moins chez les mammifères).

Ce fait est d'autant plus remarquable, que les connaissances détaillées obtenues pour chaque espèce laissent observer une très grande similarité; le tableau I 8

TABLEAU I8

Espèces ayant fait l'objet d'étude d'histocompatibilité. Comparaison des résultats Groupes de gènes et fonctions étudièes et retrouvées pour chaque espèce

Species in which histocompatibility studies have been developped. Comparative vesults. Gene groups and functions studied in each species

\begin{tabular}{|c|c|c|c|c|c|c|c|c|c|}
\hline Espèze & $\begin{array}{c}\text { Appellation } \\
\text { du } \\
\text { complexe }\end{array}$ & SD & L.D & Ia & Ir & $\begin{array}{l}\text { Complé- } \\
\text { ment }\end{array}$ & CMI, & GrHR & $\begin{array}{l}\text { Coopé:a- } \\
\text { tlon } \\
\text { ccllulaire }\end{array}$ \\
\hline 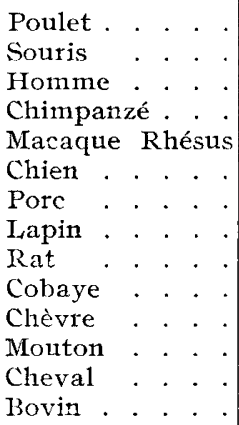 & $\begin{array}{c}\text { B } \\
\text { H-2 } \\
\text { HL-A } \\
\text { ChL-A } \\
\text { RhL-A } \\
\text { DL-A } \\
\text { SL-A } \\
\text { RL-A } \\
\text { Ag-B } \\
\text { GPL-A } \\
\text { GL-A } \\
\text { OL-A } \\
\text { EL-A } \\
\text { BoL-A }\end{array}$ & $\begin{array}{l}+ \\
+ \\
+ \\
+ \\
+ \\
+ \\
+ \\
+ \\
+ \\
+ \\
+ \\
+ \\
+\end{array}$ & $\begin{array}{l}+ \\
+ \\
+ \\
+ \\
+ \\
+ \\
+ \\
+ \\
+ \\
+\end{array}$ & $\begin{array}{l}+ \\
+ \\
+\end{array}$ & $\begin{array}{l}+ \\
+ \\
+ \\
+ \\
+\end{array}$ & $\begin{array}{l}+ \\
+ \\
+ \\
+ \\
+\end{array}$ & $\begin{array}{l}+ \\
+\end{array}$ & $\begin{array}{l}+ \\
+ \\
+\end{array}$ & + \\
\hline
\end{tabular}


visualise cette concordance des observations; les divers groupes de gènes et fonctions appartenant au complexe $\mathrm{H}-2$ (voir fig. $\mathrm{r} 8$ ) de la souris sont retrouvés dans les autres espèces, soit totalement dans les cas où les études sont très développées (chez 1'homme par exemple), soit partiellement dans les autres cas. Il apparaît alors que les caractéristiques attribuées au complexe $\mathrm{H}-2$ (voir tab1. 8), également vérifiées par les autres complexes d'histocompatibilité, peuvent être considérées plus généralement comme caractéristiques d'un complexe d'histocompatibilité majeur.

Il est actuellement impossible de comprendre dans leur complexité, l'ensemble des mécanismes et phénomènes dépendant de ce segment chromosomique. Toutefois, on peut en se basant sur divers faits expérimentaux, comme nous allons le voir en concluant, avancer quelques hypothèses sur le rôle du système qu'il contrôle.

\section{Conclusion}

Un complexe d'histocompatibilité majeur a d'abord été caractérisé par son influence essentielle sur les phénomènes de rejet des greffes. En effet, dans toutes les espèces oì des recherches approfondies ont été effectuées sur cette question, il s'est avéré que le rejet des greffes était contrôlé, pour une grande partie, par un complexe de ce type.

L'application la plus importante des connaissances acquises dans ce domaine est, bien entendu, l'utilisation du typage $\mathrm{HL}_{4}-\mathrm{A}$ pour choisir donneur et receveur en chirurgie humaine; on mentionnera, par exemple que 432 greffes de rein ont été pratiquées en I 977 en France, et que I 821 personnes en dialyses étaient recensées par France-transplant. Pour ces greffes, le pourcentage de survie passe de 30-40 p. I0o en situation d'incompatibilité, à 50-70 p. Ioo en situation de compatibilité, ceci pour des individus non apparentés et un an après la greffe. L,es variations sont dues au cas des malades préimmunisés (grossesses, transfusions). L'utilisation de ces données immunogénétiques pour d'autres types de greffe (foie, cœur, poumon) est actuellement plus restreinte. L'utilisation des greffes de peau sur le plan expérimental est en fait un test très sensible, et l'on constate qu'une amélioration de la survie du greffon de quelques jours se traduit par une survie de plusieurs années pour la transplantation d'organe, avec l'aide de traitements immunosuppresseurs.

Cependant, la transplantation d'organe ne peut prétendre représenter une finalité biologique; le rôle biologique " normal " du complexe majeur d'histocompatibilité, doit donc être recherché ailleurs, en analysant les données disponibles. Nous avons rapporté son intervention dans de nombreux mécanismes de l'immunologie, concernant la défense de l'organisme : la réponse immunitaire de type humoral, la réponse immunitaire à médiation cellulaire, les phénomènes de coopération au cours de cette réponse immunitaire sont contrôlés par des gènes situés dans le complexe. Le maintien de ce complexe au cours de l'évolution, le maintien du polymorphisme même dans des populations consanguines, le nombre plus élevé d'homozygotes chez les jeunes que chez les individus âgés d'une population (traduisant un effet d'hétérosis avantageux pour les hétérozygotes), sont des faits qui tendent à indiquer que ce système joue un rôle de défenseur de l'organisme.

L'observation, dans plusieurs espèces, d'associations entre certaines maladies et le complexe majeur d'histocompatibilité est un fait biologique marquant; chez la souris, la présence d'un gène contrôlant la susceptibilité au virus de Gross a été 
démontrée dès I966; des recherches sur d'autres virus ont également montré soit la présence de gènes de susceptibilité, soit simplement des différences de sensibilités entre lignées et on parle alors d'association. Chez le poulet, la sensibilité à la maladie de Marek est influencée par le complexe $B$ : certains haplotypes confèrent une plus grande sensibilité; de plus, dans cette espèce une association avec une thyroïdite autoimmune a été démontrée. Mais c'est chez 1'homme que l'abondance de résultats récents est remarquable. $\mathrm{D}$ a nombreuses maladies semblent associées au complexe HL-A; cependant, il est impossible de définir les critères, de définir un " portrait " de ces maladies; certaines présentent un caractère auto-immunitaire, d'autres non; en aucun cas, un germe infectieux connu ne semble intervenir; le plus souvent d'origine mystérieuse, ces maladies sont par ailleurs à pénétrance incomplète. Il faut souligner que les associations trouvées avec le complexe d'histocompatibilité ont permis dans certains cas de mieux classer les maladies, et d'autre part, de faciliter leur diagnostic; c'est une conséquence pratique qui revêt donc un intérêt indéniable en médecine. L'idée de recherche d'association entre un gène marqueur et une maladie était ancienne; longtemps infructueuses, ces recherches viennent de trouver un aboutissement spectaculaire dans l'étude des complexes d'histocompatibilité majeur.

Les mécanismes dont dépend la susceptibilité accrue à certaines maladies sont à l'heure actuelle inexpliqués; seules des hypothèses de travail ont été formulées; il est vraisemblable que les molécules gouvernées à la surface des cellules par le complexe sont des marqueurs d'une subtilité extrême par lesquels les cellules d'un même organisme se reconnaissent. Par corollaire, toute modification de ces marqueurs doit entraîner une réaction de défense, la molécule modifiée étant reconnue comme "étrangère ". Ce schéma s'applique de manière évidente au cas de greffes; mais des résultats expérimentaux montrent qu'ils pourraient également

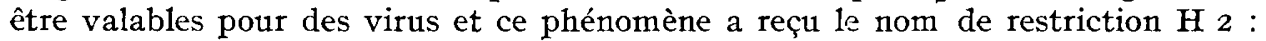
des cellules $\mathrm{T}$ sensibilisées par le virus de la variole par exemple sont capables de tuer spécifiquement non pas des cellules normales, non pas des cellules infectées par d'autres virus, ni même des cellules infectées par le même virus et différant par les antigènes $\mathrm{H}_{2}-\mathrm{K}$ et $\mathrm{D}$, mais uniquement des cellules infectées par ce virus et histocompatibles. Le même type de restriction, mais cette fois pour la région $I$, a été rapporté pour la réponse immunitaire contre une bactérie. Ces résultats, avec ceux relatés dans l'étude du complexe $\mathrm{H}-2$, confirment l'importance du complexe dans les mécanismes cellulaires au cours de la réponse immunitaire qui doit être envisagée comme résultant d'un équilibre entre plusieurs mécanismes; le défaut de fonctionnement d'un seul de ces mécanismes peut entraîner un disfonctionnement de la réponse immunitaire.

Il existe un cas où le rôle de défense du " soi " par les antigènes d'histocompatibilité semble contradictoire : c'est le cas de la fécondation et de la reproduction. En effet, le fœetus peut être considéré, d'un point de vue immunologique, comme une greffe semi-allogénique (ou haplo-identique), or, cette greffe survit, et la gestation se déroule normalement. Le fœtus est doué de propriété immunogènes; la mère est capable de développer une réponse immunitaire; contradictoirement, diverses études tendent à prouver, que la fertilité ou la croissance fœetale sont d'autant plus grandes que les incompatibilités tissulaires foto-maternelles le sont. Ces données ne sont pas encore expliquées, mais elles permettent de penser que les connaissances en histocompatibilités pourraient être également importantes dans le domaine de la reproduction. Certains auteurs interprètent ces faits en supposant un effet sélectif favorable à l'hétérozygote et expliquant le maintien di polymorphisme. 
Si tous ces faits expérimentaux ne peuvent pas encore être analysés synthétiquement, ils contribuent cependant à souligner le rôle vraisemblablement fondamental du complexe d'histocompatibilité majeur dans la biologie des espèces, tel qu'on peut le concevoir aujourd'hui; le domaine de l'histocompatibilité se présente actuellement comme un des domaines d'investigations les plus prometteurs, et son développement, déjà très important ces dernières années ne cesse de s'intensifier. Dans ces conditions, il apparaît souhaitable d'approfondir activement des recherches dans les espèces d'intérêt zootechnique, dans la mesure où la mise en évidence d'un complexe d'histocompatibilité majeur dans ces espèces, si elle est accompagnée, comme on est en droit de l'espérer aujourd'hui, de la découverte de liaisons avec des aptitudes physiologiques ou zootechniques, pourra déboucher dans l'avenir sur des applications très attendues.

Rę̧ pour publication en décembre 1979.

\section{Summary}

\section{The major histocompatibility complex in man and animals}

This bibliographical review is an up to date statement of research on the Major Histocompatibility Systems in man and animals. Initiated by experimental studies on transplantation, research on the histocompatibility systems has much developed the last few years both concerning the number of species studied as the extent of the investigations made in 6 ach species and the value of the results obtained. Thirteen animal species are considered: mcuse, rat, guinea-pig, chimpanzee, rhesus-monkey, dog, rabbit, pig, cattle, goat, sheep, horse and chicken.

The H-2 complex of the mouse is the best described today; considered as a model, it is studied in details in the first part of this review in the form of a stepwise description following as well as possible the chronology of the historical facts; the various definitions are recalled and the principle of the techniques indicated; thus, it is shown that what we call today "Major Histocompatibility Complex " is a chromosomic segment including a set of fonctionnally and topographically linked genes involved in different fundamental immunological mechanisms: some are involved in the notion of " self-recognition " and consequently play an essential role in the transplantation process; others control the humoral and /or cellular immune response; others control the mechanisms of cellular cooperation and others the synthesis of complement components.

The second part of this review gives a description of the results obtained in other species. The human HLA complex, the best known among outbred species, is extensively described taking into account its medical interest; a particular attention is paid to two important species for animal husbandry in which results of great value have already been obtained: pig and chicken; the findings concerning the other afore cited species are only briefly summarized. Hence, the great resemblance between the structure and function of the various complexes studied is shown in a comparative table.

It may be concluded from this review that although it is impossible to accuratly define the role of the Major Histocompatibility Complex, it nevertheless seems to be the immune centre of the organism; moreover, a spectacular discovery has just been made in human research: the detection of associations between HLA and diseases. Accordingly, Histocompatibility represent one of the most promising fields of investigation and even if today many possibilities of application are only perceived potentially we have the right to hope that they may be concretized some day in man and animals.

\section{Remerciements}

L'auteur tient à remercier tout particulièrement F. GROSCLAUDE (I.N.R.A., Jouy-en-Josas) pour ses nombreuses suggestions lors de la rédaction de cette revue, ainsi que M. VAIMAN (C.E.A., Jouy-en-Josas) pour ses remarques à la lecture du manuscrit. 


\section{Références bibliographiques}

Abbasi K., Demant P., Festenstein H., Holmes J., Huber B,, Rychlikova M., i973. Mouse mixed lymphocyte reactions and cell mediated lympholysis: genetic control and relevance to antigenic strength. Transplant. Proc., 5, 1329-1338.

Adler W. H., TAkiguchi T., Marsh B., SMith R. T., ig7o. Cellular recognition by mouse lymphocytes in vitro. II. Specific stimulation by histocompatibility antigens in mixed cell culture. J. Immunol., 105, 984-rooo.

ALLEN F. H. Jr., I974. Linkage of HLA and GBG. Vox. Sang., 27, 384-382.

ALLEN S. L., I955. Linkage relations of the genes histocompatibility. 2 and fused Tail, brachury and kinky tail in the mouse, as determined by tumour transplantation. Genetics, 40, 627-650.

ALPER C. A., 1976. Inherited structural polymorphism in human $\mathrm{C}_{2}$ : evidence for genetic linkage between $\mathrm{C}_{2}$ and Bf. J. Exp. Med., 147, I III.

Alter B. J., Schendel D. J., Bach M. L., Bach F. H., Klein J., Stimpfling J. H., I973. Cell mediated lympholysis: importance of serologically defined $\mathrm{H}-2$ regions. $J$. Exp. Med., 137, I303-1309.

Amerding D., KATZ D. H., I974. Activation of T and B lymphocytes in vitro. II. Biological and chemical properties of an allogenic factor (AEF) active in triggering specific $B$ lymphocytes. J. Exp. Med., 144, I9.

Amerding D., Kubo R. T., Grey M. H., KaTz D. H., i 975. Activation of T and B lymphocytes in vitro: presence of $\mathrm{\beta}_{2}$-microglobulin determinants on allogenic effect factor. Proc. Nat. Acad. Sci. (U.S.A.), 72, 4577 .

Amorena B., Stone W. H., 1978. Serologically defined (SD) locus in cattle. Science, 201, i 59I60.

Amos D. B., I953. The agglutination of mouse leucocytes by iso-immune sera. Br. J. Exp. Pathol., 34, 464-470.

Amos D. B., Gorer P. A., Mikulska Z. B., i955. An analysis of an antigenic system in the mouse (the H.2 system). Proc. Roy. Soc. B., 144, 369-380

Amsbaugho D. F., Hansen C. T., Prescott B., Stiashak P. W., Barthold D. R., Baker P. J., 1972. Genetic control of the antibody response to type III pneumococcal polysaccharide in mice. I. Evidence that an X-linked gene plays a decisive role in determiting responsiveness. J. Exp. Med., 136, 93 I-949.

Andersson L. C., Hayry P., 1973. Specific priming of mouse thymus dependent lymphocytes to allogeneic cells in vitro. Eur. J. Immunol., 3 (2), 595.

Aokr T., Hammerling U., De Harven E., Boyse E. A., Old L. J., i969. Antigenic structure of cell surfaces. An immunoferritin study of the occurence of topography of $\mathrm{H}-2, \theta$ and TL alloantigens on mouse cells. J. Exp. Med., 130, 979-г оо I.

BACH F. H., HirschorN K., I964. A potential histocompatibility test in vitro. Science, 142, 8 I3-8I4.

Baсн F. H., Voynow N. K., I966. One way stimulation in mixed leucocytes cultures. Science, 153, 545-547.

BACH F. H., WIDMER M. B., BACH M. L., KLEIN J., I972. Serologically defined and lymphocyte defined components of the major histocompatibility complex in the mouse. $J$. Exp. Med., 136, I $420-1444$.

Bairey D. W., MobraAten L. E., I969. Estimates of the number of locicontributing to the histocompatibility between $\mathrm{C}_{57} \mathrm{BL} / 6$ and Balb/c strains of mice. Transplantation, 7, 394-400.

Bailey E., Stormont C., Suzuki Y., Trommershausen-Smith A., r979. Linkage of loci controlling alloantigens on red blood cells and lymphocytes in the Horse. Science, 204, 1317-1319.

BAIN B., VAS M. R. and LowENSTEIN L., I964. The development of large immature mononuclear cells in mixed leucocyte culture. Blood., 23, ro8-r r6.

BAKER I. N., ANDRESEN E., I964. Skin grafting in pigs: evidence for a histocompatibility mechanism· Transplantation, 2, I I 8-I I 9.

Balcarova J., Hal K., Hraba T., r973a. Differences in the intensity of antibody formation to different antigens in inbred lines of chickens. Folia biol. (Praha), 19, 329-336.

Balcarova J., Hala K., Hraba T., r973b. Differences in antibody formation to the dinitrophenol group in inbred lines of chickens. Folia. Biol. (Praha), 19, 19-24.

Balcarova J., MEdrin J., HALA K., Hraba T., I974. Immune response to pneumococcal polysaccharide in inbred lines of chickens. Folia Biol. (Praha), 20, 221-224. 
BAr,NER H., DERSJANT H., VAN ROOD J. J., I965. Leukoagglutinating iso-antibodies in rhesus monkeys. Transplantation, 3, 402-422.

Balner H., VAN Leeuwen A., Dersjant H., VAN Rood J. J., I967. Defined leucocyte antigens of chimpanzees. Use of chimpanzee isoantisera for leucocyte typing in man. Transplantation, 5, 624-642.

Bal,ner H., VAN Lefuwen A., Van VReeswijk W., Dersjant H., VAN Rood J. J., I97I. Leucocyte antigens of Rhesus monkeys (RhL-A) and chimpanzees (ChL-A); similarities with the human HL-A system. Tissue Antigens, 1, 229-238.

Balner H., GabB B. W., D'Amaro J., Van VreeswiJk W., Visser T. P., i974. Evidence for two linked loci controlling the serologically defined leukocyte antigens of chimpanzees (ChL-A). Tissue Antigens, 4, 313-328.

BARNeS A. D. et KROHN P. L., I957. The estimation of the number of histocompatibility genes controlling the successful transplantation of normal skin in mice. Proc. Roy. Soc., 146, 505-526.

BAUER J. A., I960. Genetics of skin transplantation and an estimate of the number of histocompatibility genes in inbred guinea pigs. Ann. N. Y. Acad. Sci., 87, 78-92.

Bechtol K. B·, Wegmann 'T. G., Freed J. H., Grumet F. C., Chesebro B. W., Herzenierg L. A., Mc DeviT' H. O., I 974. Genetic control of the immune response to (T,G)-A--I, in $\mathrm{C}_{3} \mathrm{H}$. C57 tetraparental mice. Cell. Immunol., 13, $264-277$.

Benacerraf B., Mc DewitT H. O., 1972. Histocompatibility linked immune response genes. Science, 175, 273-279.

BENACERRAF B., KATZ D. H., I975. The nature and function of histocompatibility linked immune response genes, pp. I18-177 in immunogenetics and immunodeficiency, BENACERRAF (Ed), University Park Press, Baltimore.

Benacerraf B., Kapp J. A., Debre P., Pierce C. W., DE La Croix F., I975. The stimulation of specific suppressor $\mathrm{T}$ cells in genetic non reponder mice by linear random copolymers of L-amino acids. Transplant. Rev., 26, 2 I.

Benedict A. A., Polifard L. W., Morrow P. R., Abplanalp H. A., Maurer P. H., Briles W. E., 1975. Genetic control of immune responses in chickens. Immunogenetics, 2, 313-324.

Brnns, R. M. I 968 . The ontogeny of immur,e responses in the pig. Thesis, University of Cambridge. St John's College.

Bogden A. E., Aptekmann P. M., i960. Thie " R - I " factor a histocompatibility antigen in the rat. Cancer Res., 20, 1272-1 282.

BOYER G., I96o. Chorioallantoic membrane lesions produced by inoculation of adult fowl leucocytes. Nature, 185, 327-328.

BOYSE E. A., OLD L. J., STOCKERT E., I968. An approach to the mapping of antigens on the cell surface. Proc. Nat. Acad. Sci. (USA), 60, 886 .

Bradley B. A., Eldwards J. M., DUNn D. C., CALne R. Y., 1972. Quantitation of mixed lymphocyte reaction by gene dosage phenomenon. Nature, 240, 54 .

Brambilla G., Cavanna M., Parodi S., Baldini L., I970. Time dependence of the number of histocompatibility loci in skin graft rejection of mice. Experientia, 26, I I 40, I I4I.

BRILES W. E., Mc GibBON W. H., I948. Heterozygosity of inbred lines of chickens at two loci effecting cellular antigens. Genetics, 33, 605 .

Briles W. E., Mc Grbbon W. H., IRwin M. R., I948. Studies of the time of development of cellular antigens in the chicken. Genetics, 33, 97.

Brondz B. D., Egorov J. G., DrizlikH G. I., 1975. Private specificities of H.2K and H.2D loci as possible selective targets for effector lymphocytes in cell-mediated immunity. $J$. Exp. Med., 141, I I-26.

Brown J. L., Kato K., Silver J., NaThenson S. G., I974. Notable diversity in peptide composition of mutine $\mathrm{H}_{2}-\mathrm{K}$ and $\mathrm{H}_{2}-\mathrm{D}$ alloantigens. Biochimistry, 13, 3174-3178.

BURnet F. H., Boyer G., I961. The chorioallantoic lesion in the Simonsen phenomenon. $J$. Pathol. Bacteriol., 81, I4I-I5o.

Caldweli, J., Bryan C. F., Cumberland P. A., Weseli D. F., i977. Serologically detected lymphocyte antigens of Hostein cattle. Anim. Blood. Grps. biochem. Genet., 8, 197-207.

Caldwel, J., Cumberland P. A., 1978. Cattle lymphocyte antigens. Transplant. Proc., 10 (4), 889-892.

Calne R. Y., White H. J. C., Yofra D. E., Binns R. M., Maginn R. R., Herbertson B. M., Militard P. R., Molina V. P., Davis D. R., 1967. Prolonged survival of liver transplants in the pig. Brit. Med. J., 4, 645-648.

Capcova J., Deman'T P., I974. Genetic studies of the H-2 associated complement gene. Folia Biol. (Praha), 20, IoI-I 5. 
Chanh T. C., Benedict A. A., Abplanal P., I976. Association of serum hemolytic complement levels with the major histocompatibility complex in chickens. J. Exp. Med., 144, 555-561.

Charmot D., Mawas C. E., Saspor'TEs M., I975. Secondary response of in vitro primed human lymphocytes to allogenic cells. II. Role of HLA, MLR stimulating determinants and non specific mitogens in the generation of secondary cytotoxic effectors. Immunogenetics, 2, 465-483.

Christen Y., 1975. Compatibilité donneur-receveur : des tests plus précis. La Recherche, $\mathbf{n}^{\circ}$ 53, fév. 75, I $7 \mathbf{I}$.

Cloudman A. M., I932. A comparative study of transplantability of eight mammary gland tumors arising in inbred mice. Am. J. Cancer, 16, 568-630.

Cock A. G., Cr.ough M., I956. Successful skin homografts in inbred chickens. Nature, 78, 136I37.

CoHEN C., I958. On blood groups and confusion in the rabbit. Transplant. Bull., 5, 2 I-23.

Colombani J., I975. Immunogénétique du complexe majeur d'histocompatibilité (H-2) chez la souris. Bull. Inst. Pasteur, 73, 305-356.

Colombani J., I978a. Le modèle murin : H-2. In : Le complexe principal d'histocompatibilité de l'Homme (HIA). Cours supérieur d'histocompatibilité. J. DAusset Organisateur, janvier 1978 .

Colombani J., 1978b. Spécificités HLA-DR. In: Le complexe principal d'histocompatibilité de l'Homme (HLA). Couvs supérieur d'histocompatibilité. J. Dausse'r, Organisateur, janvier 1978.

Colombani J., Colombani M., Benajan A., Dausset J., i967. Leucocyte and platelet antigens defined by platelet complement fixation test. In: Histocompatibility testing, Munksgaard, Copenhague.

Colombani J., Colombani M., ShrefFler D. C., David C. S., r975. A lymphocyte and platelet complement fixation microtechnique for the study of $\mathrm{H}-2$ region and I-region associated antigens. Transplantation, 20 (I), 84-88.

Corombani J., Colombani M., ShrefFler D. C., David C. S., I976. Separation of anti Ia from anti H-2 antibodies in complex sera by absorption on blood platelet. Description of three new Ia specificities. Tissue Antigens, 7 (2), 74 .

COOK R., VITETTA E. S., CApra J. D., UHR J. W., I977. The partial amino and sequence of a Murine Ia molecule : lack of homology between murine I- $C_{\beta}^{d}$ and Human P. 29. Immunogenetics, $5(5), 437-444$.

COUNCE S., SWITH P., BARTh R., SNELL G. D., I956. Strong and weak histocompatibility differences in mice and their role in the rejection of homografts of tumors and skin. Ann. Surg., 144, I $98-204$.

Cramer D. V., Shonnard J. W., Davis B. K., Gil. T. J., I977. III. Polymorphism of the mixed lymphocyte response of wild norway rats. Transplant. Proc., 9, 559-562.

Crosier P. S., Sasportes M., Mawas C. E., Charmot D., Fradelizi D., Dausset J., i977. HLA$\mathrm{D}$ clusters using in vitro primed lymphocytes. Tissue Antigens, 10, 337-342.

Cullen S. E., David C. S., ShrefFler D. C., NATHenson S. G., 1974. Membrane molecules determined by the $\mathrm{H}-2$ associated immune response region: isolation and some properties. Proc. Nat. Acad. Sci., 71, 648-652.

Cullen S. E., Freed J. H., Atminson P. H., NAThenson S. G., 1975. Evidence that protein determines Ia antigenic specificity. Transplant. Proc., 7, 237-242.

CUllen S. E., FreEd J., NATHENSON S. G., I976. Structural and serological properties of murine Ia alloantigens. Transplant. Rev., 30, 236-27I.

Cullum P. A., Baum M., Clarke A., Wemyss-Gorman P. B., Howard E., Mc Cleiliand R.M.A., I970. Orthotopic transplantation of the pig heart. Thorax, 25, 744-747.

Cunningham B. A., I977. The structure and function of histocompatibility antigens. Scientific Amevican, 96, 107.

CURIE-COHEN M., USINGER W. R., STONE W. H., I978. Transitivity of response in the mixed lymphocyte culture test. Tissue antigcns, 12, I $7^{0-1} 7^{8}$.

Curman B., Ostberg L., Sandberg L., Malmheden-Eriksson I., Stalenheim G., Rask L., PETERSON P. A., I975. H-2 linked Ss protein is $\mathrm{C}_{4}$ component of complement.' Naiure, 258, 243-245.

Cury A. R., Dierich M. P., Peilegrino M. A., Hoch J. A., 1976. Evidence for linkage between HL-A and receptors for complement components $C_{3} b$ and $C_{3} d$ in human-mouse hybrids. Immunogenetics, 3, 47 I.

Dausseit J., r 958. Iso-leuco-anticorps. Acta. Hematol. (Basel), 20, I 56-I 58.

DAusser J., I977. Le système HL-A et les maladies. La Recherche, 77, 335-343. 
Dausse't J., I978. Les séries alléliques HL-A (A, B, C). In: Le complexe principal d'histocompatibilité de l'Homme (HL-A). Cours supérieur d'histocompatibilité. J. DAUssE'T, Organisateur, janvier 1978 .

Dausseri J., Nenna A., 1952. Présence d'une leuco-agglutinine dans le sérum d'un cas d'agranulocytose chronique. C. R. Soc. Biol. (Paris), 146, I 539-I 54r.

David C. S., I977. The Major Histocompatibility system of the Mouse. In: The major histocompatibitity system in Man and animals; GoTzE D. (Editor); Springer Verlarg-Berlin.

DAVID C. S., SHREFFLER D. C., I974a. Lymphocyte antigens controlled by the Ia region of the mouse H-2 complex. Detection of new specificities with anti $\mathrm{H}-2$ reagents. Transplantation, 17, $462-469$.

DAVID C. S., SHRFFFI,ER D. C., I974b. I region associated antigen system (Ia) of the mouse H-2 gene complex. Further definition of Ia specificities with restricted anti Ia antisera. Transplantation, 18, 313-321.

DAviES D. A. L., HESs M., I974. New allo-antigen genetically linked to the major histocompatibility locus of the mouse. Nature, 250, 228-230.

Davis W. C., Silverman L., I968. Localization of mouse H-2 histocompatibility antigen with ferritin labeled antibody. Transplantation, 6, 536.

DEBRE P., I978. Physiologie de la coopération cellulaive et des gènes de réponse immunologique. In: Le complexe principal d'histocompatibilité de l'Homme (HL-A). Cours supérieur d'histocompatibilité. J. Dausset, Organisateur, janvier 1978.

Debre P., KAPP J. A., DorF M. E., BenaCerRaF B., I975. Genetic control of specific immune suppression. II. H-2 linked dominant genetic control of immune suppression by the random copolymer L glutamic acid 5o-L tyrosine $5^{\circ}$ (GT). J. Exp. Med., 142, 1447.

Debre P., Waltenbaugh W. C., Dorf M., Benacerraf B., I976. III. Mapping of H-2 complementing genes controlling immune suppression by the random copolymer L. glutamic acid 5o-L tyrosine (GT). J. Exp. Med., 144, 272.

DEgos L., Dausser J., I975. Comparison of genetic (factorial correspondance analysis) and geographical distances. Tissue antigens, 5, 464-466.

DEMant P., I966. Polymorphism of leucocyte antigens in Rabbit. Pages 48I-484 in Proc-Xth European Congres on animal blood groups and biochemical polymorphism. Paris I 966, I.N.R.A.Paris.

DEMaNr P., r968. Histocompatibility antigens in rabbits and their significante for the survival of maternal skin grafts in newborn rabbits. Folia Biol. (Praha), 14, 9-2o.

DEMANT P., I970. Genetics of graft versus Host reaction in the mouse. Proc. Symp. Immunogenetics of the H-2 system, p. I94-196. Prague, I970.

Deman' P., 1973. H-2 genes complex and its role in alloimmune reactions. Transplant. Rev. 15, I64-200.

Demant P., Capkova J., Hinzova E., Voracova B., 1973. The role of the histocompatibility. 2-linked Ss-Slp region in the control of mouse complement. Proc. Nat. Acad. Sci. (U.S.A.), 70, 863 .

DE WeCK A. L., Blak L., SATo W., FREy J. R., I971. Determination of histocompatibility antigens by leucocyte typing in outbred guinea pigs and effect of matching on skin graft survival. Transplant. Proc., 3, I92-I 94.

DORF M. E., Stimpfing J. H., Benacerraf B., i975. Requirement for two H-2 complex Ir genes for the immune response to the L-Glu-L Lys-L-Phe terpolymer. J. Exp. Med., 141, I459.

Dorf M. E., Maurer P. H., Merryman C. F., Benacerraf B., i976a. Inclusion group systems and cis-trans effects in responses controlled by the two complementing Ir-GL $\varphi$ genes. $J$. Exp. Med., 143, 889-896.

Dorf M. E., Twigg M. B., BenacerraF B., I976b. Genetic control of the immune response to the random linear terpolymer of $\mathrm{L}_{\text {-glutamic }}$ acid-L,-lysine and L,-leucine (GL,-leu) by complementing Ir genes. Euv. J. Immunol., 6, 552-556.

DroBNA V., HALA K., I969. The use of the cluster analysis for blood typing of outbred population by sera produced on inbred lines in chickebs. Proc. roth Eur. Annu. Blood. Groups conf. I968.

Dupont B., STAub-Neilsen L., SvejgaARd A., r97r. Relative importance of four and LA loci in determining mixed lymphocytes reaction. Lancet, 2, 1336.

Dupont B. O., Jersild C., Hansen G. S., Staub-Neilsen L., Thomsen M., SvejgaArd A., I973, Typing for MLC determinants by means of LD-homozygous and LD-heterozygous cells. Transplant. Proc., 5, I543. 
Dutron R. W., I966a. Spleen cell proliferation in response to homologous antigens studied in congenic resistant strains of mice. J. Exp. Med., 123, 665-67I.

Dutron R. W., I $966 b$. Symposium on "in vitro " studies of the immune response. II. Significance of the reaction of lymphoid cells to homologous tissue. Bacteriol. Rev., 30, $397-407$.

Dyminski J. W., Smith R. T., 1975. Evidence for a B-cell like helper function in mixed lymphocyte culture between immunocompetent thymus cells. $J$. Exp. Med., 141, 360-373.

EHLERS N., AHRoNS S., I97I. The influence of histocompatibility upon the corneal immune reaction after intralamellar allotransplantation in rabbits. Tissue antigens, 1, 23-3I.

Eijsvooger, V. P., VAN Rood J. J., Toir E. D., Schelilenkens P. T. A., i972. Position of a locus determining mixed lymphocyte reaction distinct from the known HL-A loci. Eur. $J$. Immunol., 2, 4 I3.

Eilkins W. L., PaLM J., I966. Identification of a single strong histocompatibility locus in the rat by normal spleen-cell transfer. Ann. N. Y. Acad. Sci., 129, 573-580.

Eillman L., Green I., Martin J., Benacerraf B., I97o. Linkage between the poly-L-1ysine gene and the locus controlling the major histocompatibility antigens in strain 2 guinea pigs. Proc. Nat. Acad. Sci. (U.S.A.), 66, 322-328.

ERB P., FELDMANN M., 1975. The role of macrophages in the generation of $T$ helper cells. II. The genetic control of the macrophage-T-cell interaction for helper induction with soluble antigens. J. Exp. Med., 142, 460 .

ERB P., MEIER B., FELdmann M., I976. Two genes control of T helper cell induction. Nature, 263, 60I.

Fathmann C. G., Colland D., Davies S., Nabholz M., i977. In vitro secondary MLR. I. Kinetics of proliferation and specificity of in vitvo primed cells. J. Immunol., 118, I232.

Feingold N., I966. Utilisation du coefficient de corrélation dans l'étude des groupes leucocytaires. Rev. Franç. Etud. Clin. et Biol., XI, ro36-1039.

FELlous M., 1978. Le groupe de liaison génétique du complexe HL-A. In: Cours supérieur d'histocompatibilité HLA-I978. J. Dausset (Éditeur).

Fellous M., Bir.lardon C., Dausset J., Frezal J., i97I. Linkage probable entre les locus HL-A et P. C. R. Acad. Sci. Paris, t. 272, série D. I 356.

Feilious M., Hors M. C., Rebourcet R., Finaz C., Weil D., heuertz S., Wiels J., Mahouy G., FRIDMAN W. H., I 977 . The expression and relation of HLA, $\beta_{2}$ microglobulin and receptor for marmoset red blood cells on man/mouse and $\mathrm{man} /$ chinese hamster hybrid cells. Eur. $J$ Immunol., 7, 22-26.

Ferreira A., Nussenzweig V., I976. Controle of $\mathrm{C}_{3}$ levels in mice during ontogeny by a gene in the control region of the $\mathrm{H}-2$ complex. Nature, $260,6 \mathrm{I} 3$.

Festenstein H., DFmant P., I973. Workshop summary on genetic determinants of cell mediated immune reactions in the mouse. Transplant. Proc., 5, I321-1 327.

Ford C. H. J., I975. Genetic studies of sheep leucocyte antigens. J. Immunogenetics, 2, 3 I-40.

FORMAN J., MOLLER G., I974. Generation of cytotoxic lymphocytes in mixed lymphocyte reactions. II. Importance of private and public $\mathrm{H}-2$ alloantigens on the expression of cytotoxicity. Immunogenetics, 1, 2 I I-225.

Forman J., KLErN J., 1975. Analysis of H 2 mutants: Evidence for multiple CML target specificitics controlled by the $\mathrm{H}-2 . \mathrm{K}^{b}$ gene. Immunogenetics, 1, 469-48I.

Fradeirizi D., I978. Physiologie de la véponse allogénique chez l'homme. In: Le complexe principal d'histocompatibilité de l'Homme (HL-A). Cours supérieur d'histocompatibilité 1978. J. Dausseir, Organisateur.

FRADFirizI D., DAUSSET J., I975. Mixed lymphocyte reactivity of human lymphocytes primed in vitro. I. Secondary response to allogenic lymphocytes. Eur. J. Immunol., 5, $29530 \mathrm{r}$.

Fradelizi D., Mawas C., Charmot D., Sasportes M., 1975. In vitro primed cells: a probe for LD typing; In: Histocompatibility testing I975. KISSMEYER-NIELSEN, Ed., Munksgaard, Copenhagen.

Fradelizi D., Charmot D., Mawas C., Sasporties M., I976. Secondary response of in vitro primed human lymphocytes to allogeneic cells. III. Specificity for the mixed lymphocyte reaction stimulating determinants of the secondary proliferative response. Immunogenetics, 3, 29-49.

Fradelizi D., Nunez-Roldan A., Sasportes M., i978. Human Ia like DRw lymphocyte antigens stimulating activity in primary mixed lymphocyte reaction. Eur. J. Immunol., 8 (2), 88-93.

Francke W., Peliegrino M. A., I977. Assignment of the major histocompatibility complex to a region of the short arm of human chromosome 6. Proc. Nat. Acad. Sci. (U.S.A.), 74, I I47. 
FREed J. H., NATHenson S. G., 1977. Similarity of the carbohydrate structures of $\mathrm{H}-2$ and Ia glycoproteins. J. Immuniol., 119 (2), 477-482.

Fu S. M., Kunkel H. G., Brushman H. P., Allen F. H., Fotrino, 1974. Evidence for linkage between HL-A histocompatibility genes and those involved in the synthesis of the second component of the complement. J. Exp. Med., 140, i ro8.

Garnier H., Clot J. P., Bertrand M., Campreiz P., Kunlin A., Gorin J. P., Le Goaziou F., LEVY R., Cordier G., I 965 . Greffe de foie chez le porc; approche chirurgicale. C. R. Acad. Sc. Paris, 260, 562 1-5623.

GASSER D. L., I969. Genetic control of the immune response in mice. I. Segregation data and localization to the fifth linflage group of a gene affecting antibody production. J. Immunol., $103,66-70$.

GASSER D. L., SIIVERS W. K., I974. The genetic determinants of immunological responsiveness. Adv. Immunol., 18, I-68.

Gatti R. A., Neuwissen H. J., Terasaki P. I., Good R. A., I971. Recombination within the HLA locus. Tissue antigens, 1, 239.

GERSION R. K., Kondo K., I970. Cell interaction in the induction of tolerance. Immunology, 18,723 .

Gfrishon R. K., Maurer P. M., Merrymann C. F., i973. Cellular basis for genetically controlled immunological unresponsiveness in mice: Tolerance induction in T cell. Proc. Nat. Acad. Sci. (U.S.A.), 70, 250.

GiLmovr D. G., I960. Blood groups in chickens. Brit. Poult. Sci., 1, 75.

.Gluckman E., Bussel A., Marty M., Dausset J., 1975. Parent child bone marrow grafting. Experimsntal Hematology. 4th Annu. Conf. Int. Soc. Exp. Hematol., Trogir, Yougoslavia.

GORER P. A., I936. The detection of antigenic differences in mouse erythrocytes by employement of immune sera. Brit. J. Exp. Path., 17, 42-50.

GorER P. A., I937. The genetic and antigenic basis of tumour transplantation. J. Path. Bact., 44, 69I-697.

GORER P. A., I938. Antigenic basis of tumour transplantation. J. Path. Bact., 47, 23I-252.

Gorer P. A., Ly.MAN S., S.Eeli G., I948. Studies on the genetic and antigenic basis of tumour transplantation. Linkage between a histocompatibility gene and "fused" in mice. Proc. roy. Soc. $-B-$, 135, 499-505.

GJRER P. A., MukUlska $Z$. B., 1954. The antibody response to tumor inoculation. Improved methods of antibody detection. Cancer. Res., 14, 65I-655.

Gorer P. A., O'Gorman P., I956. The cytotoxic activity of isoantibodies in mice. Transplant. Bull., 3, I42-143.

GOTZE D., REISFELD R. A., KrEIN J., I973. Serologic evidence for antigens controlled by the Ir region in mice. J. Exp. Med., 138, 1003-1008.

GRAFF R. J., BAILEY D. W., I973. The non $\mathrm{H}-2$ histocompatibility loci and their antigens. Transplant. Rev., 15, 26-49.

Gunter E., Balcarova J., Hala K., Rude E., Hraba T., I974. Evidence for an association between immune responsiveness of chicken to ( $T, G$ )-A--L and the major histocompatibility system. Eur. J. Immunol., 4, 548-553.

HALA K., I967. The occurrence of erythrocyte antigens on cells from various tissues of the pigs. Folia biol. (Praha), 13, 189-192.

HALA K., I969. Syngeneic lines of chickens. III. The number of different histocompatibility loci between the lines. Folia biol. (Praha), 15, i $36-$ r 40.

HaLA K., HASEK M., I97I. Comparative aspects of the $B$ system in chicken's and the H-2 system in mice. Proc. Symp. Immunogenetics of the H-2 systems, Prague 1970, p.334-340.

Hala K., Vilinelmova M., Hartmanova J, 1976. Probable crossingover in the B blood group system of the chicken. Immunogenetics, 3, 97-I04.

Hammerling G. L., Deak B. D., Mauve G., Hammerling U., Mc Devitt H. O., i974. B lymphocyte alloantigens controlled by the I region of the major histocompatibility complex in mice. Immunogenetics, 1, 58-8I.

HAN T., DADEY B., I976. T and B lymphocytes. Immunology, 31, 643-648.

HanaU A., I889. Erfolgreiche experimentelle Uebertragung von Carcinom. Fortsch. Med., 7, $32 \mathrm{I}-339$.

HANSEN T. H., SHIN H., SHREFFLER D. C., I975. Evidence for the involvement of the Ss protein of the mouse in the hemolytic complement system. J. Exp. Med., 141, I2I6.

HAUPTFELD V., HAUPTFELD M., KLEIN J., 1973. Serological identification of an I-region product. Science, 181, I67-169. 
HauptFeld V., HatptFeid M., Klein J., I974. Tissue distribution of I region associated antigens in the mouse. J. Immunol., 113, I8I-I 88 .

HERBER-KATZ G., WILSON D. B., I975. Collaboration of allogenic $T$ and B lymphocytes in the primary antibody response to sheep erythocytes in vitro. $J$. Exp. Med., 142, 928.

Histocompatibility testing, i972. Dausset J. et Colombani J., Ed. Munksgaard, Copenhagen, I 973 .

Hruban V., Simon M., Hradecky J., I974. Histocompatibility studies in pigs from outbred and semi-inbred families. Anim. Blood grps. Biochem. Genet., 5, I 7 I-I 76.

Hruban V., Simon M., Hradecky J., Jilek F., I976. Linkage of the pig main histocompatibility complex and the J blood groups system. Tissue antigcns, 7, 267-271.

Ivanyi P., I970. The major histocompatibility antigens in various species. Curr. Top. Microbiol. Immunol., 53, I-90.

JAFFE W. P., Mc DERMID E. M., I962. Blood groups and splenomegaly in chick embryos. Science, 137, 984 .

JAFFE W. P., Symes M. O., Terblanche J., I967. Observations on the immunological reactions of pigs, In: The liver, READ A. E. (Ed.). Butterworths, London, p. $35 \mathrm{I}$.

JENSEN C. O., I903. Experimentelle Untersuchungen uber Krebs bei Mausen. Zbl. Bakt., 34, 28-34 et 122-143.

Jongsma A., Van Someren H., Westerveid A., Hagemeijer A., Pearson P., 1973. Assigment of $\mathrm{PGm}_{3}$ to chromosome $\mathrm{C} 6$ and regional mapping of the $\mathrm{PGD}, \mathrm{PGm} \mathrm{m}$ and Pep-Cgenes on chromosome Al. Humangenetik, 20, 195-202.

JORGENSEN F., LAMM L. U., KISSMEYER NIEISEN F., 1973. Mixed lymphocyte cultures with inbred individuals: an approach to MLC typing. Tissue antigens, 3, 323.

Kandutsch A. A., REINERT-WENCK U., I957. Studies on a substance that promotes tumor homograft survival (the "enhancing substance"). Its distribution and some properties. $J$. Exp. Med., 105, I 25.

KANTOR F. S., OJEDA A., BENacerraf B., I963. Studies on artificial antigens. I. Antigenicity of DNP-poly-lysine and DNP-copolymers of lysine and glutamic acid in guinea pigs. $J$. Exp. Med., 117, 55-69.

KapP J. A., Pierce C. W., Benacerraf B., 1976. Suppressor activity of splenic extracts from non responder mice injected with GAT. In: The role of the products of the histocompatibility genes complex in immune response. KATZ D. H., BeNACERRAF B., Ed. Academic Press, New York, $\mathbf{5 6 9}, 1976$.

Karakoz J., Krejci J., Hala K., Blaszczyk B., Hraba T., Pekarek J., i974. Genetic differenciation of tuberculin hypersensitivity in chicken inbred lines. Eur. J. Immunol., 4, 545-548.

Kasakura S., Thomas E. D., Ferrebee J. W., I964. Leucocytotoxic isoantibodies in the dog. Transplantation, 2, 274-280.

Katz D. H., Hamaoka T., Dorf M. E., Maurer P. H., Benacerraf B., I973. Cell interactions between histocompatible $T$ and $B$ lymphocytes. IV. Involvement of the immune response (Ir) gene in the control of lymphocytes. J. Exp. Med., 138, 734.

Katz D. H., Graves M., Dorf M. E., Dimuzio H., BenacerraF B., I975. Cell interactions between histocompatible $\mathrm{T}$ and $\mathrm{B}$ lymphocytes. VII. Cooperative responses between lymphocytes are controlled by genes in the I region of the $\mathrm{H} 2$ complex. J. Exp. Med., 141, 263.

KaTz D. H., DORF M. E., Benacerraf B., I976. Control of T 1ymphocyte and B lymphocyte

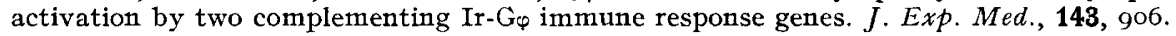

Keaveny T. V., Aglubat F., Beizer F. D., i97o. Porcine small bowel transplantation. Ir. J. Med. Sci., 3, 483-487.

KISSMEYER-NIELSEN F., SVEJGAARD A., Thorsby E., I97I. Human transplantation antigens. The HL-A system. Bibl. Haematol., 38, 276-281.

KLEIN J., I97I. Private and public antigens on the mouse $\mathrm{H} 2$ system. Nature, 229, 635-637.

KLEIN J., SHREFFLER D. C., I97I. The H-2 model for the major histocompatibility systems. Transpl. Rev., 6, 3-29.

KLEIN J., PARK J. M., I973. Graft versus host reaction across different regions of the $\mathrm{H}-2$ complex of the mouse. J. Exp. Med., 137, I 2 I 3-1225.

Klein J., Bach F. H., Festenstein F., Mc Devitit H. O., Shreffler D. C., SNei. G. D., StimpFLING J. H., I974. Genetic nomenclature for the $\mathrm{H} 2$ complex of the mouse. Immunogenetics, 1, I 84-1 88 .

KOCH C., HENRIKSEN K., JUHI, F., MUliER-BERAT N., 1973. Bone-marrow transplantation from an HL-A non-identical but mixed-lymphocyte-culture identical donor. Lancet, 1, I 146.

KOCH C., SIMONSEN M., I977. Immune response genes in chickens. Antibody response to TGAL and GT. Immunogenetics, 5 (I-2), I6I-I 70. 
KOZELKA A. W., I93I, Genetic and physiological factors involved in the absorption of integumental grafts in the leghorn fowl. Anat. Rec., 48, 24 .

KOZELKA A. W., I $933 a$. Individuality of the red blood cells of inbred strains of fowls. $J$. Immunol., 24, 5I9-530.

KOZELKA A. W., I933b. Serological studies of tissue antagonism in the domestic fowl. Physiol. Zool., 6, I 59-184.

KRISTENSEN T., GRUNNET N., 1975. Cell mediated lympholysis in man. Evidence of a separate CML locus within the major histocompatibility complex and an approach to CML typing. In. Histocompatibility testing 1975, pp. 835-844, Munksgaard, Copenhagen.

LAChManN P. J., GRENnAN D., MarTin A., I975. Identification of Ss protein as murine C . Nature, 258, 242-243.

LAMm L. U., SvejgaARd A., KISSMeYer-Nielsen F., I97I, PGM-3-HL-A is another linkage in man. Nature, N. B., 231, 109.

Lamm L. U., Friedrich U., Peterersen G. B., Jorgensen J., Nielsen J., Therkelsen A. J., KISSMEYER-NIELSEN F., 1974. Assigment of the major histocompatibility complex to chromosome $\mathbf{n}^{\circ} 6$ in a family with a pericentric inversion. Hum. Heved., 24, 273-284.

LANDSTEINER K., MLLLER P. C., 1924. On the individual differences of the blood of chickens and duks. Proc. Soc. Exp. Biol. Med., 22, I о0-го2.

LANE J. Y., LING N. R., 1973. Rat thymocytes. The allogeneic response and syngeneic effects in mixed culture with tissue cells from various organs. Transplantation, 16, 602-609.

Lebrun A., Sasportes M., Dausset J., I97I. Rôle prépondérant du deuxième locus HL-A ou d'un gène lié dans la réaction de culture mixte lymphocytaire. C. R. Acad. Sci. Paris, 273, 2130.

LEMONS R., O'Brien S. J., SHerr C. J., I977. A new genetic locus, Bevi, on human chromosome which controls the replication of baboon type $C$ virus in human cells. Cell., 12, $25 \mathrm{I}-262$.

LEVEZIEL H., I978. Essai de mise en évidence d'un complexe d'histocompatibilité majeur chez les bovins. Thèse de Docteur-Ingénieur, Université de Paris VI.

LEEVINe B. B., OJEDA A., Benacerraf B., I963. Studies on artificial antigens. III. The genetic control of the immune response to hapten-poly-L-lysine conjugates in guinea pigs. J. Exp. Med., 118, 953-957.

Lightbody J., Bernoco D., Miggrano V. C., Ceppelini R., i97r. Cell mediated lympholysis in man after sensitization of effector lymphocytes through mixed leucocyte culture. G. Bact. Virol. Immunol., 64, 243-26o.

LITTIE C. C., I94I. The genetics of tumor transplantation,. In: Biology of the Laboratory mouse (G. D. SNELI). Blakiston, Philadelphia.

LitTLE C. C., Tyzzer E. E., I9I6. Further experimental studies on the inheritance and suceptibility to a transplantable tumor carcinoma (J.W.A.) of the Jappanese Waltzing mice. $J$. Med. Res., 33, 393-453.

LitTLE C. C., Strong L. C., I924. Genetic studies on the transplantation of two adenocarcinomata. J. Exp. Zool., 41, 93-II4.

LOEB L., I9OI. On transplantation of tumors. J. Med. Res., 6, 28-38.

LOEB L., I945 The biological basis of individuality. Springfield, Ch. C. Thomas.

Lohrmann H. P., Novikovs L. D., GRaw R. G., I974. Stimulatory capacity of human T and B lymphocytes in mixed leucocyte culture. Nature, 250, I 44.

LONGSTER G., GILES C. M., 1976. A new antibody specificity anti-Rga reacting with a red cell and serum antigen. Vox sang., 30, 175 .

LozNer E. C., SAchs D. H., Shearer G. M., TERry W. D., I974. B-cell alloantigens determined by the H-2 linked Ir region are associated with mixed lymphocyte culture stimulation. Science, 183, 757-759.

LUMSDEN T., r938. Agglutination tests in the study of tumour immunity, natural and acquired. Am. J. Cancer, 32, 395-4I 7

MANGi R. Y., MARDINEy M. R., I97I. The mixed lymphocyte reaction. Transplantation, 11, 369-373.

MATEJ H., r970. Further studies on antigenic differenciation of rabbit lymphocyte. Arch. Immunol. Ther. Exp., 18, I73-184.

Mawas C., Charmot D., Sasportes M., I975. Secondary response of in vitro primed lymphocytes to allogeneic cells. I. Role of $\mathrm{HL}_{-}-\mathrm{A}$ antigens and mixed lymphocyte reaction stimulating determinants in secondary in vitro proliferation responses. Immungenetics, 2, 449-463.

Mc DERMID E. M., I964. Immunogenetics of the chicken. Vox Sang., 9, 249.

Mc Dewit' H. O., SELA M., 1965. Genetic control of the antibody response. J. Exp. Med., 122, 5 r $7-53$ r. 
Mc DewiTr H. O., I968. Genetic control of the antibody response. II. Qualitative and quantitative characterization of the antibody response to $(\mathrm{T}, \mathrm{G})-\mathrm{A}-\mathrm{L}$ in $\mathrm{CBA}$ and $\mathrm{C}_{57}$ mice. J. Immunol. 100,485 .

MI DEWITT H. O., TYAN M. L., r968. Genetic control of the antibody response in inbred mice. Transfer of response by spleen cells and linkage to the $\mathrm{H}-2$ locus. $J . \operatorname{Exp} . M c d ., 128, \mathrm{I}-\mathrm{I}$ I.

Mc Dewitit H. O., Benacerraf B., I969. Genetic control of specific immune responses. $A d v$. Immunol., 11, 31 .

Mc Dewiti H. O., Deak B. D., Shreffler D. C., Klein J., Strmpfiring J. H., Snell G. D., 1972. Genetic control of immune response. Mapping of the Ir-I locus. J. Exp. Med., 135, I 259-I 278 .

MEDAWAR P. B., I944. Behaviour and fate of skin autografts and homografts in rabbits. $J$. Anat., 78, I $76-199$.

MEDAwar P. B., I945. A second study of the behaviour and fate of lomografts in rabbits. J. Anat., 79, I $57-176$.

MEMPEL, W., Albert E., Burger A., i972. Further evidence for a separate MLC locus. Tissue antigens, 2, $25^{\circ}$.

Mempel, W., Grosse-Wilde H., Baumann P., Netzel B., Steinbauer-Rosenthal I., Schol, S., BERTRAMS J., ALBERT E. D., 1973. Population genetics of the MLC response: typing for MLC determinants using homozygous and heterozygous reference cells. Transplant. Proc., 5 , I 529-I 534.

Meo T., Vives G., Rijnbeek A. M., Miggiano V. C., Nabholz M., Shreffler D. C., i973. A bipartite interpretation and tentative mapping of $\mathrm{H}-2$ associated MLR determinants in the mouse. Transplant. Proc., 5, I 339-1350.

Meo T., Vives J., Miggiano V., ShrefFler D. C., I973b. A major role for the Ir-I region of the mouse H-2 complex in the mixed lymphocyte reaction. Transplant. Proc., 5, 377-381.

MEO T., KRASTEFF T., SHREFFI,ER D. C., I975a. Immunochemical characterization of murine H-2 controlled Ss protein through identifiation of its homologue as the fourth component of complement. Proc, nat. Acad. Sci. (U.S.A.), 72, 4536.

Meo T., David C. S., Rijnbeck A. M., Nabholz M., Miggiano V., Shreffler D. C., $1975 . \quad$ Inhibition of mouse MLR by anti-Ia sera. Transplant. Proc., 7, I 27 -r 29.

Middieton J., Crookston M. C., Falk J. A., Robson E. M., Cook P. J. L., Batchelor J. R., Bodmer J., Ferrera G. B., Festenstein H., Harris R., Kissmeyer-Nielsen F., Lawler S. D., SACHS J. A., Wolf E., I974. Linkage of Chido and HL-A. Tissue Antigens, 4, 366-373.

Miggiano V. C., Birgen J., PrNk J. R. L., I974. The mixed leucocyte reaction in chickens. Evidence for control by the major histocompatibility complex. Eur. J. Immunol., 4, 397-401 .

Millo' P., r97I. Détermination d'antigènes lymphocytaires chez les ovins. C. R. Acad. Sc. Paris, 273, 2028-2030.

MrLLot P., 1978. Existence chez le mouton (Ovis aries) d'un complexe majeur d'histocompatibilité et de deux loci mineurs d'antigènes lymphocytaive. Thèse, Université de Paris VI.

MoEschlin S., WAGNER R., I952. Agranulocytosis due to the occurrence of leucocyte agglutinins (pyramidon and cold agglutinins). Acta. Haematol., 8, 29-4I.

MOLLER G., I96I. Demonstration of mouse isoantigens at the cellular level by fluorescent antibody technique. $J$. Exp. Med., 114, 4I5.

MOREAU H., I 894. Recherches expérimentales sur la transmissibilité de certains néoplasmes. Arch. Méd. Exp., 6, 677-705.

Mozes E., Mc DewitT H. O., JaTON J. C., SELA M., I969. The genetic control of antibody specificity. J. Exp. Med., 130, I 263-I 278.

Mozes E., FUCHS S., I974. Linkage between immune response potential to DNA and the $\mathrm{X}$ chromosome. Nature, 249, I67-169.

Munro A. J., Taussig M. J., Campbeil, R., Williams H., Lawson Y., I974. Antigen specific $T$ cell factor in cooperation: physical properties and mapping in the left hand $(K)$ half of $\mathbf{H}-2$. J. Exp. Med., 140, I 579 .

MunRo A. J., TAUssig M. J., I975. Two genes in the major histocompatibility complex control immune response. Nature, 256, I03.

Muramatsu T., Nathenson S. G., I97o. Studies on the carbohydrate portion of membranelocated mouse $\mathrm{H}-2$ alloantigens. Biochemistry, 9, 4875 .

Murphy D. B., I974. Cross-reactivity between $H-2 K$ and $H-2 D$ products. Ph. D. Thesis, University of Michigan.

MURPHY D. B., ShrEFFLER D. C., I975. Cross reactivity between H-2K and H-2D products. I. Evidence for extensive and reciprocal serological crossreactivity. $J$. Exp. Med., 141, 374-391. 
Nabholz M., Vives J., Young H. M., Meo T., Miggiano V., Rijnbeiek A., Shreffler D. C., 1974. Cell mediated lysis " in vitro ": genetic control of killer cell production and target specificties in the mouse. Eur. J. Immunol., 4, 378-387.

Nabholz M., Young H., Meo T., Miggiano V., Rijnbeek A., Shreffler D. C., i975. Genetic analys's of an $\mathrm{H}-2$ mutant, B6.C-H-2 ${ }^{b a}$, using cell-mediated 1ympholysis. T and B cell dictionnaries for histocompatibility determinants are different. Immunogenctics, 1, 457-468.

Nathenson S. G., I970. Biochemical properties of histocompatibility antigens. Ann. Rev. Genet., 4, 69 .

NAThenson S. G., CUliten S. E., 1974. Biochemical properties and immunochemical genetic relationships of mouse $\mathrm{H}-2$ alloantigens. Biochim. Biophys. Acta, 344, I-25.

Nathenson S. G., Muramatsu T., I97I. Properties of the carbohydrate portion of mouse $H-2$ alloantigen glycoproteins. Page 245 in G. A. JAMIESON and J. GREENWALT eds: Glycoproteins of blood cells and plasma. Lippincott, Philadelphia, Pennsylvania.

Neauport-Sautes C., Silvestre, D., Lilly F., Kourilsky F. M., i973. Molecular independance of $\mathrm{H}-2 \mathrm{~K}$ and $\mathrm{H}-2 \mathrm{D}$ antigens on the cell surface. Transplant. Proc., 5, 443.

Niethammer D., Goldmann S. F., Hass R. J., Dietrich M., Flad H. D., Fliedner T. M., KIEIHAUER E., I976. Bone marrow transplantation for severe combined immunodeficiency with the HLA-A incompatible but MLC identical mother as a donor. Transplant. Proc., 8, 623.

Nunez-Roldan A., SAsportes M., Fradelizi D., I978. Analysis of products involved in primary and secondary allogenic proliferation in man. II. Detection of products different from Ia-like, DRW antigens, activating secondar allogenic proliferation in man. Immunogcnctics, 6 (I), 43-54.

Oppltova L., Deman' P., I973. Genetic determinants for the graft versus host reaction in the H-2 complex. Transplant. Proc., 5, I367-1 37 I.

Oriol, R., Cartron J., Yvart J., Bedrossian J., Duboust a., Bariety J., Gluckman J. C., GaGnadoux M. F., I977. Rôle des systèmes sécréteurs Se-se et Lewis (le-le) dans le rejet des greffes rénales. C. R. Acad. Sci. Paris, 285, I083-1085.

OTT J., Linder D., Kaiser M. Caw B., Lovrien E. W., Hechi F., I976. Estimating distance from the centromere by means of benign ovarian teratomas in man. Ann. Human Gonet., 40, I9I-I96.

Pancake S. J., NAThenson S. G., 1973. Selective loss of $\mathrm{H}-2$ antigenic reactivity after chemṭcal modification. J. Immunol., 11, I086.

PAyNe R., Rolfs M. R., 1958. Fetomaternal leucocyte incompatibility. J. Clin. Invest., 37, I 756-I 763 .

PAyNe R., Tripp M., Weigle J., Bodmer W., Bodmer J., I964. A new leucocyte iso-antigen system in man. Cold Spring Harbor Symp. Quant. Biol., 29, 285-295.

Pazderka F., Longenecker B. M., LAw G. R. J., Ruth R. F., I975. Review: the major histocompatibility complex of the chicken. Immunogenetics, 2, 10I-I 30.

PECK A. B., ClICK R. E., I973. Immune responses in vitro. VIII. Mixed leucocyte culture reactivity induced by $\theta$ antigen. Transflantation, 16, 339-342.

PECK A. B., Wigzeil H., Janeway J. R., ANDERsson L. C., i977. Environmental and genetic control of $T$ cell activation in vitro: a study using isolated alloantigen-activated $T$ cell clones. Transplant. Rev., 35, I46.

Pellegrino M. A., Ferrone S., Peliegrino A. G., Hoch J. A., i975. Linkage between the B-cell specific receptor for monkey red blood cells and HL-A antigens in man-mouse hybrids. Immunogcnetics, 2, 543 .

Pink J. R. L., Droege W., Hala K., Miggiano V. C., Ziegler A., i977. A three-locus model for the chicken major histocompatibility complex. Immunogenetics, 5, 203-216.

Plate J. D. H., Mc KenZIE J. F. C., I973. B cell stimulation of alloantigenic T cell proliferation in mixed lymphocyte cultures. Nature, 245, 247.

PREHN R. T., MAIN J. M., 1958. Number of mouse histocompatibility genes involved in skin grafting from strain BALB/cAn to strain DBA/2. J. Nat. Cancer Inst., 20, 207-209.

RAMSEIER H., LindenManN J., 1972. Allotypic antibodies. Transplant. Rev., 10, 57-96.

RANK W. R., 1974. Mouse News letter, 51, 27.

RIBLET R., COHN M., WEIGERT M., I975. Linkage analysis of the dextran response gene. Immunogenetics, 1, 525-526.

Ritiner C., Hauptmann G., Grosshans F., Mayr S., I975. Linkage betreen HL-A and genes controlling the synthesis of the fourth component of complement. Histocompatibility Testing I975, Munksgaard (Ed.), Copenhagen. 
Rogentine G. N., VAll L., Elis E. B., Darrow C.C.I.I., I97I. Rhesus lymphocyte alloantigens. I. Identification of a major alloantigen system. Transplantation, 12, 267-270.

Rosenthal A. S., SHevach E. M., I973. The function of macrophages in antigen recognition by guinea pig $T$ lymphocytes. I. Requirement for histocompatibility macrophages and lymphocytes. J. Exp. Med., 138, I 94 .

RUDDLE F. H., I973. Linkage analysis in man by somatic cell genetics. Nature, 242, I65.

Rychl,IKova M., DEMaNT P., IVANYI P., I970. Further studics on mixed lymphocyte reaction in $H_{-2}$ incompatibility. In: Proc. Symp. Immunogenetics of the H-2 System. Prague I97o, p. I 78-I $8 \mathrm{I}$.

Rychlikova M., Demant P., IVANyi P., I97I. Histocompatibility gene organization and mixed lymphocyte reaction. Nature, 230, $27 \mathrm{I}-272$.

Rychlikova M., Demant P., Egorov I. K., I972. Mixed lymphocyte reaction caused by an H-2D mutation. Folia. Biol. (Praha), 18, 360-363.

Rychlikova M., Demant P., Ivanyi P., I973. The mixed lymphocyte reaction in $\mathrm{H}-2 \mathrm{~K}, \mathrm{H}-2 \mathrm{D}$ and non $\mathrm{H}-2$ incompatibility. Biomedicine, 18, $40 \mathrm{I}-407$.

Ryder L. P., Andersen E., Svejgaard A., i978. An HLA map of Europe. Hum. Hered., 28 (3), I 7 I-200.

SACHS D. H., CONE J. L., I973. A mouse " B " alloantigen determined by a gene (I) linked to the major histocompatibility complex. J. Exp. Med., 138, I289-1 304 .

SaIson R., InGRam D. G., I963. Production of specific haemagglutinins in pigs after receiving skin homografts. Nature, 197, 296-297.

SANDBERG L., THORSBY E., KISSMEYER-NIELSEN F., LiNDHOLM A., I97o. Evidence of a third sublocus within the $H L-A$ chromosomal region, p. I65-17o, in : Histocompatibility testing, I 970 , Munksgaard Ed., Copenhagen.

Sanderson A. R., DAviEs D. A. L., I974. Genetic control of cell surface antigens. Prog. Immunol., 2, 364-367.

SASPORTES M., I978. Culture mixte lymphocytaire et système HLA-D. In: Cours supérieur d'histocompatibilité. J. DAUSSET, Organisateur, janvier 1978 .

SASPORTES M., IEBRUn A., Rapaport F. T., DAUSSET J., I972. Studies of skin allograft and mixed lymphocyte culture reaction in HL-A genotyped families. Transplant. Proc., 4, 209.

Sasportes M., Mawas C., Bernard A., Christen Y., I973. MLR in families with one HI,A haplotype shared by parents: recombination between $\mathrm{SD}_{2}$ and $\mathrm{LD}_{3}$, possible evidence for one LD3 locus. Transplant. Proc., 5, I5I 7 .

Sasportes M., Mawas C., Crosier P., Charmot D., Legrand L., Dausset J., i976. Détection par trois techniques d'immunologie cellulaire des déterminants antigéniques du système $\mathrm{Ly}-\mathrm{Li}$ exprimés sur les lymphocytes B humains. C. R. Acad. Sci. Paris, 283, 663-666.

Sasportes M., Fradelizi D., Nunez-Roldan A., Wollman E., Grannopory 2 S Z., Dausset $\mathrm{J}$, I978. Analysis of stimulating products involved in primary and secondary allogenic proliferation in man. I. Preponderant role of the Ia-like DR (Ly-Li) antigens as stimulating products in secondary allogenic response in man. Immunogenetics, 6 (I), 29-42.

Schendel D. J., BACH F. H., I974. Genetic control of cell mediated lympholysis in mouse. J. Exp. Med., 140, I 534 -I 546.

Scher I., Franz M. M., Steinberg A. D., I973. The genetics of the immune response to a synthetic double-stranded RNA in a mutant CBA mouse strain. I. Immunol, 110, I396-I40I.

Schierman L. W., Nordskog A. W., r96r. Relationship of blood type to histocompatibility in chickens. Science, 134, Ioo8.

Schierman L. W., Nordskog A. W., I962. Relationship of erythrocyte to leucocyte antigens in chickens. Science, 137, 620 .

SCHIERMAN L. W., NORDSkOG A. W., I965. Evidence for a second blood group histocompatibility system in chickens. Transplantation, 3, 44-48.

SCHIERMAN L. W., Mc BRIDE R. A., I 969 . Evidence for a mutational event at the B blood group histocompatibility locus in chickens. Transplantation, 8, 5 I 5-5 I6.

SCHREK R., DONNEI, W. J., I96r. Differences between lymphocytes of leukemic and no leukemic patients with respect to morphologic features, motility and sensitivity to guinea pig serum. Blood, 28, 56I-577.

Schwartz B. D., Nathenson S. G., I97I. Regeneration of transplantation antigens on mouse cells. Transplant. Proc., 3, I8o.

Schwartz B. D., Kato K., Cullen S. E., Nathenson S. G., i973. H-2 histocompatibility alloantigens. Some biochemical properties of the molecules solubilized by NP-40 detergent. Biochemistry, 12, 2 I 57 . 
Sheehy M. J., Sondel P. M., Bach M. L., Wank R., Bach F. H., i975. HLA-D (D) typing; a rapid assay with primed lymphocytes. Science, 188, 1308-1310.

Shimada A., Nathenson S. G., I 969 . Murine histocompatibility 2 (H-2) alloantigens. Purification and some chemical properties of soluble products of $\mathrm{H}-2 \mathrm{~b}$ and $\mathrm{H}-2 \mathrm{~d}$ genotypes released by papain digestion of membrane fractions. Biochemistry, 8, 4048 .

SHREFFLER D. C., I965. The Ss system of the mouse. Quantitative serum protein difference genetically controlled by the $H-2$ region. In: J. PALM (ed.): Isoantigens and cell interactions, p. I I (Philadelphia: Wistar Institute Press).

SHREFFLER D. C., I970. Immunogenetics of the mouse H-2 system, in "Blood and Tissue antigens "(D. AminofF), p. 85-99. Acad. Press. New York.

SHREFFLER D. C., I974. Genetic fine structure of the $H-2$ gene complex. Pages 83-IOo in G. M. EDELMAN, Ed. Cellular selection and regulation in the immune response. Raven, New York.

SHREFFLER D. C., OWEN R. D., I963. A serologically detected variant in mouse serum: inheritance and association with the histocompatibility-2 locus. Genetics, 48, 9-25.

SHREFFlER D. C., Amos D. B., MARK R., 1966. Serological analysis of a recombinaticn in the $\mathrm{H}-2$ region of the mouse. Transplantation, 3, 300-322.

SHREFFleR D. C., PASSMORE H. C., I97I. Genetics of the $H$-2 associated Ss-Slp trait. In : Immunogenetics of the $\mathrm{H}-2$ system, p. 58 (Basel : Karger).

ShrEFFlek D. C., DAVId C. S., PAssmore H. C., KLEIN J., I97I. Genetic organization and evolution of the mouse H-2 region: duplication model. Transplant. Proc., 3, I76-179.

SILVER J., HOOD I., I974. Detergent-solubilized $\mathrm{H}-2$ alloantigen is associated with a small molecular weight polypeptide. Nature, 249, 764

Silver J., Cecka J. M., Mc Milian M., HoOD L., 1976. Chemical characterization of products of the H-2 complex. Cold Spring Harbor. Symp. Quant. Biol., 61 (I), 369.

Simonsen M., I957. The impact on the developping embryo and newborn animal of adult homologues cells. Acta. Pathol. Microbiol. Scand., 40, 480-500.

SIMONSEN M., I962. Graft versus host reastions. Their natural history, and applicability as tool of research. Prog. Allergy, 6, 349-467.

Suith R. T., I972. Specific recognition reactions at the cellular level in mouse lymphoreticular cell subpopulations. Transplant. Rev., 11, I 78-2 r6.

SNary D., Barnstable C., Bodmer W. F., Goodiellow P., Crumpton M. J., i976. Human Ia antigens. Purification and molecular structure. Cold Spring Harbor Symp. Quant. Biol., 61 (1), 379-386.

SNELL G. D., I948. Methods for the study of histocompatibility genes. $J$. Genet., 19, 87-108.

SNEI, G. D., I95I. A fifth allele at the histocompatibility-2 locus of the mouse as determined by tumour transplantation. J. Nat. Cancer. Inst., 11, I229-1305.

SNelL G. D., Borges P. R. F., KelTon D. E., AlLEN S. L., I952. Histocompatibility genes in the mouse: methods of study, and some results. Genetics, 37, 626-636.

SNeli, G. D., SMITH P. S., Gabrielson F., I953. Analysis of the histocompatibility-2 locus in the mouse. J. Nat. Cancer. Inst., 14, 457-480.

SNell G. D., Stimpfling J. H., I966. Genetics of tissue transplantation. In: Biology of the laboratory mouse (Ed. E. L. GREEN). New York: Mc Graw-Hill, Co, 1966.

SNeli, G. D., Cherry M., Demant P., I97I. Evidence that the H-2 private specificities can be arranged in two mutually exclusive systems possibly homologous with the two subsystems of HL-A. Transplant. Proc., 3, 183-186.

Snell G. D., Dausseir J., Nathenson S., 1976. Histocompatibility. Academic Press, New York.

Solliday S., BACH F. H., I970. Cytotoxicity: Specificity after in vitto sensitization. Science, 170, I 406-I 409 .

Sondei, P. M., Chess I., Mc DermotT R. P., Schlossman S. F., I975. Immunologic fonctions of isolated human lymphocyte subpopulations. III. Specific allogeneic lympholysis mediated by human $\mathrm{T}$ cells alone. $J$. Immunol., 114, 982-987.

Spooner R. L., Leveziel H., Grosclaude F., Oliver R. A., Vaiman M., i978. Evidence for a possible major histocompatibility complex in cattle. J. Immunogenet., 5, 335-346.

Spooner R. L., Oliver R. A., Sales D. I., Mc Coubrey C. M., Mililar P., Morgan A. G., Amorena B., Bailey E., Bernoco D., Brandon M., Bull R. W., Caldwell. J., CWik S., Van Dam R. H., Dodd J., Gahne B., Groscladde F., Hall J. G., Hines H., Leveziel H., NewMan M. J., Stear M. J., Stone W. H., VAIMAN M., I 979. Analysis of alloantisera againts, bovine Iymphocytes. Joint report of the ist International Bovine Lymphocyte antigen (BoLA) workshop. Anim. Blood Grps biochem. Genet., 10, 63-86. 
STAATS J., I966. Th. Laboratory mouse. In: "Biology of the laboratory mouse " (E. I. GREEN) p. I-IO. Mc Graw-Hill, New York.

STARK O., KREN V., I967. Erythrocyte and transplantation antigens in inbred strains of rats. VI. The histocompatibility-I system and its alleles. Folia Biol. (Praha), 13, 356-36o.

StrmpFling J. H., ז96r. The use of PVP as a developping agent in mouse hemogglutination tests. Transplant. Bull., 27, I 09-I I I.

STIMPFi,ING J. H., I97I. Recombination within a histocompatibility locus. Ann. Rev. Genet., 5, I 2 I-I 42 .

Stimpfling J. H., Durham T., I972. Genetic control by the $\mathrm{H} 2$ genes complex of the alloantibody response to an $\mathrm{H}-2$ antigen. $J$. Immunol., 108, 947.

TADA T., TANIGUCHI M., 1976. Characterization of the antigen specific suppressive $T$ cell factor with special reference to the expression of I region genes in " the role of products of the histocompatibility gene complex in immune responses ". In: KATZ D. H., BENACERRAF B., Ed., Academic Press, New York, 1976.

TADA T., TANIGUChI M., David C. S., I976. Properties of the antigen specific suppressive T cell factor in the regulation of antibody response in the mouse. IV. Special subregion assignment of the gene (s) that code for the suppressive $\mathrm{T}$ cell factor in the $\mathrm{H}-2$ histocompatibility complex. J. Exp. Med., 144, 713.

TANiguchi M., TAda T., TokUhisa T., r976. Properties of the antigen specific suppressive $T$ cell factor in the regulation of antibody response of the mouse. III. Dual gene control of the cell mediated suppression of the antibody response. $J$. Exp. Med., 144, 20.

TAUSSIG M. J., r974. T cell factor which can remplace $T$ cells in vivo. Nature, 248, 234.

TAussig M. J., Munro A. J., I975. Two genes in the major histocompatibility complex control immune response. Nature, 256, I03.

Teisberg P., Akesson I., Olaisen B., Gedde-Dahl T. Jr., Thorsby E., i976. Genetic polymorphism of $\mathrm{C}_{4}$ in man and localization of structural $\mathrm{C}_{4}$ locus to the $\mathrm{HL}-\mathrm{A}$ gene complex of chromosome 6. Nature, 264, 253-254.

Terasaki P. I., Bold E. J., Cannon J. A., Longmire W. P., I96r. Antibody response to homografts. VI. In vitro cytotoxins produced by skin homografts in rabbits. Proc. Soc. Exp. Biol. Med., 106, I33-I 38 .

TERASAKI P. I., Mc CLELLAND J. D., I964. Microdroplet assay of human serum cytotoxins. Nature, 204, 998-1000.

Thorsby E., Hirschberg H., Hel,gesen A., i973. A second locus determining human MLC response; separate lymphocyte populations recognize the products of each different MLC locus allele in allogeneic combinations. Transplant. Proc., 5, 1523.

TISSOT R. G., COHEN C., 1972. Histocompatibility in the rabbit. Identification of the major locus. Tissue antigens, 2, 267-279.

Tisso'T R. G., CoHEN C., I 974. Histocompatibility in the rabbit. Linkage between RL-A, MLC and the He blood group locus. Transplantation, 18, 142-149.

TodD C., 1930. Cellular individuality in the higher animals, with special reference to the individuality of the red blood corpuscules. I. Proc. $R$. Soc. Lond. B, 106, 20-44.

TopD C., I93I. Cellular individuality in the higher animals with special reference to the individuality of the red blood corpuscules. II. Proc. R. Soc. Lond. B, 107, 197-205.

TURNER M. J., STRominger J. L., SANDERSON A. R., I972. Enzymic removal and re-expression of a histocompatibility antigen, $\mathrm{HL}-\mathrm{A2}$, at the surface of human peripheral lymphocytes. Proc. Nat. Acad. Sci., U.S.A., 69, 200.

TYZZER E. E., I908. A study of heredity in relation to the development of tumors in mice. J. Med. Res., 17, 199-2 I I.

Unanue E. R., Dorf M. E., David C. S., Benacerraf B., I974. The presence of Ia antigens on $\mathrm{B}$ cells in molecules distinct from $\mathrm{Ig}$ and $\mathrm{H}-2 \mathrm{~K}$ and $\mathrm{H}-2 \mathrm{D}$. Proc. Nat. Acad. Sci. (U.S.A.), 12, 5014-5016.

VaIman M., I974. Le complexe d'histocompatibilité majeur $S L-A$ du porc. Mise en évidence. Étude. Rôle dans les allogreffes. Rapport CEA-R, 458I. Thèse, Paris VII.

VAIMAN M., 1978. Le complexe majeur d'histocompatibilité chez les animaux. In : Cours supérieur d'histocompatibilité. Paris, J. DAUSSET, Organisateur.

Vaiman M., Renard C., IaAfage P., Ameteau J., Nizza P., 1970. Evidence for a histocompatibility system in swine (SL-A). Transplantation, 10, I55-I64.

Vaiman M., Renard C., Ponceau M., Lecointre, J., Vilitiers P. A., i975. Alloantigène sous la dépendance de la région SL-A contrôlant la réaction lymphocytaire mixte chez le porc. C. R. Acad. Sci. Paris, 280, 2809-28I 2. 
Van Dam R. H., Van Werkhoven C. B., Van der Donk J. A., Goudswaard J., i976. Histocompatibility in ruminants. The production and evaluation of allo-antibodies for GL-A typing in goats. $J$. Immunogenetics, 3, $237-244$.

Van den Tweel J. G., Van oud alblas Blusse A., Keuning J. J., Goulmy E., TermijTELEN A., BACH M. L., VAN Rood J. J., I973. Typing for MLC (LD); I-lymphocytes from cousin-marriage offspring as typing cells. Transplant. Proc., 5, 1535.

VAN Rood J. J., EERNISSE J. G., VAN LEeUwEN A., I958. Leucocyte antibodies in sera from pregnant women. Nature, 181, I 735-I 736.

VAN ROOD J. J., VAN LEUWEN A., I963. Leucocyte grouping. A method and its applications. J. Clin. Invest., 42, 1382-1390.

VAN ROOD J. J., VAN LEUWEN A., BALNER H., I972. HL-A and ChL-A: similarites and differences. Transplant. Proc., 4, 55-62.

Van Someren H., Westerveld A., Hagemeijer A., Mees J. R., Khan P. M., ZaAlberg O. B., 1974. Evidence for syntheny between the HL-A, PGm3, MEr, IPo-B loci. Proc. Nat. Acad. Sci. (U.S.A.), 71, 962-965.

VETTO R. M., BURGER D. R., I972. Endothelial cell stimulation of allogeneic lymphocytes. Transplantation, 14, 652-654.

VITETTA E. S., KLEIN J., UHR J. W., I974. Isolation and partial characterization of Ia antigens from murine lymphoid cells. Immunogenetics, 1, 82-9o.

Vitetta E. S., Uhr J. W., Klein J., Pazderka F., Moticka E. J., Ruth R. F., Capra J. D., 1977. Homology of (murine) H-2 and (human) HL-A with a chicken histocompatibility antigen. Nature, $270(5637), 535-536$.

VON Bofhme, H., Hudson L., SPRENT J., I975. Collaboration of histocompatible T and B lymphocytes using cells from tetraparenteral bone marrow chimeras. $J$. Exp. Med., $142,899$.

VRIESENDORP H. M. et al., I976. Joint report of the second international workshop on canine immunogenetics. Transplant. Proceed., 8, 289-3 I 4.

Waldmann H., Munko A. J., 1973. T cell dependent mediator in the immune response. Natuve, 243, 356.

Waldmann H., Pope H., Munro A. J., 1976. Cooperation across the histocompatibility barrier. Nature, 258, 728 .

WALFord R. L., ANderson E. R., Carter P. K., Mihajlovic F., i962. Leucocyte antibodies in inbred strains of guinea pigs following first- and second-set skin homografts. $J$. Immunol., $89,427-433$.

Weitkamp L. R., Townes D. L., May A. G., I975. Probably genetic linkage between a locus for human urinary pepsinogen and the HL-A loci. Am. J. Hum. Gcnet., 27, 486.

WEITKAMP L. R., I976. Linkage of Glo with HL-A and Bf. Effect of population and sex on recombination frequency. Tissue Antigens, 7, 273.

Williams M., MOORE M. J., 1976. Genetic recombination between serologically defined antigens and mixed lymphocyte reactivity in the rat major histocompatibility complex. In : M. STEPHENSON and A. BRZYTWA (Eds), Transplantation Abstracts, Sixth international Congress of the transplantation Society 1976, pp. 66-67, Grune and STraTron, New York.

WINKLER M. A., SANDERS B. G., I977. Chemical and immunologic characterization of a $\beta_{2}-$ microglobulin-like protein isolated from chichen sera. Immunochemisiry, 14 (8), 615-619.

Yunis E. J., Amos D. B., I97 I. Three closely linked genetic systems relevant to transplantation. Proc. Nat. Acad. Sci. (U.S.A.), 68, $303 \mathrm{r}$.

ZIEGLER A., PINK J. R. L., i975. Characterization of major histocompatibility (B) antigens of the chicken. Transplantation, 20, 523-527.

ZIEGLER A., PINK J. R. L., I976. Chemical properties of two antigens controlled by the major histocompatibility complex of the chicken. J. Biol. Chem., 251, 539I-5396. 